Fellipe Magioli Cadan

\title{
OTIMIZAÇÃO DA SÍNTESE DE NITRETO DE CARBONO GRAFÍTICO E A FORMAÇÃO DE HETEROESTRUTURAS COM TRIÓXIDO DE TUNGSTÊNIO
}

Dissertação apresentada ao Instituto de Química de São Carlos da Universidade de São Paulo como parte dos requisitos para a obtenção do título de mestre em ciências.

Área de concentração: Química Analítica e Inorgânica Orientador: Prof. Dr. Eduardo Bessa Azavedo

\section{Exemplar revisado}

O exemplar original encontra-se em acervo reservado na Biblioteca do IQSC-USP

São Carlos 
Aos meus familiares, em especial aos meus pais, José Carlos e Izirda, por acreditarem em mim. E à Bianca, que inspira a me tornar melhor a cada dia. Vocês são responsáveis pelas minhas vitórias e por tudo que sou. 


\section{AGRADECIMENTOS}

Aos meus pais, José Carlos Cadan e Izirda Magioli Cadan, pelo amor, incentivo e confiança, sempre.

À minha namorada Bianca Maria Silva Machado, que esteve ao meu lado em todos os momentos.

Ao Prof. Dr. Eduardo Bessa Azevedo, pela confiança e orientação.

À Embrapa Instrumentação, na pessoa do Dr. Caue Ribeiro de Oliveira, pela oportunidade e orientação.

Ao Instituto de Química de São Carlos, pela estrutura e apoio.

Às técnicas responsáveis pelos laboratórios Vânia Cardoso Fernandes, Silviane Zanni Hubinger e Adriana Coatrini Thomazi, pelo auxílio nas análises.

Aos meus companheiros mestrandos e doutorandos, pelo convívio e auxílio quando necessário.

Ao CNPq, pelo auxílio financeiro e pela bolsa.

Aos membros e amigos da República Lado Podre, pela amizade e momentos passados.

Enfim, a todos que conviveram comigo de qualquer forma. 


\section{RESUMO}

Este estudo propôs uma avaliação do papel dos três principais parâmetros clássicos da síntese do nitreto de carbono grafítico: temperatura final, tempo de permanência na temperatura final e taxa de aquecimento. Realizou-se a otimização da síntese, via metodologia de superfície de resposta, usando-se como variável-resposta a degradação fotocatalítica de um poluentemodelo (tartrazina). A significância estatística dos fatores foi confirmada, com 95\% de confiança. Em seguida, um modelo de segunda ordem foi ajustado às melhores respostas e, no ponto de máxima degradação, as condições foram: $605^{\circ} \mathrm{C}$ por $183 \mathrm{~min}$, com taxa de aquecimento de $5^{\circ} \mathrm{C} \min ^{-1}$. A taxa de degradação com o fotocatalisador sintetizado foi aproximadamente três vezes maior que a da fotólise. As amostras da região de melhores respostas foram analisadas em uma série de experimentos de caracterização, sendo eles: difratometria de raios $\mathrm{X}$, espectroscopia na região do infravermelho médio, área superficial específica, microscopias de varredura (MEV e MEV-FEG), potencial zeta e espectroscopia de reflectância difusa na região do ultravioleta-visível. O fotocatalisador com maior atividade apresentou menor energia de band gap e maior área superficial especifica do que as relatadas na literatura $(2,59$ $\mathrm{eV}$ e $29,5 \mathrm{~m}^{2} \mathrm{~g}^{-1}$, respectivamente). Foram criadas heteroestruturas entre o fotocatalisador sintetizado e o trióxido de tungstênio. A partir de uma série de caracterizações básicas, confirmou-se a formação da heteroestrutura. Com essa heteroestrutura, a taxa de degradação foi aproximadamente cinco vezes maior que a com o nitreto de carbono grafítico.

PALAVRAS-CHAVE: $\mathrm{g}-\mathrm{C}_{3} \mathrm{~N}_{4}$, fotocatálise, otimização, melamina, heteroestrutura, $\mathrm{WO}_{3}$, tartrazina. 


\begin{abstract}
This study proposed an assessment of the role of the three major classical parameters for synthesizing graphitic carbon nitride: final temperature, residence time at the final temperature and heating rate. The synthesis was optimized, via response surface methodology, using the photocatalytic degradation of a model pollutant (tatrazine) as the response-variable. The statistical significance of the factors was confirmed, within $95 \%$ confidence level. Afterwards, a second-order model was adjusted to the better responses and, at the maximum degradation point, the conditions were: $605^{\circ} \mathrm{C}$ for $183 \mathrm{~min}$, with heating rate of $5^{\circ} \mathrm{C} \mathrm{min}^{-1}$. The degradation rate with the synthetized photocatalyst was approximately three times greater than the photolytic one. The samples from the better response region were analyzed in a series of characterization experiments: $\mathrm{X}$ ray diffractometry, mid-infrared spectrometry, specific surface area, scanning electron microscopy (SEM and FEG-SEM), zeta potential, and ultravioletvisible diffuse reflectance spectroscopy. The most active photocatalyst showed smaller band gap energy and greater specific surface area than the ones reported in literature $(2.59 \mathrm{eV}$ and $29.5 \mathrm{~m}^{2} \mathrm{~g}^{-1}$, respectively). Heterostructures were formed between the synthetized photocatalyst and tungsten trioxide. A series of basic characterization techniques confirmed the heterostructure formation. Using this heterostructure, the degradation rate was approximately five times greater than the one with graphitic carbon nitride.
\end{abstract}

KEYWORDS: $\mathrm{g}-\mathrm{C}_{3} \mathrm{~N}_{4}$, photocatalysis, optimization, melamine, heterostructures, $\mathrm{WO}_{3}$, tartrazine. 


\section{LISTA DE FIGURAS}

Figura 1 - Modelo da separação de cargas geradas a partir da excitação de um semicondutor

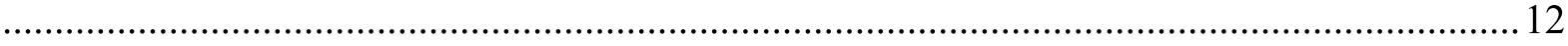

Figura 2 - Heptazina ou tri-s-triazina. $\mathrm{R}_{1}, \mathrm{R}_{2}$ e $\mathrm{R}_{3}$ são substituintes arbitrários ......................14

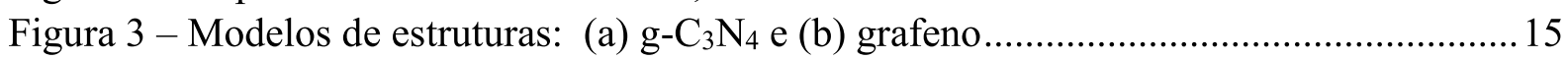

Figura 4 - Micrografias de nanoestruturas: (a) lamelas (TEM), (b) tubos, (c) fibras e (d)

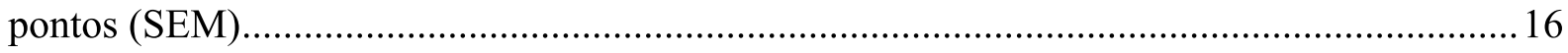

Figura 5 - Rota de polimerização do nitreto de carbono grafítico a partir da melamina ..........17

Figura 6 - Níveis de energia do g- $\mathrm{C}_{3} \mathrm{~N}_{4}$ em relação ao eletrodo normal de hidrogênio (ENH)

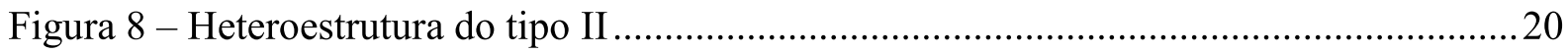

Figura 9 - Exemplo de estrutura de CB e VB proporcionada por heterojunções g- $\mathrm{C}_{3} \mathrm{~N}_{4} / \mathrm{g}-\mathrm{C}_{3} \mathrm{~N}_{4}$

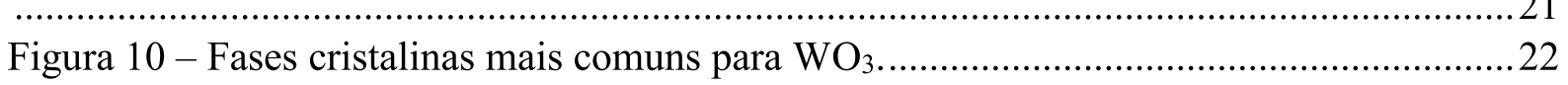

Figura 11 - Níveis de energia para $\mathrm{WO}_{3}$ em relação ao ENH ................................................2

Figura 12 - Possível heteroestrutura do tipo II para o g- $\mathrm{C}_{3} \mathrm{~N}_{4}$ e o $\mathrm{WO}_{3} \ldots \ldots \ldots \ldots \ldots \ldots \ldots \ldots \ldots \ldots \ldots \ldots . . . .24$

Figura 14 - Representação espacial da matriz inicial de experimentos, planejamento

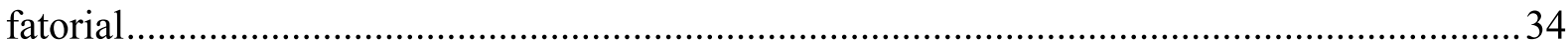

Figura 15 - Representação espacial da matriz de experimentos de composto central ..............35

Figura 16 - Reator próprio para fotocatálise (a) fechado e (b) aberto ......................................36

Figura 17 - Gradiente de eluição....................................................................................... 37

Figura 18 - Espectro de emissão de lâmpada de vapor de mercúrio média pressão, modelo

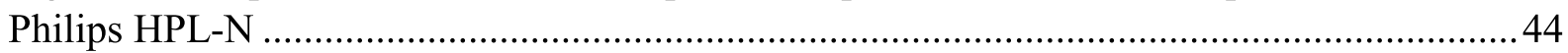

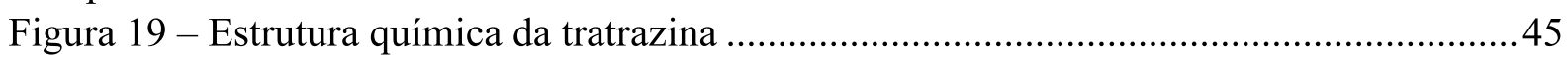

Figura 20 - Cromatogramas de soluções de tartrazina: (a) inicial e (b) após degradação .......45

Figura 21 - Gráfico de Pareto para a \% de degradação de tartrazina (planejamento fatorial, sem interações) ............................................................................................................. 47

Figura 22 - Gráfico de Pareto para a \% de degradação de tartrazina (planejamento composto

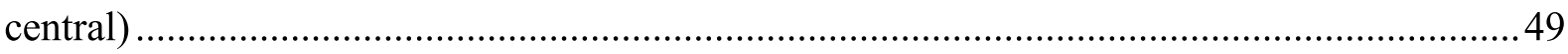

Figura 23 - Remoção de tartrazina: (a) superfície de resposta e (b) localização do ponto

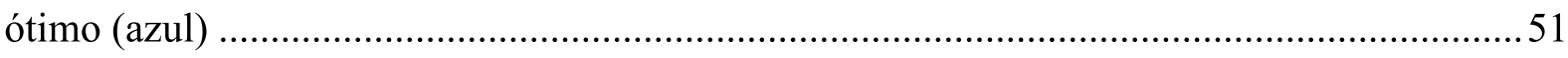

Figura 24 - Cinética de remoção de tartrazina: (অ) adsorção, $(\bullet)$ fotólise e ( $(\boldsymbol{\Delta})$ fotocatálise

Figura 25 - Condições experimentais para os pontos: (1) planejamento fatorial, (2) caminho de máxima inclinação, (3) planejamento composto central e (4) ponto ótimo..........................53 Figura 26 - Padrão de difração para amostras sintetizadas em condições brandas $\left(500^{\circ} \mathrm{C}\right) \mathrm{e}$

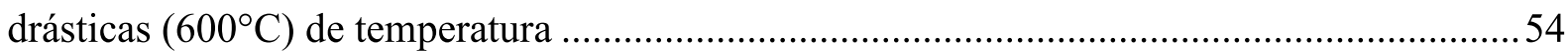

Figura 27 - Espectro de FTIR típico de amostra relativa aos experimentos finais ...................56

Figura 28 - Espectros FTIR normalizados para amostras da região de melhor resposta..........57

Figura 29 - Localização de grupos aminas terciárias (negrito), secundárias (azul) e primárias (vermelho) em um segmento hipotético com cinco unidades de heptazina ..............................57

Figura 30 - Ciclo final de síntese e suas respostas em área superficial BET, $\mathrm{em} \mathrm{m}^{2} \cdot \mathrm{g}^{-1}$.........59 Figura 31 - SEM das amostras dos experimentos finais da síntese: (a) melhor condição, (b) CF1, (c) CF2, (d) CF3, (e) CF4 e (f) CF5 
Figura 32 - SEM-FEG das amostras dos experimentos finais da síntese: (a) melhor condição, (b) CF1, (c) CF2, (d) CF3, (e) CF4 e (f) CF5 .

Figura 33 - Variação do potencial zeta em relação ao $\mathrm{pH}$ da suspensão 63

Figura 34 - Possíveis reações dos grupamentos amina na superfície do g- $\mathrm{C}_{3} \mathrm{~N}_{4}$ : (a) terciárias e

(b) primárias e secundárias

Figura 35 - Espectros de reflectância para todas amostras do ciclo final de experimentos .....65

Figura 36 - Valores estimados de $E_{\mathrm{g}}$ para as amostras: (a) OT, (b) CF1, (c) CF2, (d) CF3, (e)

CF4 e (f) CF5 (Continua) .

Figura 37 - Comparação entre a ASE e a $E_{g}$ de diversos materiais: (ם) relatados na literatura

e (•) deste trabalho

Figura 38 - TGA das amostras de heteroestruturas

Figura 39 - Padrão de difração para o $\mathrm{WO}_{3}$ monoclínico (JCPDS 89-4476) e para a amostra

CNO.

Figura 40 - Difratogramas das amostras CN0, CN20, CN35, CN72, CN80 e CN100

Figura 41 - MEV-FEG das amostras: (a) CN0, (b) CN20, (c) CN20 com elétrons retroespalhados, (d) CN35, (e) CN35 com elétrons retroespalhados, (f) CN72, (g) CN72 com elétrons retroespalhados, (h) $\mathrm{CN} 80$, (i) $\mathrm{CN} 80$ com elétrons retroespalhados e (j) CN100 .....75 Figura 42 - Imagens de TEM das amostras: (a) CN100, (b) CN0, (c) CN0 em alta resolução, (d) $\mathrm{CN80}$, (e) CN80 em alta resolução.

Figura 43 - Região original e mapeamento dos elementos: C (amarelo), N (lilás), W (azul) e

$\mathrm{O}$ (verde) 79

Figura 44 - Espectros de reflectância das amostras de heteroestruturas 79

Figura 45 - Valores estimados de Eg para as amostras: (a) CN100, (b) CN80, (c) CN71, (d)

CN35, (e) CN20 e (f) CN0 80

Figura 46 - Cinética de remoção da tartrazina: (ロ) fotólise, $(\bullet)$ fotocatálise com g- $\mathrm{C}_{3} \mathrm{~N}_{4} \mathrm{e}$

( $\Delta$ ) fotocatálise com g- $\mathrm{C}_{3} \mathrm{~N}_{4} / \mathrm{WO}_{3}(\mathrm{CN} 80)$... 


\section{LISTA DE TABELAS}

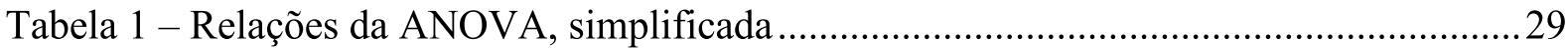

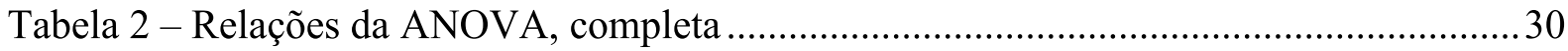

Tabela 3 - Matriz inicial de ensaios. Planejamento fatorial $2^{3}$............................................. 33

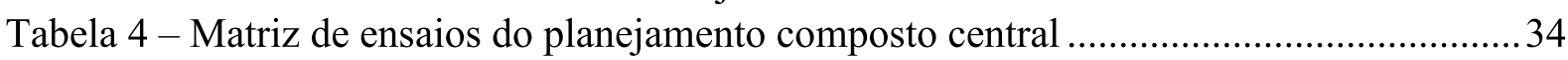

Tabela 5 - Massas utilizadas para criação de heteroestruturas ...............................................42

Tabela 6 - Níveis e, portanto, unidades codificadas dos três fatores ......................................46

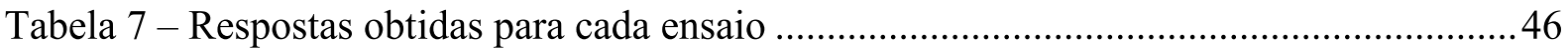

Tabela 8 - Condições de cada passo do caminho de máxima inclinação e suas respostas

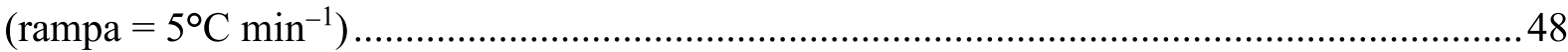

Tabela 9 - Níveis dos fatores do planejamento composto central ..........................................48

Tabela 10 - Condições do planejamento composto central e suas respostas ...........................49

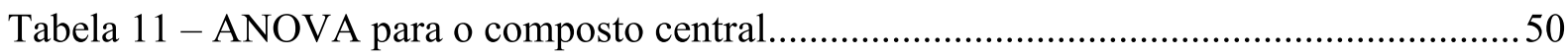

Tabela 12 - Experimentos adicionais e suas respostas previstas e experimentais ...................51

Tabela 13 - Taxas de remoção do corante tartrazina por fotólise e fotocatálise $\left(\mathrm{g}-\mathrm{C}_{3} \mathrm{~N}_{4}\right) \ldots \ldots . .52$

Tabela 14 - ASE e Eg relatadas na literatura para materiais obtidos sob diversas condições de

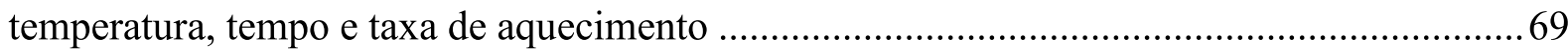

Tabela 15 - Proporções planejadas, reais e sua nomeação................................................... 72

Tabela 16 - Remoção de tartrazina por fotocatálise com as heteroestruturas .......................... 81

Tabela 17 - Taxas de remoção do corante tartrazina por fotólise e fotocatálise $\left(\mathrm{g}-\mathrm{C}_{3} \mathrm{~N}_{4}\right.$ e g$\left.\mathrm{C}_{3} \mathrm{~N}_{4} / \mathrm{WO}_{3}\right)$ 


\section{LISTA DE ABREVIATURAS E SIGLAS}

ANOVA - Analysis of Variance, análise de variância;

ASE - Área superficial específica;

ATR - Attenuated Total Reflectance, reflectância total atenuada;

CB - Conduction band, banda de condução;

$\mathrm{E}_{\mathrm{g}}$ - Energia de band gap;

EDX - Energy Dispersive X-ray Analisys, análise de raios X por energia dispersiva;

ENH - Eletrodo normal de hidrogênio;

FEG - Field Emission Gun, canhão de emissão por campo;

FTIR - Fourier Transform Infrared Spectroscopy, espectroscopia no infravermelho com transformada de Fourier;

g- $\mathrm{C}_{3} \mathrm{~N}_{4}-$ Nitreto de carbono grafítico;

HRTEM - High Resolution Transmission Electron Microscopy, microscopia eletrônica de transmissão de alta resolução;

IUPAC - International Union of Pure and Applied Chemistry, União Internacional de Química Pura e Aplicada;

JCPDS - Joint Committee on Powder Diffraction Standards, Comitê Conjunto sobre Padrões de Difração em Pó;

MQ - Média quadrática;

POA - Processos oxidativos avançados;

SEM - Scanning Electron Microscopy, microscopia eletrônica de varredura;

SQ - Soma quadrática;

TEM - Transmission Electron Microscopy, microscopia eletrônica de transmissão;

TGA - Thermal Gravimetric Analysis, análise termogravimétrica;

VB - Valence band, banda de valência. 


\section{SUMÁRIO}

1 INTRODUÇÃO

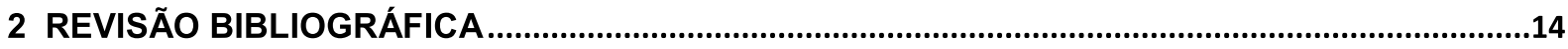

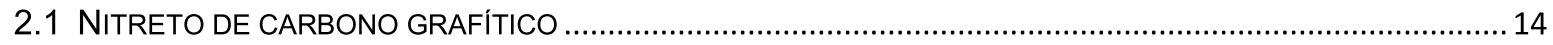

2.2 NITRETO DE CARBONO GRAFITICO MODIFICADO

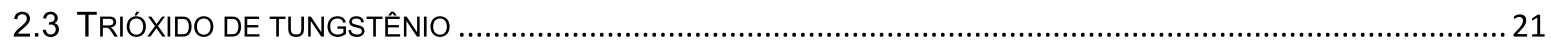

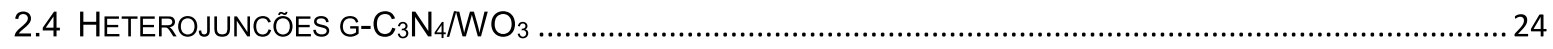

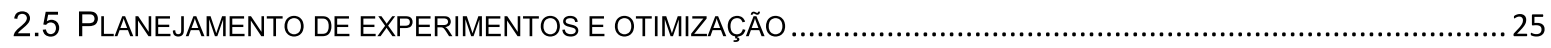

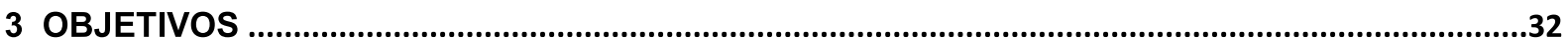

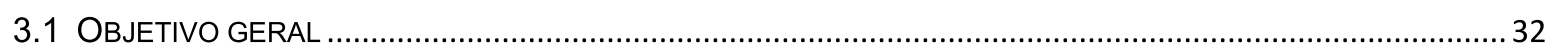

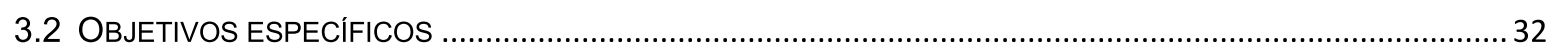

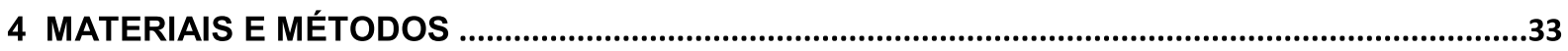

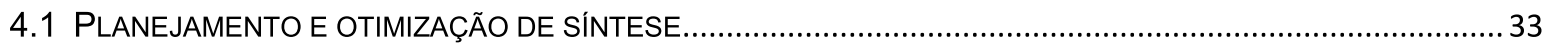

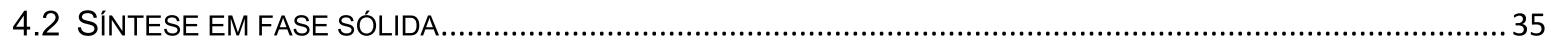

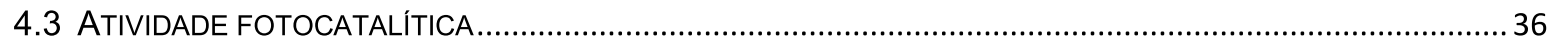

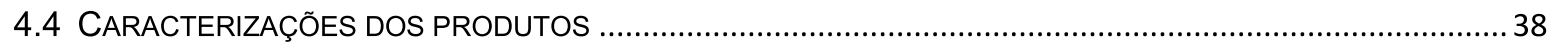

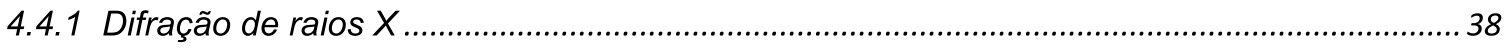

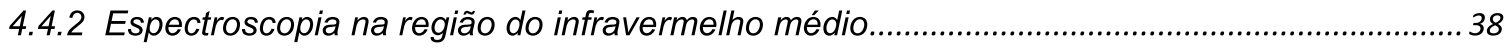

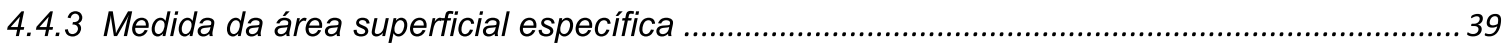

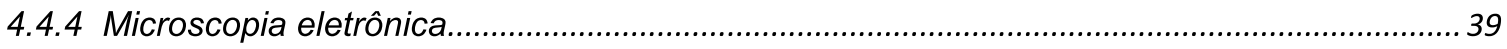

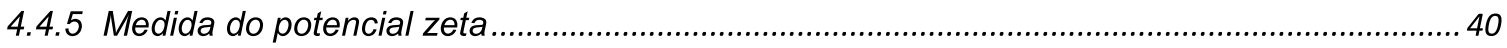

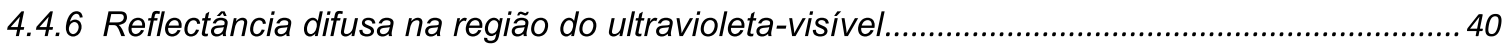

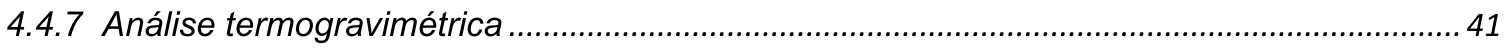

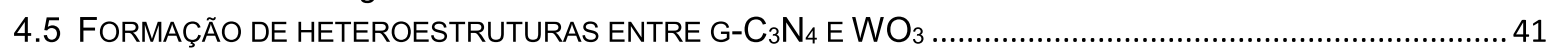

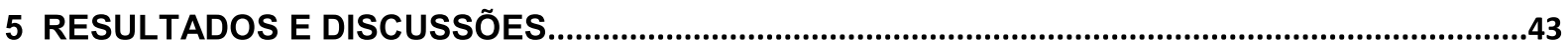

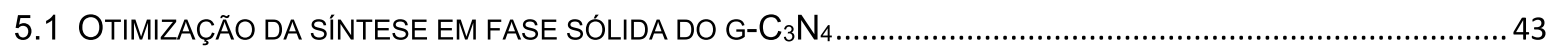

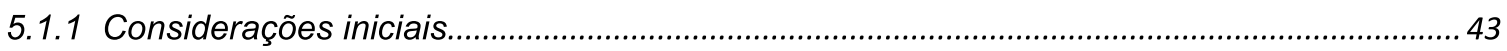

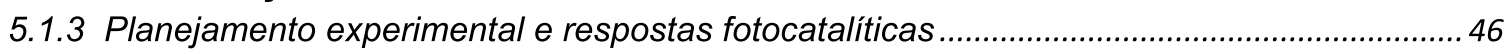

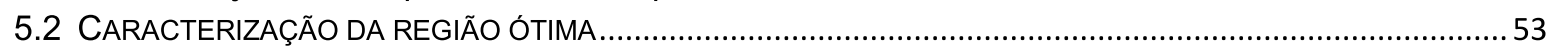

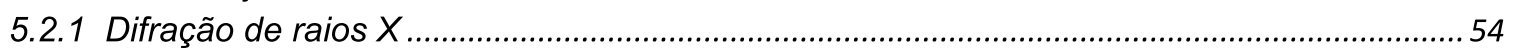

5.2.2 Espectroscopia na região do infravermelho médio com transformada de Fourier .................55

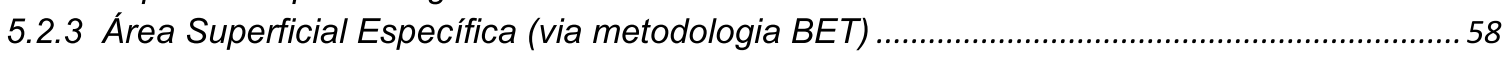

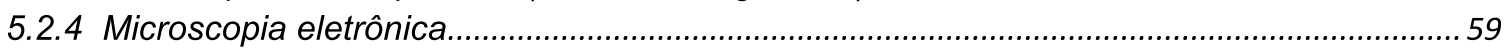

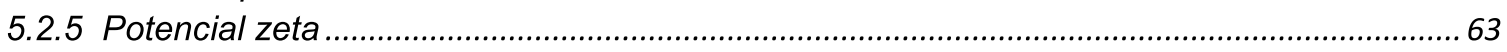

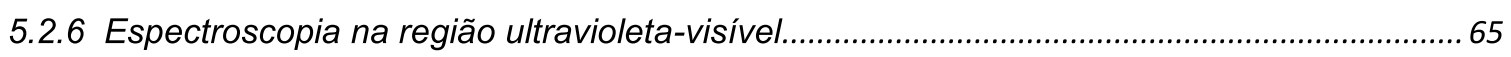

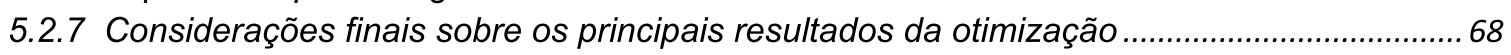

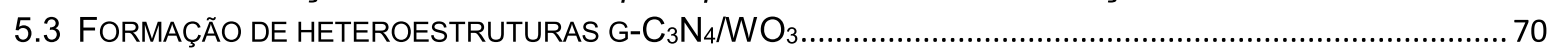

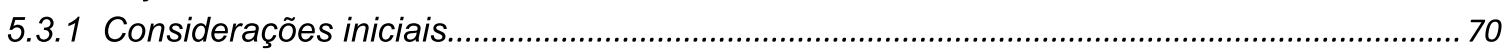

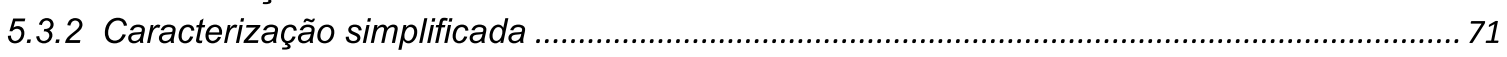

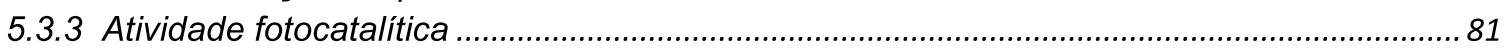

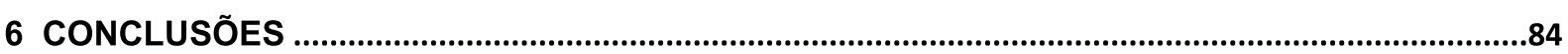

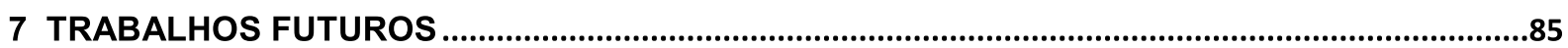




\section{INTRODUÇÃO}

Os Processos Oxidativos Avançados (POA) são uma série de metodologias de degradação de poluentes orgânicos via oxidantes fortes, geralmente utilizando radiações de alta energia como promotoras de reações de oxidação (LEGRINI; OLIVEROS; BRAUN, 1993). Suas principais aplicações são relacionadas à melhoria da qualidade de águas e à desinfecção e ao tratamento químico de efluentes.

Têm por característica principal a geração in situ de radicais hidroxila e seus principais exemplos incluem os processos Fenton (BARBENI; MINERO; PELIZZETTI, 1987), a fotocatálise (MILLS; DAVIES; WORSLEY, 1993), os processos com radiação ultravioleta (UV) em vácuo (GONZALEZ et al., 2004) e os processos que utilizam radiação ultravioleta e agentes oxidantes $\left(\mathrm{H}_{2} \mathrm{O}_{2} / \mathrm{UV}, \mathrm{O}_{3} / \mathrm{UV}\right)$ (LEGRINI; OLIVEROS; BRAUN, 1993).

Mais especificamente, no escopo deste estudo e de acordo com a União Internacional de Química Pura e Aplicada (IUPAC, International Union of Pure and Applied Chemistry), fotocatálise é:

\footnotetext{
"(...) a mudança na taxa de reação química ou sua iniciação, sob ação de radiação ultravioleta, visível ou infravermelha, na presença de uma substância - o fotocatalisador - que absorve a luz e a envolve nas transformações de seus parceiros reacionais." (IUPAC, 1997)
}

Em um sistema fotocatalítico heterogêneo, estas transformações ocorrem na superfície de um catalisador sólido, ou seja, na sua interface com o meio (BYRNE et al., 2015). No caso do fotocatalisador ser um semicondutor, a absorção de energia gera uma separação de cargas capaz de promover reações de oxirredução nos compostos adsorvidos, como exemplificado na Figura 1. 
Figura 1 - Modelo da separação de cargas geradas a partir da excitação de um semicondutor

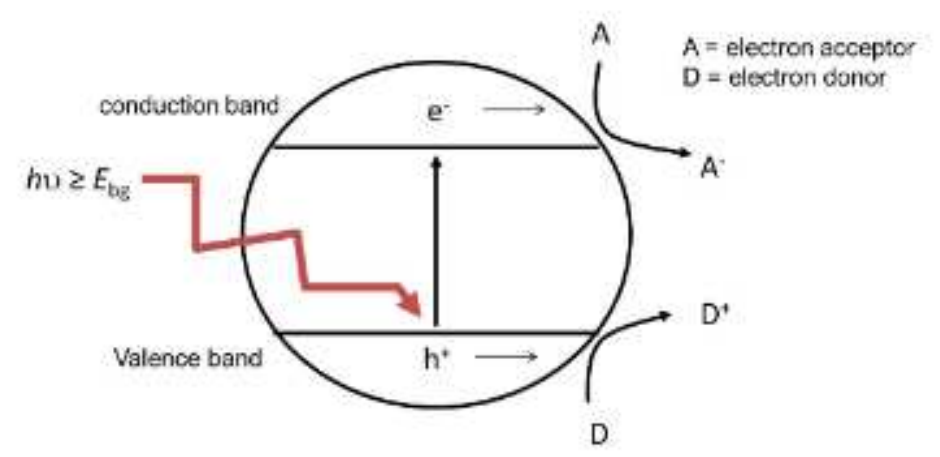

Fonte: Byrne et al. (2015).

Como todo POA, a eficiência da fotocatálise está relacionada à capacidade de geração de radicais altamente oxidantes. Há, porém, fatores específicos à fotocatálise heterogênea que influenciam na geração de radicais e na posterior eficiência de degradação (HOFFMANN et al., 1995).

A diferença de energia entre as bandas de valência e de condução do semicondutor ( $\mathrm{CB}$, conduction band; VB, valence band), chamada de energia de band gap ( $\left.\mathrm{E}_{\mathrm{g}}\right)$, exerce papel fundamental na sua atividade fotocatalítica (LINSEBIGLER; LU; YATES, 1995). Caso esta diferença seja muito grande, será necessária uma alta energia para a promoção de elétrons para a CB. Caso a diferença seja pequena, não haverá potencial suficiente para a formação do radical. Além disso, uma possível recombinação de cargas do semicondutor é favorecida com a menor distância entre os níveis energéticos (LINSEBIGLER; LU; YATES, 1995).

A área superficial específica (ASE) ativa do fotocatalisador também é um fator a se considerar (LINSEBIGLER; LU; YATES, 1995). Como é um processo heterogêneo, ou seja, acontece na superfície do catalisador, é favorecida a atividade fotocatalítica de materiais com maior ASE. Entretanto, outros fatores de superfície, como interações eletrostáticas, defeitos na estrutura cristalina ou presença de moléculas adsorvidas podem também interferir positiva ou negativamente no processo como um todo (HOFFMANN et al., 1995).

Nas últimas décadas, vêm-se estudando as características e vantagens de semicondutores em escala nanométrica (MOURÃO et al., 2009), nas mais diversas estruturas. Um dos semicondutores de interesse recente é o nitreto de carbono grafítico $\left(\mathrm{g}-\mathrm{C}_{3} \mathrm{~N}_{4}\right)$. Este fotocatalisador apresenta qualidades desejáveis, como a possível atuação na região visível do espectro 
eletromagnético, síntese a partir de precursores baratos e de fácil acesso, ausência de metais, resistência química e baixa toxicidade (YUAN et al., 2013; ZHANG et al., 2014).

Entretanto, sua atividade fotocatalítica para a degradação de contaminantes é relativamente inferior à fotocatalisadores clássicos, devido principalmente à baixa ASE e à alta recombinação do par elétron-lacuna gerado, em seu estado bruto (ZHANG; CHEN; WANG, 2015).

Inúmeras estratégias vêm sendo desenvolvidas para a mitigação destes efeitos adversos. No entanto, a comparação entre estes diversos estudos é dificultada, principalmente devido à falta de padronização da síntese do $\mathrm{g}-\mathrm{C}_{3} \mathrm{~N}_{4}$. Há certa escolha arbitrária dos parâmetros para sua síntese, parâmetros estes que os próprios estudos apresentam como interferentes da qualidade do fotocatalisador e consequente atividade fotocatalítica.

Portanto, este trabalho propõe a otimização da síntese do $\mathrm{g}-\mathrm{C}_{3} \mathrm{~N}_{4}$, com a metodologia e o precursor mais amplamente utilizados. Em seguida, de posse desse resultado, aplicá-lo na formação de heterojunção, com o objetivo de reduzir a recombinação do par elétron-lacuna gerado. 


\section{REVISÃO BIBLIOGRÁFICA}

\subsection{NITRETO DE CARBONO GRAFÍTICO}

$\mathrm{O} g-\mathrm{C}_{3} \mathrm{~N}_{4}$ é um dos alótropos do nitreto de carbono, na forma grafítica. A sigla provém justamente deste tipo de estrutura ("g" - grafítico) e da proporção entre os átomos constituintes: carbono e nitrogênio (WANG et al., 2016; ZOU et al., 2016). Mais especificamente, compostos de estrutura grafítica são aqueles que se assemelham ao grafite ou à sua forma mais simples, o grafeno.

A unidade monomérica do $\mathrm{g}-\mathrm{C}_{3} \mathrm{~N}_{4}$ é a heptazina, também conhecida como tri- $s$ triazina (HOSMANE; ROSSMAN; LEONARD, 1982). Ela consiste do $\mathrm{C}_{6} \mathrm{~N}_{7}$, que é um grupo triangular, planar, de três anéis triazínicos fundidos, com três substituintes nos vértices do triângulo, como na Figura 2.

Figura 2 - Heptazina ou tri-s-triazina. $\mathrm{R}_{1}, \mathrm{R}_{2}$ e $\mathrm{R}_{3}$ são substituintes arbitrários<smiles>[R]C1=NC2=NC([R])=NC3=NC([R])=NC(=N1)N23</smiles>

Fonte: Autoria própria.

$\mathrm{Na}$ fase cristalina mais comum deste polímero, a heptazina está unida, por três grupamentos amina a outras seis heptazinas (Figura 3a). Além dos grupamentos amina, há de se destacar a presença da função imina em todos os carbonos. Sendo assim, são polímeros lamelares constituídos por folhas de anéis fundidos (semelhantes ao grafeno, Figura 3b), de alta resistência, grande área superficial e, potencialmente, alta condutividade elétrica (SENGUPTA et al., 2011; ZHANG; CHEN; WANG, 2015). 
Figura 3 - Modelos de estruturas: (a) g- $\mathrm{C}_{3} \mathrm{~N}_{4} \mathrm{e}$ (b) grafeno

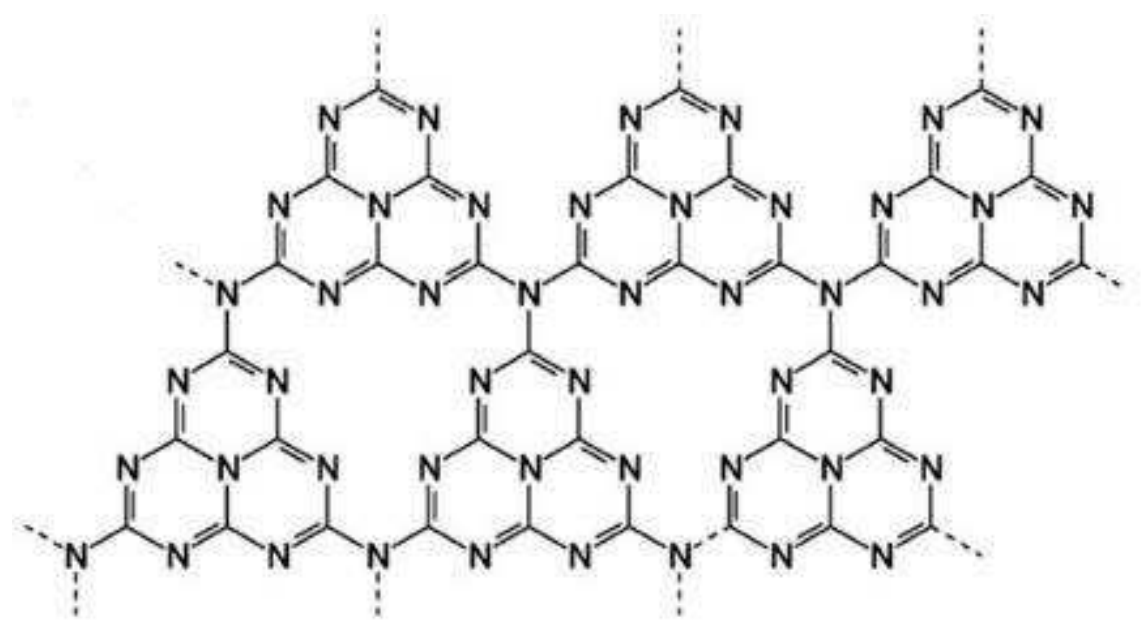

(a)

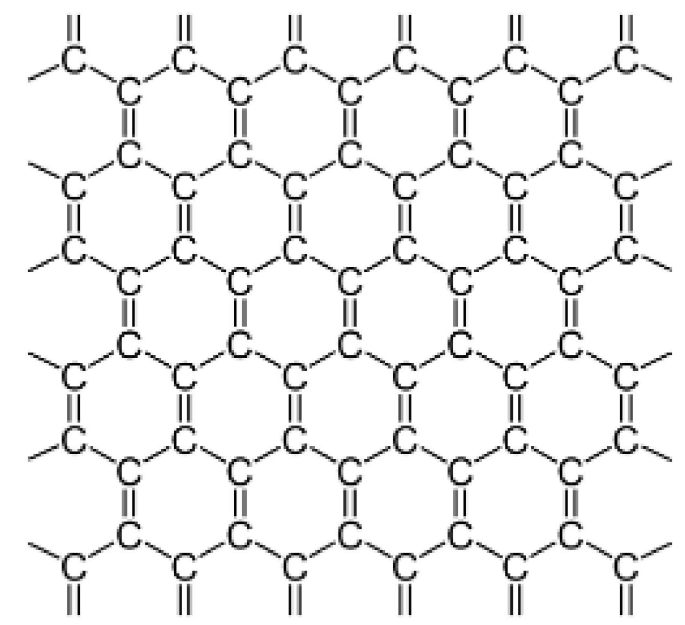

(b)

Fonte: (a) Zhang et al. (2013); (b) Wikimedia Commons (2013).

Utilizando-se de diversas estratégias, inúmeras morfologias em escala nanométrica, foram relatadas para o $\mathrm{g}_{-} \mathrm{C}_{3} \mathrm{~N}_{4}$ : lamelas (SHI et al., 2014), fibras (TAHIR et al., 2015), tubos (TAHIR et al., 2015), pontos (ZHANG et al., 2014), morfologias amparadas por moldes (YANG et al., 2011) e estruturas altamente porosas (OVCHAROV et al., 2015). A Figura 4 apresenta algumas destas possibilidades. 
Figura 4 - Micrografias de nanoestruturas: (a) lamelas (TEM), (b) tubos, (c) fibras e (d) pontos (SEM)

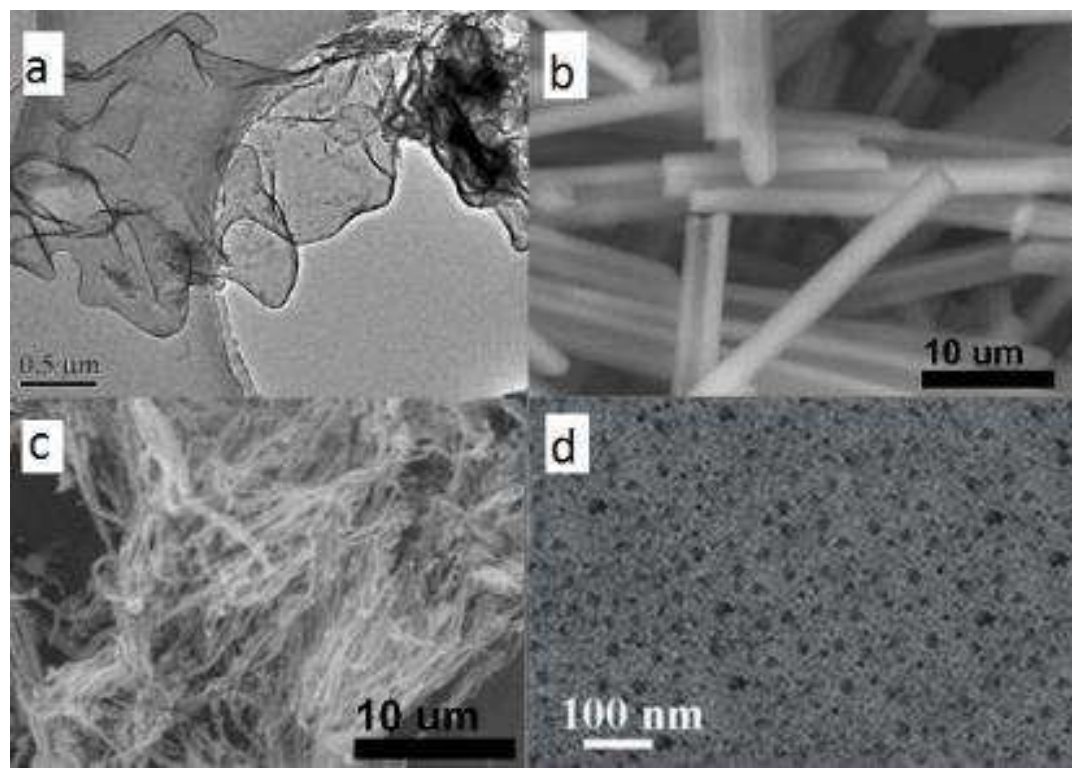

Fonte: Shi et al. (2014); Tahir et al. (2015); Zhang et al. (2014).

A síntese do g- $\mathrm{C}_{3} \mathrm{~N}_{4}$ se baseia na policondensação de precursores orgânicos ricos em nitrogênio, tais como: melamina (KUANG et al., 2015; SHI et al., 2015), ureia (DONG et al., 2011; SUN et al., 2015), tioureia (XIAO et al., 2016; ZHANG et al., 2012), dicianodiamina (XIAO et al., 2016; YUAN, B. et al., 2014), guanidina (GIBOT; SCHNELL; SPITZER, 2016; SHI et al., 2014) entre outros (XU et al., 2015).

Neste tipo de síntese, o precursor sofre uma série de desaminações, gerando estruturas intermediárias que por fim serão condensadas na forma polimérica. Apesar das rotas dos precursores serem inicialmente distintas, em um dado momento é gerada a melamina (SHI et al., 2014), a partir da qual a rota sintética segue o que se mostra na Figura 5.

A metodologia de policondensação em fase sólida é a mais comumente empregada para a produção do g- $\mathrm{C}_{3} \mathrm{~N}_{4}$ (YE et al., 2015). O procedimento se baseia no simples aquecimento de precursores ricos em nitrogênio em fornos a altas temperaturas por várias horas ou dias. É um processo com alto custo energético e de tempo, além do produto ter suas propriedades físicas e fotocatalíticas afetadas por uma série de fatores, tais como: atmosfera reacional, tempo de poli-condensação e taxa de aquecimento (YE et al., 2015). 
Figura 5 - Rota de polimerização do nitreto de carbono grafítico a partir da melamina

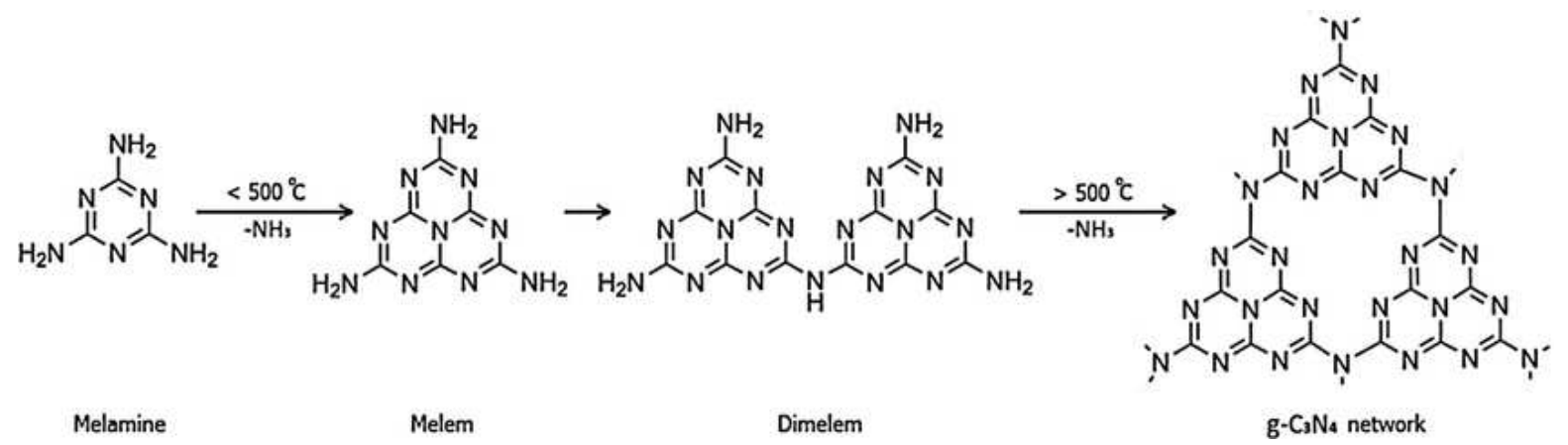

Fonte: Papailias et al. (2015).

Outras estratégias de síntese vêm sendo desenvolvidas, como a síntese em fase sólida assistida por micro-ondas (DAI et al., 2013; YUAN, P. et al., 2014), síntese em meio de líquidos iônicos (XU et al., 2014) e síntese em meio de sais fundidos (BOJDYS et al., 2008; GAO et al., 2013).

Estas estratégias oferecem, geralmente, um produto final de melhor qualidade em comparação ao controle (YE et al., 2015), preparado em metodologia de síntese em fase sólida. Entretanto, visto a ampla utilização da síntese clássica, torna-se interessante um estudo sobre a capacidade fotocatalítica do $\mathrm{g}-\mathrm{C}_{3} \mathrm{~N}_{4}$ originário desta metodologia.

\subsection{NITRETO DE CARBONO GRAFÍTICO MODIFICADO}

$\mathrm{O}$ g- $\mathrm{C}_{3} \mathrm{~N}_{4}$ é um material com resposta na região visível do espectro eletromagnético, possuindo uma $\mathrm{E}_{\mathrm{g}}$ em torno de 2,7 eV (CAO et al., 2015). Seus níveis de VB e CB possuem boa localização em relação ao eletrodo normal de hidrogênio (ENH), sendo eles +1,6 e -1,1 V, respectivamente (YE et al., 2015). Como a Figura 6 demonstra, esses níveis permitem realizar as reações de oxirredução clássicas para a fotocatálise heterogênea para degradação de contaminantes.

As principais reações é a formação de radicais oxidantes, como o hidroxila e o superóxido. Para o radical hidroxila, a energia necessária para sua formação é de 1,6 V em relação ao ENH (LOPES et al., 2014). Já o radical superóxido é de -0,3 V (LOPES et al., 2014). 
Figura 6 - Níveis de energia do g- $\mathrm{C}_{3} \mathrm{~N}_{4}$ em relação ao eletrodo normal de hidrogênio (ENH)

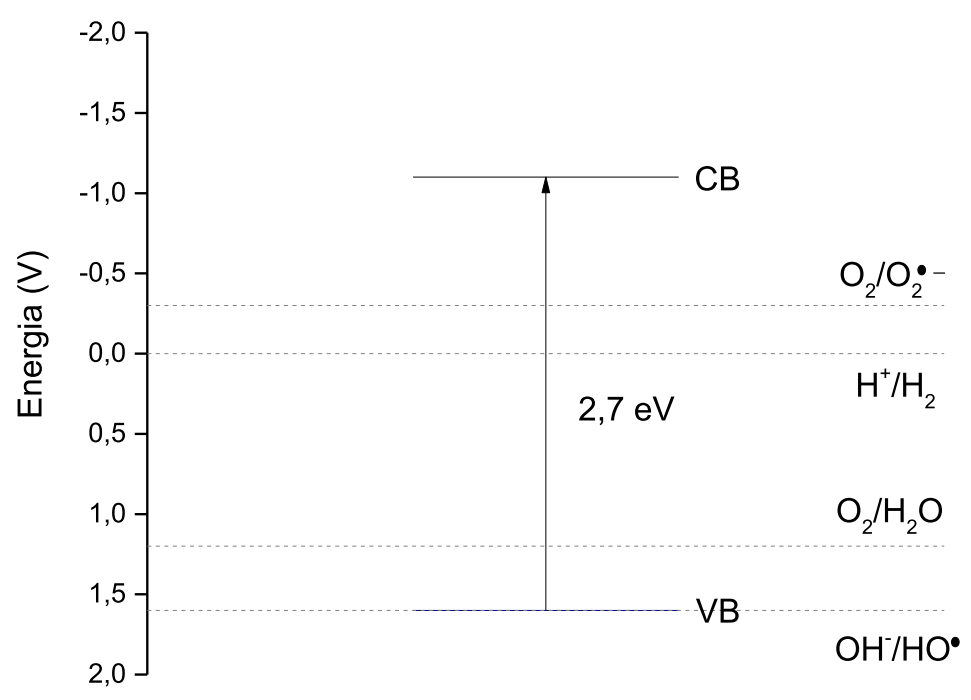

Fonte: Autoria própria.

Apesar da estrutura energética favorável, o g- $\mathrm{C}_{3} \mathrm{~N}_{4}$ no estado bruto possui limitada resposta fotocatalítica. Entretanto, estudos focados nas suas condições de síntese apontam que, mesmo em estado bruto, uma relativa melhora pode ser obtida.

Trabalhos foram realizados relacionando a temperatura final de condensação com a atividade fotocatalítica do produto (PAPAILIAS et al., 2015; ZHANG et al., 2012). Foi observado que, dentro dos limites destes experimentos, uma maior temperatura de condensação pode gerar melhores resultados. Porém, após certo limite de temperatura, os produtos passam a perder atividade ou a se decompor rapidamente.

Do mesmo modo, estudo pode ser realizados relacionando o tempo de condensação com o potencial de degradação de poluentes (DONG et al., 2013). Neste estudo, novamente, foi observada uma melhora até certo nível de tempo e posterior piora ou manutenção de resultados.

Em relação a outros semicondutores capazes de atuar como fotocatalisadores de reações de oxirredução, o g- $\mathrm{C}_{3} \mathrm{~N}_{4}$ grafítico em estado bruto sofre de algumas limitações intrínsecas, como uma inferior ASE e alta recombinação do par elétron-lacuna devido à polimerização defeituosa e pobre cristalinidade (ZHANG; CHEN; WANG, 2015). 
Assim, diversas estratégias de modificação vêm sendo sugeridas no sentido de sanar estas limitações, incluindo as esfoliações, heterojunções, as dopagens e as sensibilizações.

O fotocatalisador recém-sintetizado estará, provavelmente, em um estado bruto de agregação. As estratégias baseadas em esfoliação, portanto, valem-se de técnicas de separação lamelar, tendo em vista o aumento de sua ASE. A literatura relata que esse produto bruto possui menor atividade catalítica que seu análogo esfoliado (SHI et al., 2014).

Portanto, diversas abordagens vêm sendo utilizadas para a separação das lamelas de nitreto de carbono. Essas abordagens podem ser divididas em duas categorias (ZHANG; CHEN; WANG, 2015), ambas mostradas na Figura 7: as que partem do composto bruto e visam desestabilizar as interações interlamelares (top-down) (YANG et al., 2013) e as que se utilizam de moldes capazes de guiar a policondensação, de modo que a síntese se dê em conjunto com a desagregação lamelar (bottom-up) (GIBOT; SCHNELL; SPITZER, 2016).

Figura 7 - Estratégias de separação lamelar

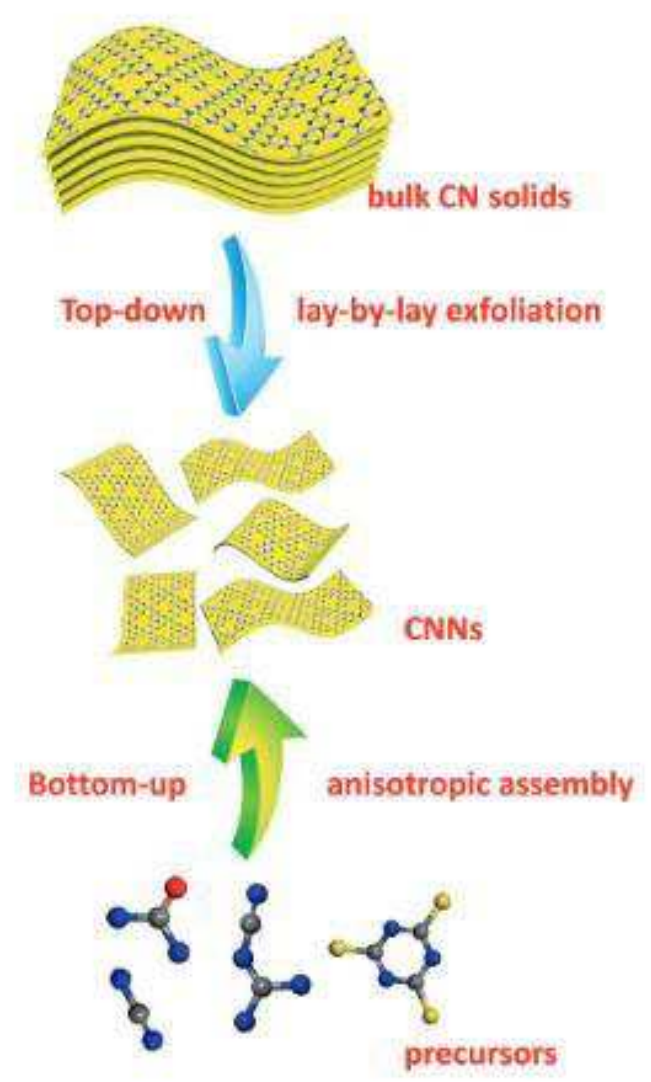

Fonte: Zhang, Chen e Wang (2015). 
As demais estratégias de aumento da atividade fotocatalítica (heteroestruturas, dopagem e sensibilização) visam modificar ou gerar níveis de energia compatíveis com as $\mathrm{CB}$ e $\mathrm{VB}$ do $\mathrm{g}-\mathrm{C}_{3} \mathrm{~N}_{4}$.

Especificamente, a heterojunção é a junção de dois ou mais materiais cristalinos diferentes, na qual as suas estruturas cristalinas formam uma interface (CALOW et al., 1967). As heterojunções podem se apresentar comumente de três formas, organizados a partir da energia relativa das $\mathrm{CB}$ e VB dos seus materiais formadores. Nas heterojunções de tipo I, as CB e VB de um componente encontram-se entre as CB e VB do outro. Nas heterojunções do tipo II, as $\mathrm{CB}$ e VB dos componentes se alternam. Já nas heterojunções do tipo III, um dos componentes possui VB maior que a $\mathrm{CB}$ do outro.

No caso de semicondutores em fotocatálise, as heterojunções mais eficientes são as de níveis de energia escalonados (WANG, H. et al., 2014), de tipo II, como na Figura 8. Esta formação é capaz de transferir as cargas geradas pelos semicondutores, reduzindo a probabilidade de sua recombinação (WANG, H. et al., 2014). Em outras palavras, essas cargas podem ser melhor direcionadas às reações de oxirredução para a degradação de contaminantes.

Figura 8 - Heteroestrutura do tipo II

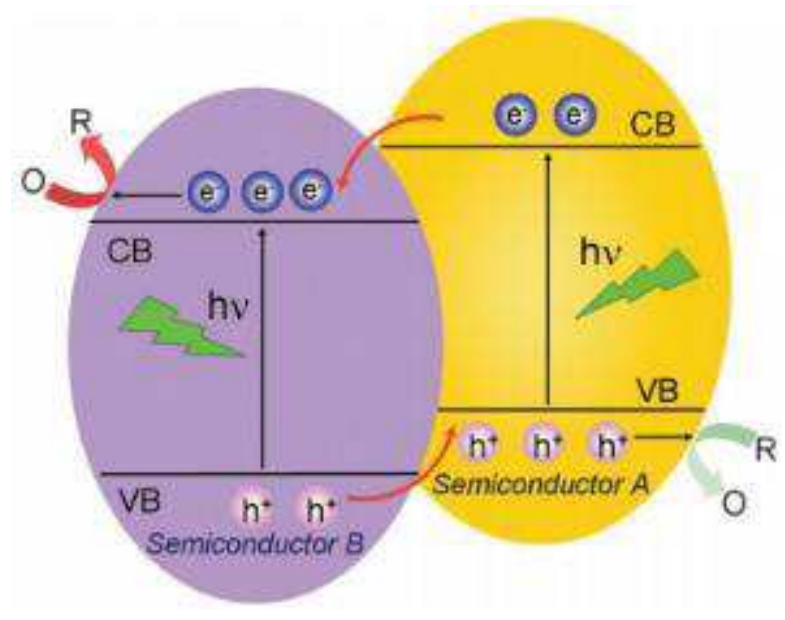

Fonte: Wang et al. (2014).

A heterojunção do $\mathrm{g}-\mathrm{C}_{3} \mathrm{~N}_{4}$ com outra estrutura em escala nanométrica pode não só facilitar a separação das cargas, mas também estender a faixa de absorção solar (YE et al., 2015). 
Diversos semicondutores foram utilizados para esse propósito: óxidos (CHEN et al., 2015), sulfetos (CAO et al., 2013), complexos de níquel (YU et al., 2013), grafeno (XIANG; YU; JARONIEC, 2011), fósforo vermelho (YUAN et al., 2013) etc.

Como observado na Figura 9, há também a possibilidade de heterojunções entre nitretos de carbono grafíticos originários de precursores diferentes como, por exemplo, a partir de ureia e tioureia (DONG et al., 2011).

Figura 9 - Exemplo de estrutura de CB e VB proporcionada por heterojunções g- $\mathrm{C}_{3} \mathrm{~N}_{4} / g-\mathrm{C}_{3} \mathrm{~N}_{4}$

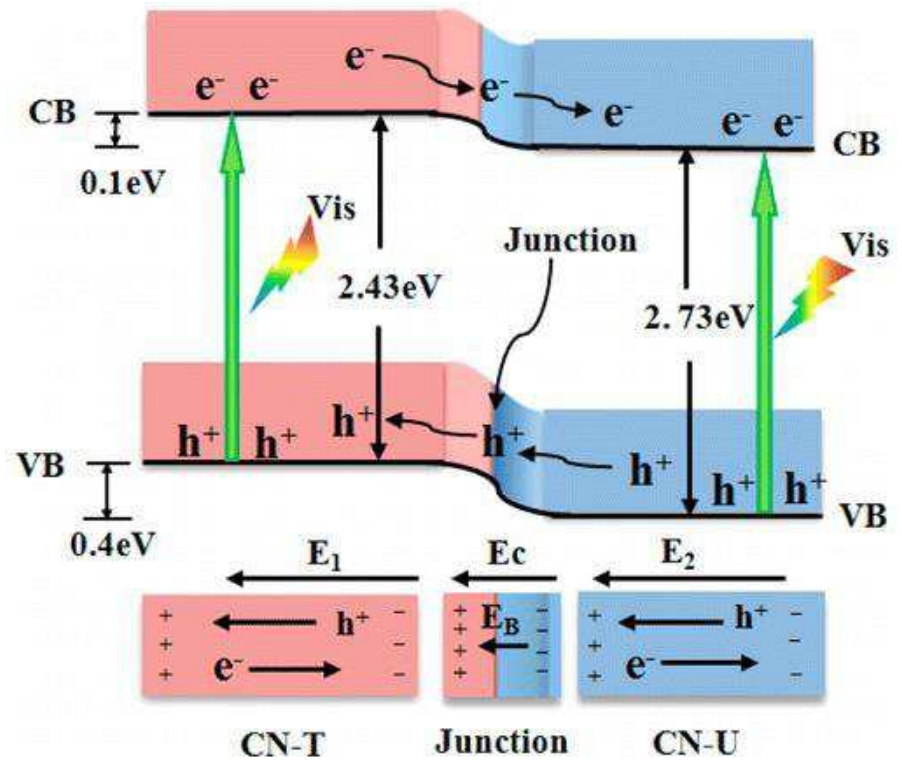

Fonte: Dong et al. (2013).

Esses dois estudos sobre heterojunções apresentaram melhores resultados de degradação fotocatalítica em relação ao estado bruto do $\mathrm{g}-\mathrm{C}_{3} \mathrm{~N}_{4}$. Tendo isto em mente, uma abordagem neste estudo para uma heterojunção é bem vista. Um dos semicondutores utilizados para tal, e também de qualidades desejáveis à fotocatálise é o trióxido de tungstênio $\left(\mathrm{WO}_{3}\right)$.

\subsection{TRIÓXIDO DE TUNGSTÊNIO}

$\mathrm{O} \mathrm{WO}_{3}$ é um óxido metálico capaz de gerar heterojunções adequadas com o $\mathrm{g}-\mathrm{C}_{3} \mathrm{~N}_{4}$. São conhecidas as suas propriedades não estequiométricas, sendo possível a observação de 
formações do tipo $\mathrm{WO}_{2,9}, \mathrm{WO}_{2,83}$ e $\mathrm{WO}_{2,72}$, todas resultantes de deficiências de oxigênio na estrutura cristalina (HUANG et al., 2015).

Sua estrutura cristalina pode apresentar várias fases, sendo as mais comuns: monoclínica, ortorrômbica e hexagonal (HUANG et al., 2015) (Figura 10). Entretanto, a fase cristalina monoclínica tem sido considerada a de maior estabilidade e atividade fotocatalítica (DONG et al., 2017; BAMWENDA; ARAKAWA, 2001; KAILASAM et al., 2015; LUEVANO-HIPOLITO et al., 2014). As fases cristalinas podem ainda sofrer transições entre si em etapas de aquecimento e resfriamento (HUANG et al., 2015), sendo observada uma transição para fase monoclínica em condições de alta temperatura (KIM et al., 2010).

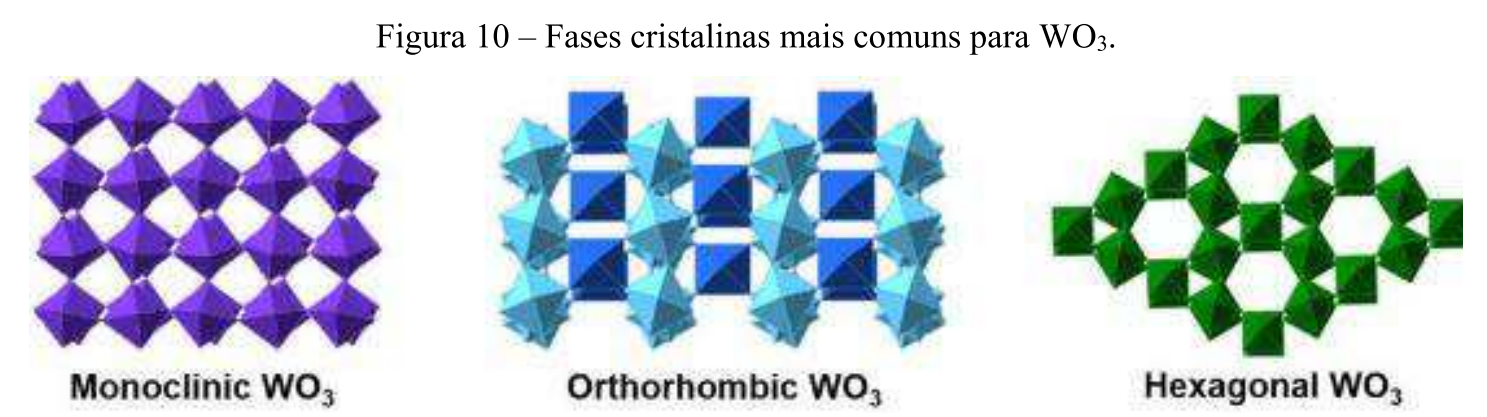

Fonte: Marques et al. (2015).

Devido a diversas qualidades específicas, esse é um importante material em várias áreas, como: sensores solares, supercondutividade, separação fotoeletroquímica da água e fotocatálise heterogênea (JANÁKY et al., 2013). Outras qualidades gerais incluem preço acessível, baixa toxicidade e estabilidade em meios ácidos ou básicos (DONG et al., 2017).

Sua síntese pode ser realizada de diversas maneiras, sendo as principais metodologias: calcinação simples (GEORGAKI; KENANAKIS; KATSARAKIS, 2015), sol-gel (ZHUIYKOV; KATS; KALANTAR-ZADEH, 2014), precipitação ácida (YU; QI, 2009) e oxidação de peroxo-complexos (KIM et al., 2010). Observa-se que a fase cristalina de $\mathrm{WO}_{3}$ obtida depende da metodologia escolhida para sua síntese.

Especificamente, na síntese via peroxo-complexos um precursor de tungstênio é solubilizado em solução de peróxido de hidrogênio, com a consequente formação dos peroxocomplexos. Na metodologia mais clássica, esta solução é seca, formando ácidos peroxotun- 
gísticos que serão encaminhados para calcinação a altas temperaturas (KIM et al., 2010; SAYAMA et al., 2010).

São relatadas, para o $\mathrm{WO}_{3}$, energias de band gap entre 2,4 e 2,8 eV (BAMWENDA; ARAKAWA, 2001; GRANQVIST, 2000; KWONG; SAVVIDES; SORRELL, 2012), garantindo a possibilidade de geração de cargas pela excitação de elétrons a partir de radiação na região do visível. Mais especificamente, já foi demonstrado em trabalhos com filmes que diferentes fases de $\mathrm{WO}_{3}$ podem apresentar diferentes $\mathrm{E}_{\mathrm{g}}$ (GONZÁLES-BORRERO et al., 2010) e, mesmo em uma única fase cristalina, pode haver variação devido à temperatura de calcinação (FLORES-MENA; DÍAZ-REYES; BALDERAS-LÓPEZ, 2012).

Entretanto, a energia das $\mathrm{CB}$ e VB do $\mathrm{WO}_{3}$ em fase monoclínica são mal posicionadas em relação ao ENH. Como mostrado na Figura 11, a CB tem energia mais positiva que o nível de redução do hidrogênio. Ainda, esta banda está em posição desfavorável para a redução do oxigênio e formação de radical superóxido.

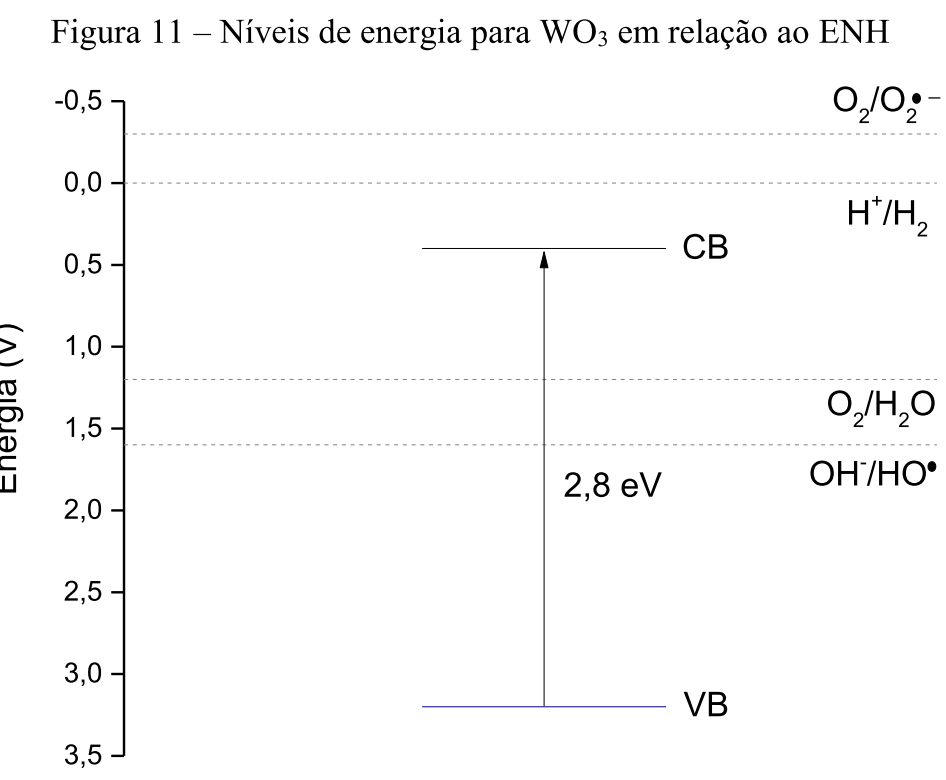

Fonte: Autoria própria.

Sendo assim, o $\mathrm{WO}_{3}$ em fase monoclínica pura não é capaz de promover a evolução fotocatalítica de hidrogênio (DONG et al., 2017). Além disso, o elétron excitado não pode ser consumido eficientemente por moléculas de oxigênio adsorvidas na sua superfície, inviabilizando toda uma rota de radicais oxidantes e, provavelmente, reduzindo sua atividade fotocatalítica para degradação de contaminantes (DONG et al., 2017). 


\subsection{HETEROJUNCÕES g-C $3 \mathrm{~N}_{4} / \mathrm{WO}_{3}$}

Como visto, os dois semicondutores isoladamente e sem modificações, apesar de apresentarem grandes qualidades intrínsecas, não possuem atividade fotocatalítica adequada. Entretanto, as suas deficiências podem ser prontamente eliminadas formando-se heteroestruturas entre eles. A recombinação de cargas facilitada do $\mathrm{g}-\mathrm{C}_{3} \mathrm{~N}_{4}$ e a defasagem dos níveis energéticos do $\mathrm{WO}_{3}$ poderiam ser controladas pela migração de cargas entre ambos os semicondutores em heterojunção do tipo II. A Figura 12 apresenta esta possibilidade.

Figura 12 - Possível heteroestrutura do tipo II para o g- $\mathrm{C}_{3} \mathrm{~N}_{4}$ e o $\mathrm{WO}_{3}$

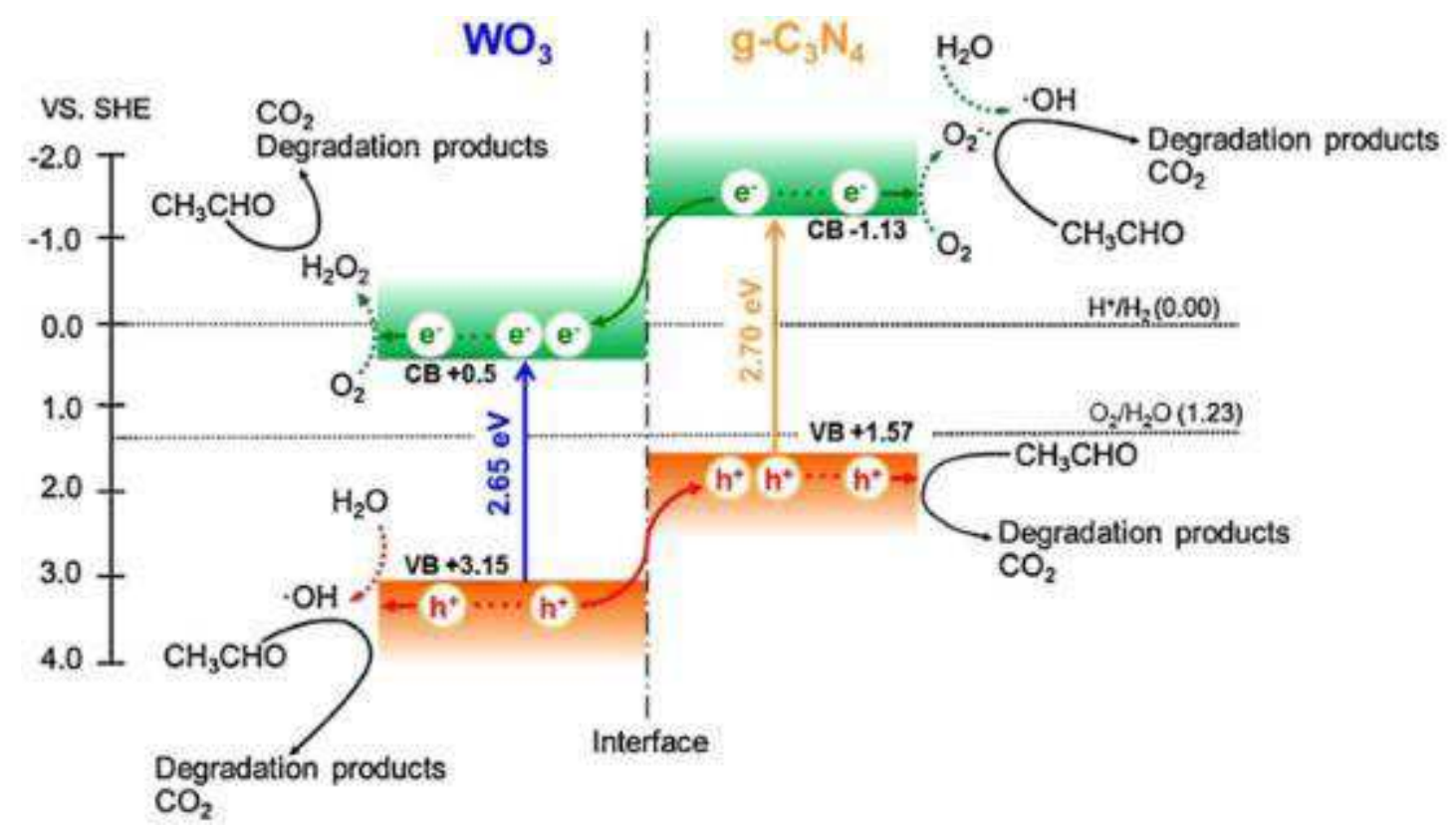

Fonte: Katsumata et al. (2013).

Como observado, várias reações de oxirredução poderiam ocorrer na superfície da heteroestrutura. Em resumo, os elétrons excitados no $\mathrm{g}-\mathrm{C}_{3} \mathrm{~N}_{4}$ poderiam reduzir diretamente o oxigênio adsorvido, gerando radicais oxidantes, ou migrar para a $\mathrm{CB}$ do $\mathrm{WO}_{3}$, com possibilidade da redução de oxigênio para formação de peróxido de hidrogênio, também capaz de degradação. Por outro lado, as lacunas formadas no $\mathrm{WO}_{3}$ poderiam ser direcionadas diretamente para oxidação de água ou compostos orgânicos, gerando radicais oxidantes, ou migrar para a camada de valência do $\mathrm{g}-\mathrm{C}_{3} \mathrm{~N}_{4}$.

De fato, estudos realizados sobre a formação desta heteroestrutura demonstram aumento da atividade fotocatalítica em relação aos semicondutores puros, inclusive a partir de 
irradiação por luz visível (ASLAM, 2014; DING et al., 2015; KATSUMATA et al., 2013; ZHAO et al., 2015).

Estes estudos, entretanto, além de se utilizarem de metodologias relativamente complexas para a incorporação dos semicondutores, sintetizaram o g- $\mathrm{C}_{3} \mathrm{~N}_{4}$ em condições arbitrárias e usaram o $\mathrm{WO}_{3}$ em fases com atividade fotocatalítica relativamente baixa.

\subsection{PLANEJAMENTO DE EXPERIMENTOS E OTIMIZAÇÃO}

Muitos estudos são focados na otimização de um processo, seja ele qual for. Porém, grande parte destes processos possui variáveis que se influenciam mutuamente e a interferência destas variáveis entre si podem gerar erros e falsas conclusões, dificultando a obtenção de uma plena otimização (BARROS NETO; SCARMINIO; BRUNS, 2007).

As metodologias de planejamento empírico são soluções para estes problemas, já que são capazes de extrair um máximo de informações a partir de um menor número de experimentos, inclusive na presença de interferência mútua (BARROS NETO; SCARMINIO; BRUNS, 2007). Dentre as técnicas possíveis de aplicação, a metodologia de superfície de resposta é muito utilizada (BEZERRA et al., 2008).

Em estudos preliminares, utiliza-se geralmente o planejamento fatorial de experimentos, com o objetivo de investigação dos principais fatores de influência nas respostas e suas possíveis interações (BARROS NETO; SCARMINIO; BRUNS, 2007). Para tanto, o planejamento de dois níveis é simples e permite a obtenção de boas informações com um número reduzido de experimentos (DEJAEGHER; HEYDEN, VANDER, 2011).

Num primeiro momento, é necessária a determinação dos fatores e respostas a serem avaliadas. O número de fatores (variáveis) determina o número mínimo de experimentos necessário para a realização do planejamento fatorial: $2^{n}$, sendo $n$ o número de fatores. Entretanto, geralmente são realizadas réplicas genuínas para se estimar o erro experimental, do- 
brando-se o número inicialmente calculado (BARROS NETO; SCARMINIO; BRUNS, 2007).

Os níveis (valores) escolhidos para cada fator são codificados dentro de uma escala adimensional, proporcional à sua localização no espaço experimental. A Equação 1 apresenta a relação entre unidades reais e codificadas (BEZERRA et al., 2008), sendo: $x_{i}$ o nível do fator $i$ codificado $(+1 \mathrm{ou}-1) ; X_{i}$ o nível do fator $i$ original; $\bar{X}_{l}$ o nível médio entre os níveis estudados; e $\frac{A}{2}$ a metade da variação entre os níveis.

$$
x_{i}=\frac{X_{i}-\bar{X}_{l}}{\frac{A}{2}}
$$

Realizados os experimentos iniciais, estes podem ser modelados por regressão linear e a avaliação dos efeitos pode ser feita. A significância dos efeitos é uma estimativa da variação média da resposta quando se passa de um nível inferior para um nível superior. É comum a apresentação da significância dos efeitos a partir de um diagrama de Pareto. O diagrama de Pareto separa os problemas em duas classes de causas: vitais e triviais (BARROS NETO; SCARMINIO; BRUNS, 2007). Em outras palavras, apesar de um problema apresentar várias causas, apenas algumas representam grande impacto na resposta avaliada. É apresentado como barras ordenadas de influência para os fatores e uma linha com o limite de confiança. Os sinais representam a relação com a resposta avaliada: se positivo, um acréscimo do fator modifica positivamente a resposta; se negativo, a resposta é modificada negativamente para uma variação positiva do fator.

Muito frequentemente, as melhores respostas não são observadas neste primeiro conjunto de experimentos. Entretanto, com as informações preliminares obtidas sobre a significância dos efeitos, pode ser realizada uma série de experimentos adicionais na busca da região ótima (caminho de máxima inclinação).

Para tanto, o fator de maior coeficiente em módulo é tomado como referência e determina-se um passo arbitrário para tal, em unidades codificadas. O deslocamento dos demais fatores é proporcional a relação entre o seu coeficiente e o de referência, como descrito na 
Equação 2, sendo: $i$ e $j$ os índices correspondentes ao fator de referência e aquele sendo calculado; e $b$ o coeficiente de cada efeito no modelo ajustado.

$$
\Delta x_{j}=\frac{b_{j}}{b_{i}} \Delta x_{i}
$$

Esta sequência é realizada, com número crescente de passos, até que seja notado um máximo ou mínimo (dependendo do objetivo) na resposta observada. A partir deste momento, em torno do máximo ou mínimo local, é realizado um novo planejamento de experimentos, desta feita com mais de dois níveis para cada fator. Isso permite que seja ajustado um modelo (polinômio) de segunda ordem aos dados experimentais.

Os planejamentos com mais de dois níveis (composto central, fatorial de três níveis, Box-Behnken e Doehlert) são capazes de avaliar curvaturas na superfície de resposta, o que o modelo fatorial de dois níveis não permite (BEZERRA et al., 2008). Assim, no ponto de máximo ou mínimo local encontrado, de provável proximidade ao ponto de melhor resposta global, é interessante a aplicação de um destes modelos.

O planejamento de composto central tem três partes distintas, podendo ser construído sequencialmente de acordo com a necessidade: (1) parcela fatorial, (2) parcela axial e (3) ponto central. Geralmente, realizam-se réplicas do ponto central para averiguação da qualidade do experimento e observação de curvatura. A Figura 13 apresenta a localização destes pontos para um planejamento composto central com três fatores.

Figura 13 - Pontos de um planejamento composto central com três fatores: (•) fatoriais, (o) axiais e ( $\square$ ) central

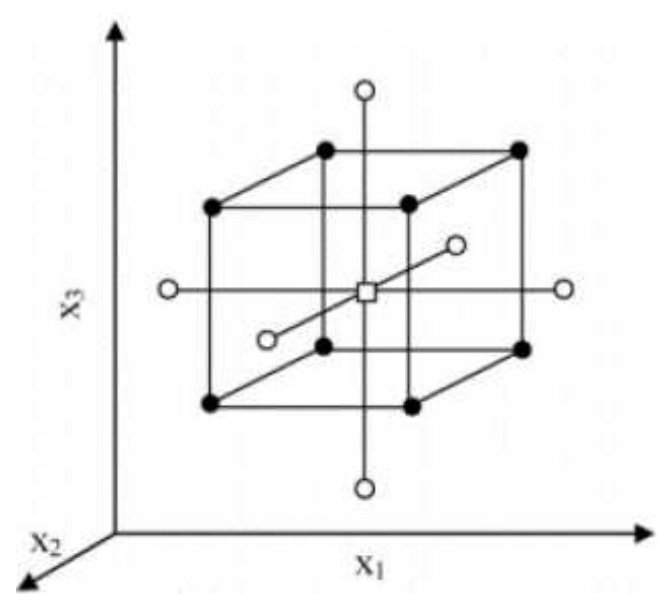

Fonte: Bezerra et al. (2008). 
Aplicados os modelos e ajustados os dados experimentais, é fundamental o exame dos resíduos observados, no sentido de avaliar a qualidade de ajuste. Num modelo ideal, todas as respostas obtidas experimentalmente coincidem com as previsões fornecidas pelo modelo, ou seja, este não possuiria resíduo. O método mais utilizado para tal averiguação é a análise de variância (ANOVA, Analysis of Variance) (BARROS NETO; SCARMINIO; BRUNS, 2007).

Neste método, há uma decomposição algébrica dos desvios das respostas observadas em relação à sua média global em duas parcelas: (1) o desvio das respostas observadas em relação às respostas previstas pelo modelo; (2) o desvio das respostas previstas pelo modelo em relação à média global das respostas observadas (BARROS NETO; SCARMINIO; BRUNS, 2007). Num modelo bem ajustado, a primeira parcela deve ser pequena.

Em termos quantitativos, são tomadas as somas quadráticas destes desvios (SQ ${ }_{\mathrm{i}}$, onde $i$ é o identificador do desvio associado). As Equações 3 e 4 apresentam estas relações, sendo $y_{i}$ a i-ésima resposta observada, $\bar{y}$ a média global das respostas observadas e $\hat{y}$ a resposta prevista pelo modelo.

$$
\begin{gathered}
\sum\left(y_{i}-\bar{y}\right)^{2}=\sum\left(y_{i}-\hat{y}\right)^{2}+\sum(\hat{y}-\bar{y})^{2} \\
S Q_{T}=S Q_{r}+S Q_{R}
\end{gathered}
$$

De posse destes valores, pode-se calcular o coeficiente de determinação $\left(\mathrm{R}^{2}\right)$, que relaciona os desvios gerados pelo modelo de regressão e o desvio total, como descrito na Equação 5. Caso não haja resíduo, $\mathrm{R}^{2}$ será igual à unidade, reduzindo-se conforme aumentam-se os resíduos.

$$
R^{2}=\frac{S Q_{R}}{S Q_{T}}=\frac{\sum(\hat{y}-\bar{y})^{2}}{\sum\left(y_{i}-\bar{y}\right)^{2}}
$$

Cada SQ está associada à um certo número de graus de liberdade, que indica quantos valores independentes observados são necessários para sua determinação (BARROS NETO; SCARMINIO; BRUNS, 2007). Dividindo-se as SQ pelos seus respectivos graus de liberdade obtêm-se as chamadas médias quadráticas $\left(\mathrm{MQ}_{\mathrm{i}}\right.$, onde $i$ é o identificador do desvio associa- 
do). A Tabela 1 apresenta essas e as relações descritas anteriormente, sendo $p$ o número de coeficientes do modelo ajustado e $n$ o número total de observações independentes.

Tabela 1 - Relações da ANOVA, simplificada

\begin{tabular}{cccc}
\hline Fonte de variação & SQ & Graus de Liberdade & MQ \\
\hline Regressão & $\sum(\hat{y}-\bar{y})^{2}$ & $p-1$ & $\frac{\sum(\hat{y}-\bar{y})^{2}}{p-1}$ \\
Resíduos & $\sum\left(y_{i}-\hat{y}\right)^{2}$ & $n-p$ & $\frac{\sum\left(y_{i}-\hat{y}\right)^{2}}{n-p}$ \\
Total & $\sum\left(y_{i}-\bar{y}\right)^{2}$ & $n-1$ & $\frac{\sum\left(y_{i}-\bar{y}\right)^{2}}{n-1}$ \\
\hline
\end{tabular}

Fonte: Autoria própria.

Se os dados possuem repetições, é possível uma estimativa do erro aleatório, gerando um critério quantitativo para julgar se o modelo escolhido é uma boa representação das observações. Para tal, e do mesmo modo que o desvio total do modelo, o desvio originário dos resíduos pode ser decomposto algebricamente em duas parcelas: (1) o desvio de cada réplica de um ensaio distinto em relação à sua própria média; (2) o desvio de cada resposta prevista em relação à média das respostas observadas para o ensaio (BARROS NETO; SCARMINIO; BRUNS, 2007).

O primeiro termo é relacionado ao erro aleatório, chamado de erro puro, refletindo apenas a dispersão dos dados, não relacionado ao modelo ajustado em si. O segundo termo, chamado de falta de ajuste, depende do modelo, sendo maior conforme desviam-se os valores previstos da resposta média observada correspondente. As SQ para estas relações são apresentadas pelas Equações 6 e 7, onde $j$ e $i$ são a j-ésima réplica para o i-ésimo ensaio distinto e $m$ o número de ensaios distintos.

$$
\begin{gathered}
\sum_{i}^{m} \sum_{j}^{n_{i}}\left(y_{i j}-\hat{y}_{i}\right)^{2}=\sum_{i}^{m} \sum_{j}^{n_{i}}\left(y_{i j}-\bar{y}_{i}\right)^{2}+\sum_{i}^{m} \sum_{j}^{n_{i}}\left(\hat{y}_{i}-\bar{y}_{i}\right)^{2} \\
S Q_{r}=S Q_{e p}+S Q_{f a j}
\end{gathered}
$$

De posse destes valores, pode-se calcular o máximo de explicação que o modelo ajustado pode fornecer sobre as respostas observadas. Para tal, desconta-se a SQ originária do 
erro puro da SQ total, sendo esta relação o desvio observado no modelo, e divide-se o resto pela SQ total, como descrito na Equação 8.

$$
R_{\text {max }}^{2}=\frac{S Q_{T}-S Q_{e p}}{S Q_{T}}
$$

Novamente, a cada SQ está relacionado um número de graus de liberdade e consequente MQ. A Tabela 2 complementa a Tabela 1, apresentando estas novas relações.

Tabela 2 - Relações da ANOVA, completa

\begin{tabular}{cccc}
\hline Fonte de Variação & SQ & Graus de Liberdade & MQ \\
\hline Regressão & $\sum_{i}^{m} \sum_{j}^{n_{i}}(\hat{y}-\bar{y})^{2}$ & $p-1$ & $\frac{\sum_{i}^{m} \sum_{j}^{n_{i}}(\hat{y}-\bar{y})^{2}}{p-1}$ \\
Resíduos & $\sum_{i}^{m} \sum_{j}^{n_{i}}\left(y_{i}-\hat{y}\right)^{2}$ & $n-p$ & $\frac{\sum_{i}^{m} \sum_{j}^{n_{i}}\left(y_{i}-\hat{y}\right)^{2}}{n-p}$ \\
Falta de Ajuste & $\sum_{i}^{m} \sum_{j}^{n_{i}}\left(\hat{y}_{i}-\bar{y}_{i}\right)^{2}$ & $m-p$ & $\frac{\sum_{i}^{m} \sum_{j}^{n_{i}}\left(\hat{y}_{i}-\bar{y}_{i}\right)^{2}}{m-p}$ \\
Erro Puro & $\sum_{i}^{m} \sum_{j}^{n_{i}}\left(y_{i j}-\bar{y}_{i}\right)^{2}$ & $n-m$ & $\frac{\sum_{i}^{m} \sum_{j}^{n_{i}}\left(y_{i j}-\bar{y}_{i}\right)^{2}}{n-m}$ \\
\hline Total & $\sum_{i}^{m} \sum_{j}^{n_{i}}\left(y_{i}-\bar{y}\right)^{2}$ & $n-1$ & \\
\hline $\mathrm{R}^{2}$ & $\frac{S Q_{R}}{S Q_{T}}$ & \\
$\mathrm{R}_{\text {max }}^{2}$ & $\frac{S Q_{T}-S Q_{e p}}{S Q_{T}}$ & \\
\hline
\end{tabular}

Fonte: Autoria própria.

Por fim, a análise da significância estatística da regressão pode ser alcançada a partir do Teste F. Este teste admite duas hipóteses: $\left(\mathrm{H}_{0}\right)$ não há diferença estatisticamente significativa entre os grupos analisados; $\left(\mathrm{H}_{1}\right)$ há diferença estatisticamente significativa entre os grupos analisados.

$$
F_{p-1, n-p} \cong \frac{M Q_{R}}{M Q_{r}}
$$

Segundo Barros Neto, Scarminio e Bruns (2007), a razão entre $M Q_{R}$ e $M Q_{r}$ segue uma distribuição F, como descrito na Equação 9. Assim, se se verificar que esta razão é maior que 
$\mathrm{F}_{\mathrm{p}-1, \mathrm{n}-\mathrm{p}}$, teremos evidência estatística suficiente para descartar a hipótese nula em que os desvios gerados pela regressão são iguais aos desvios gerados pelos resíduos. Quanto maior a razão, maior esta evidência. 
3 OBJETIVOS

\subsection{OBJETIVO GERAL}

Otimizar a síntese do nitreto de carbono grafítico, via condensação em fase sólida, a partir do precursor melamina.

\subsection{OBJETIVOS ESPECÍFICOS}

- Observar e discutir os principais fatores que regem a síntese via condensação em fase sóli$\mathrm{da} ;$

- Estimar a região de melhores respostas, a partir dos modelos obtidos na otimização;

- Caracterizar a região otimizada e observar os parâmetros principais para a melhoria da atividade fotocatalítica;

- Observar a formação de heteroestruturas de nitreto de carbono grafítico e trióxido de tungstênio e sua atividade fotocatalítica. 


\section{MATERIAIS E MÉTODOS}

\subsection{PLANEJAMENTO E OTIMIZAÇÃO DE SÍNTESE}

Planejou-se um estudo multivariado da síntese em fase sólida via metodologia de superfícies de resposta (BARROS NETO; SCARMINIO; BRUNS, 2007) com três fatores e dois níveis.

Seguindo a metodologia, criou-se uma matriz de ensaios variando-se todos os fatores simultaneamente, em dois níveis (representados por +1 e -1 ), com duplicatas genuínas e ensaios em sequência aleatória (BARROS NETO; SCARMINIO; BRUNS, 2007). A Tabela 3 e a Figura 14 representam a matriz dos experimentos realizados.

\begin{tabular}{cccc} 
Tabela 3 - Matriz inicial de ensaios. & \multicolumn{3}{c}{ Planejamento fatoria } \\
\hline Ensaio & Fator 1 & Fator 2 & Fator 3 \\
\hline E1 & +1 & +1 & +1 \\
E2 & -1 & -1 & +1 \\
E3 & +1 & -1 & -1 \\
E4 & -1 & -1 & -1 \\
E5 & +1 & -1 & +1 \\
E6 & -1 & -1 & -1 \\
E7 & -1 & +1 & +1 \\
E8 & -1 & +1 & -1 \\
E9 & +1 & -1 & -1 \\
E10 & -1 & +1 & +1 \\
E11 & +1 & +1 & +1 \\
E12 & -1 & +1 & -1 \\
E13 & +1 & +1 & -1 \\
E14 & -1 & -1 & +1 \\
E15 & +1 & +1 & -1 \\
E16 & +1 & -1 & +1 \\
\hline
\end{tabular}

Fonte: Autoria própria.

A partir dos resultados obtidos, avaliou-se a significância dos fatores estudados e estimou-se o erro experimental. Ajustou-se um modelo linear aos dados experimentais e realizou-se uma série de experimentos no sentido de máxima inclinação deste modelo. 
Figura 14 - Representação espacial da matriz inicial de experimentos, planejamento fatorial

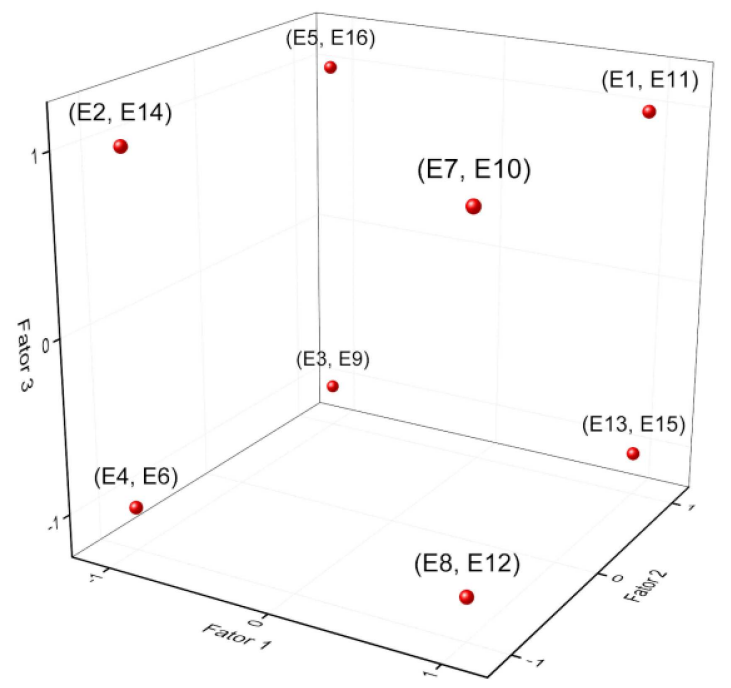

Fonte: Autoria Própria.

Ao redor do ponto de máximo local desta série, foi executado um novo planejamento experimental, desta vez um composto central com dois fatores. Novos níveis foram criados, sendo para cada fator acrescentado os níveis 0 (ponto central) e \pm 1,414 (BARROS NETO; SCARMINIO; BRUNS, 2007). A Tabela 4 e a Figura 15 apresentam estas mudanças, com cinco réplicas genuínas no ponto central.

Tabela 4 - Matriz de ensaios do planejamento composto central

\begin{tabular}{ccc}
\hline Ensaio & Fator 1 & Fator 2 \\
\hline CC1 & -1 & +1 \\
CC2 & 0 & 0 \\
CC3 & 0 & 0 \\
CC4 & 0 & 0 \\
CC5 & $-1,414$ & 0 \\
CC6 & 0 & 0 \\
CC7 & 0 & $+1,414$ \\
CC8 & 0 & $-1,414$ \\
CC9 & -1 & -1 \\
CC10 & 0 & 0 \\
CC11 & +1 & +1 \\
CC12 & +1 & -1 \\
CC13 & $+1,414$ & 0 \\
\hline
\end{tabular}

Fonte: Autoria própria. 
Figura 15 - Representação espacial da matriz de experimentos de composto central

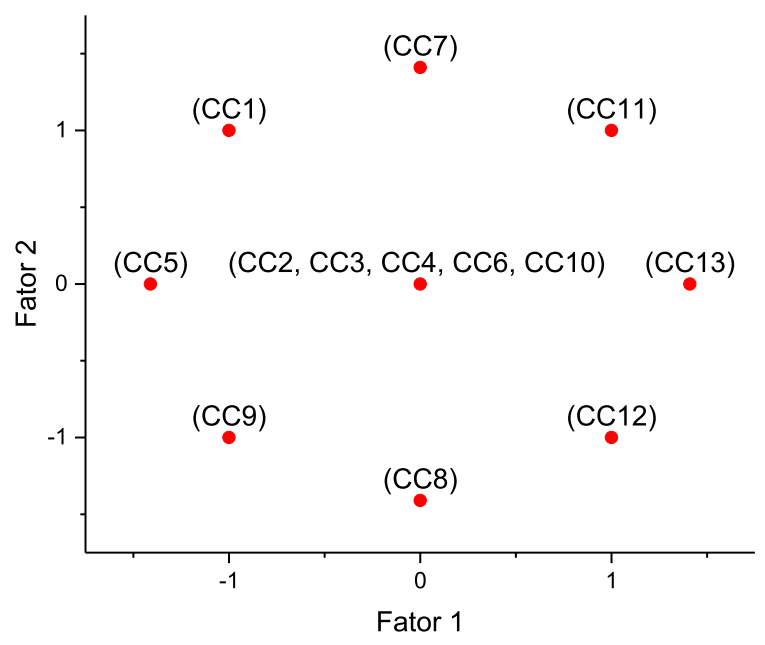

Fonte: Autoria Própria.

Para análise da qualidade das respostas, foi realizada a estimativa dos erros experimentais, a partir da variância global, e ANOVA (BARROS NETO; SCARMINIO; BRUNS, 2007).

\subsection{SÍNTESE EM FASE SÓLIDA}

A síntese em fase sólida foi realizada a partir do precursor melamina (ALDRICH Chemistry, 99\%). Dois gramas foram adicionados a um cadinho de porcelana com tampa (Chiarotti A-45) e tratados sob as condições estabelecidas para cada ensaio da matriz do planejamento em um forno de temperatura controlada (EDG 7000 acoplado a aquecedor EDG EDGCON 3P), sendo o cadinho posicionado no centro do forno durante o tratamento.

Decorrido o tempo de policondensação, o forno foi desligado e resfriado lentamente até a temperatura ambiente. Após o resfriamento, o cadinho foi colocado em um dessecador, nele permanecendo por aproximadamente $24 \mathrm{~h}$.

O sólido resultante foi então pesado, transferido para um almofariz de ágata, triturado manualmente, lavado com $1 \mathrm{~mL}$ de água ultrapura para cada $1 \mathrm{mg}$ de catalisador, seco e no- 
vamente triturado manualmente. Por fim, foi armazenado em um frasco limpo de vidro âmbar.

\subsection{ATIVIDADE FOTOCATALÍTICA}

A avaliação da atividade fotocatalítica do $\mathrm{g}-\mathrm{C}_{3} \mathrm{~N}_{4}$ sintetizado foi avaliada pela degradação de um corante em solução em reator próprio, como mostrado na Figura 16.

Figura 16 - Reator próprio para fotocatálise (a) fechado e (b) aberto

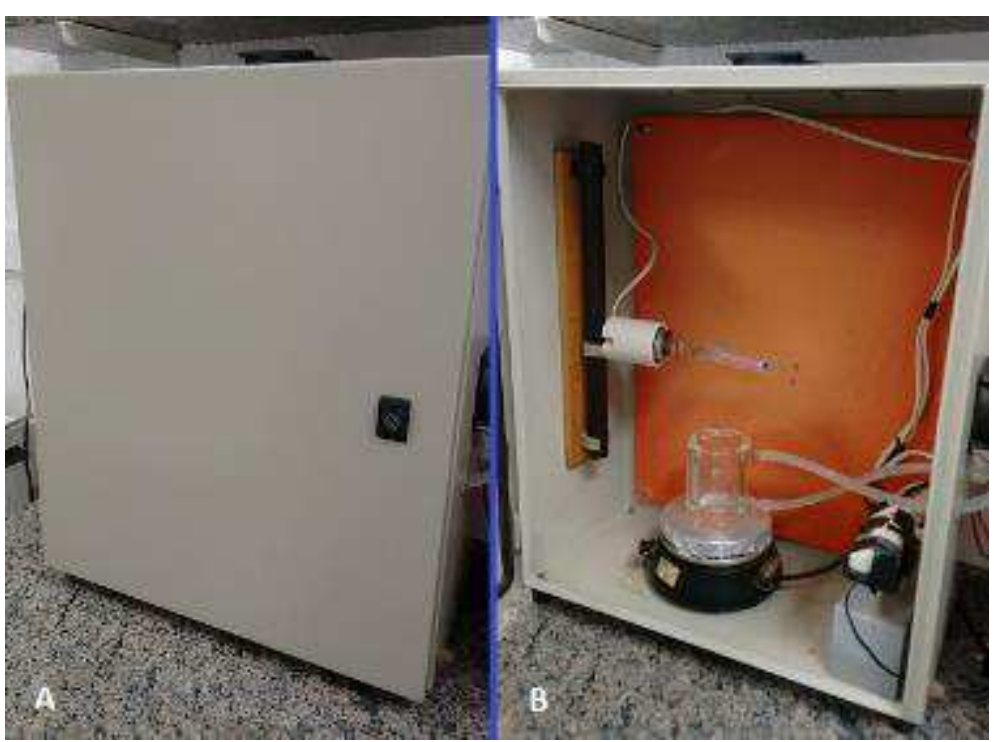

Fonte: Autoria Própria.

Inicialmente, foi preparada uma solução de referência do corante tartrazina na concentração de $20 \mathrm{mg} \mathrm{L}^{-1}$. Esta solução, em seu estado natural, apresenta pH entre 5,5 e 6.

Cinquenta mililitros da solução de referência foram transferidos para um béquer encamisado no interior do reator de fotocatálise, inicialmente nas seguintes condições: $20^{\circ} \mathrm{C}$, mantida por banho termostático; agitação magnética suficiente para manter o sólido (fotocatalisador) em suspensão; e borbulhamento de ar, mantido por meio uma de pequena bomba em

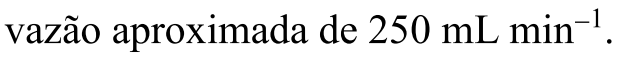

Vinte e cinco miligramas do produto sintetizado foram então adicionados ao béquer. Posteriormente, o béquer foi irradiado com uma lâmpada de vapor de mercúrio de média pres- 
são, modelo Philips HPL-N $250 \mathrm{~W}$, com seu bulbo externo removido, posicionada a $\mathrm{cm}$ da superfície do líquido no béquer, por $30 \mathrm{~min}$.

Em seguida, a suspensão foi filtrada a vácuo em filtros de $0,45 \mu \mathrm{m}$. A concentração resultante de Tartrazina foi avaliada via cromatografia líquida de alta eficiência com detector de arranjo de diodos (HPLC-DAD, High Performance Liquid Chromatography, Diode Array Detector), Agilent Technologies, a partir de adaptação de metodologia desenvolvida anteriormente (FRACCA, 2014).

As condições de análise cromatográfica foram: coluna Agilent ZORBAX SB-C18 $5 \mu \mathrm{m}, 0,3 \times 250 \mathrm{~mm}$, aquecida a $30^{\circ} \mathrm{C}$ e sob vazão constante de $1 \mathrm{~mL} \mathrm{~min}{ }^{-1}$. A eluição ocorreu com um gradiente entre uma solução-tampão acetato $(\mathrm{pH} 4$, preparada a partir de $20 \mathrm{mmol}$ de acetato de amônio e $10 \mathrm{~mL}$ de ácido acético, para $1 \mathrm{~L}$ de água) e metanol, como descrito na Figura 17. O detector DAD foi ajustado para adquirir dados em $427 \mathrm{~nm}$, comprimento de onda de máxima absorção da tartrazina.

Figura 17 - Gradiente de eluição

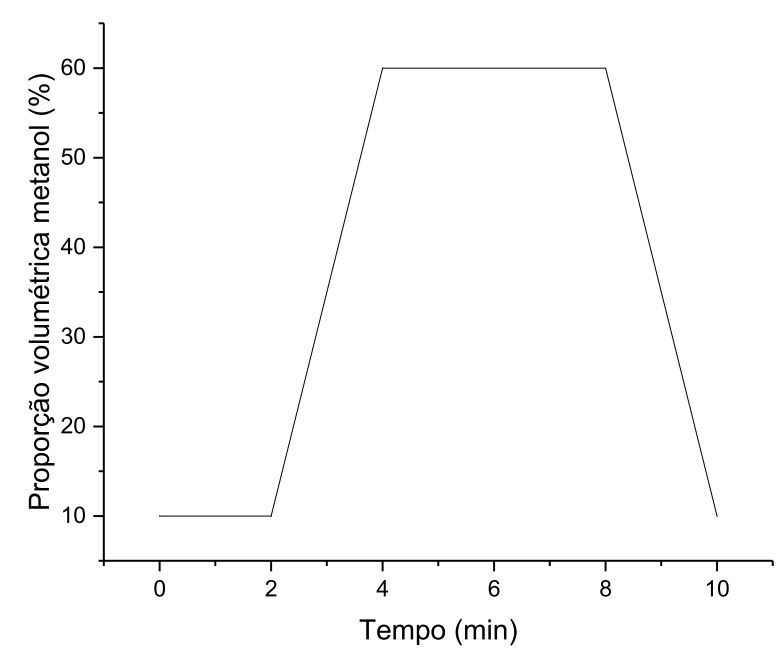

Fonte: Autoria Própria. 
Os cálculos referentes à área dos picos cromatográficos (necessários para avaliação da degradação do corante) foram realizados pelo próprio software que controla o equipamento, Agilent ChemStation ${ }^{\circledR}$.

\subsection{CARACTERIZAÇÕES DOS PRODUTOS}

\subsubsection{DIFRAÇÃO DE RAIOS X}

As análises foram realizadas em equipamento Shimadzu XRD 6000. Foi utilizado filtro de níquel resultando numa radiação de comprimento de onda de $0,154 \mathrm{~nm}$, referente à linha de emissão $\mathrm{Cu} \mathrm{K} \alpha$. As condições de rotina utilizadas nas análises foram passo angular e tempo de integração de $0,02^{\circ}$ e 4 segundos, respectivamente. O instrumento foi operado em voltagem de $30 \mathrm{kV}$ e corrente de $30 \mathrm{kA}$, em varredura contínua, de 5 a $60^{\circ}$ para amostras do nitreto de carbono em estado bruto e de de 5 a $70^{\circ}$ para amostras de heteroestruturas.

Para o cálculo da distância entre planos cristalográficos, foi utilizada a lei de Bragg (Equação 10), sendo $n$ um número inteiro, $\lambda$ o comprimento de onda dos feixes de raios $\mathrm{X}$, $d$ a distância entre planos e $2 \theta$ o ângulo de incidência (SKOOG; HOLLER; NIEMAN, 2002).

$$
n \lambda=2 d \cdot \sin (\theta)
$$

\subsubsection{ESPECTROSCOPIA NA REGIÃO DO INFRAVERMELHO MÉDIO}

As análises na região do infravermelho, com transformada de Fourier, (FTIR, Fourier Transform Infrared Spectroscopy) em equipamento Bruker VERTEX 70, via reflectância total atenuada (ATR, Attenuated Total Reflectance), a partir do pó da amostra em estado bruto, sem diluições. Foi obtido o espectro de reflectância, em 32 varreduras, na faixa de 400 aos 4000 $\mathrm{cm}^{-1}$, sob resolução de $4 \mathrm{~cm}^{-1}$. 


\subsubsection{MEDIDA DA ÁREA SUPERFICIAL ESPECÍFICA}

A medida de ASE foi realizada utilizando-se da modelagem BET (Brunauer, Emmet e Teller) (FAGERLUND, 1973) em equipamento Micromeritics ASAP 2020. Anteriormente à obtenção das isotermas de adsorção, as amostras foram submetidas a um pré-tratamento (fase de degaseificação) sob baixa pressão à temperatura de aproximadamente $90^{\circ} \mathrm{C}$, até atingirem pressão de degaseificação inferior a $6 \mu \mathrm{mHg}$.

\subsubsection{MICROSCOPIA ELETRÔNICA}

As medidas por microscopia eletrônica de varredura (SEM, Scanning Electron Microscopy) foram realizadas em um microscópio JEOL JSM 6510. Na preparação das amostras para a análise de SEM utilizou-se um porta-amostras com fita de carbono. O pó dos materiais sintetizados foi depositado com cuidado sobre a fita e o excesso removido.

As medidas por microscopia eletrônica de varredura com canhão de elétrons do tipo emissão por campo (FEG, Field Emission Gun), foram feitas em equipamento modelo FEG-SEM, JEOL JSM 6701F. Para as amostras de heteroestruturas também foram obtidas microfotografias com detector de retroespalhamento de elétrons (BSED, Backscatter Eléctron Detector). A preparação das amostras foi realizada a partir do gotejamento de uma suspensão pouco concentrada do material em suporte de sílicio, fixado em porta-amostra com fita de carbono. A suspensão foi feita em isopropanol e mantida em banho de ultrassom por $10 \mathrm{~min}$.

Além disso, materiais foram estudados através da microscopia eletrônica de transmissão (TEM, Transmition Electron Microscopy) e também no modo de alta resolução (HRTEM, High Resolution Transmition Electron Mocroscopy). O equipamento utilizado foi o microscópio TECNAI G2 F10-LaB6, operando a 200 kV. A composição semiquantitativa dos elementos foi analisada por energia dispersiva de raios X (EDX, Energy Dispersive X-ray Analysis), acoplado ao microscópio. As amostras foram preparadas de maneira similar às do SEM-FEG, porém o gotejamento foi feito em grids de cobre recobertos de carbono. 


\subsubsection{MEDIDA DO POTENCIAL ZETA}

As medidas de potencial zeta foram realizadas em equipamento Malvern Zetasizer Nano - ZS. As amostras foram dispersas em água de alta pureza por sonicação. A dispersão foi realizada em vários $\mathrm{pHs}$, partindo-se da neutralidade até meios altamente ácidos.

\subsubsection{REFLECTÂNCIA DIFUSA NA REGIÃO DO ULTRAVIOLETA-VISÍVEL}

A determinação do valor da $\mathrm{E}_{\mathrm{g}}$ dos materiais foi realizada utilizando-se um equipamento espectrômetro Varian Cary 5G, no modo de reflectância difusa (DRS, Diffuse Reflectance Spectroscopy), disponível no LIEC - UFSCar. A varredura feita foi de 200 a $800 \mathrm{~nm}$, sem diluições, após a moagem inicial em almofariz de ágata, utilizando-se sulfato de bário $\left(\mathrm{BaSO}_{4}\right)$ como padrão.

O modelo utilizado para a interpretação das curvas é descrito pela Equação 11, conhecida como transformada ou função de reflectância de Kubelka-Munk (GIANNAKOPOULOU et al., 2017), $F_{\mathrm{R}}$. Nela, $R_{\lambda}$ corresponde ao valor de reflectância para um dado comprimento de onda.

$$
F_{R}=\frac{\left(1-R_{\lambda}\right)^{2}}{2 R_{\lambda}}
$$

Os valores de reflectância, $F_{\mathrm{R}}$, calculados por essa função, são utilizados na Equação 12 ( $E_{\lambda}$ é a energia de um dado comprimento de onda), para a obtenção da função de absorção, $f_{\mathrm{E}}$.

$$
f_{E}=\sqrt{E_{\lambda} \cdot F_{R}}
$$

$O$ termo $E_{\lambda}$ pode ser estimado dividindo-se 1.240 pelo respectivo comprimento de onda. Plotando-se $f_{\mathrm{E}}$ vs. $E_{\lambda}$, a $\mathrm{E}_{\mathrm{g}}$ pode ser estimada pela intersecção da tangente à curva com a abscissa, como descrito na metodologia de extrapolação das curvas de Tauc (TAUC; 
GRIGOROVICI; VANCU, 1966). Na Equação 12, o expoente 0,5 foi utilizado devido ao caráter indireto das transições tanto para o $\mathrm{g}-\mathrm{C}_{3} \mathrm{~N}_{4}$ em estado bruto, quanto para o $\mathrm{WO}_{3}$ (ZHANG; CHEN; WANG, 2015; GRANQVIST, 2000).

\subsubsection{ANÁLISE TERMOGRAVIMÉTRICA}

As análises termogravimétricas (TGA, Thermal Gravimetric Analysis) foram realizadas em um equipamento TA Instruments Q500, nas condições: intervalo de 30 a $700^{\circ} \mathrm{C}$, taxa

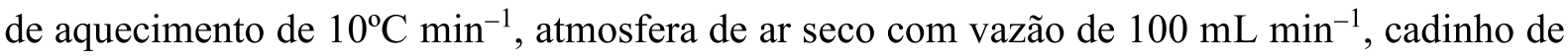
platina e massa da amostra de aproximadamente $7 \mathrm{mg}$.

\subsection{FORMAÇÃO DE HETEROESTRUTURAS ENTRE $\mathrm{g}-\mathrm{C}_{3} \mathrm{~N}_{4} \mathrm{E} \mathrm{WO}_{3}$}

Com o objetivo de se obter heteroestruturas com o $\mathrm{WO}_{3}$, o material sintetizado no ponto ótimo foi utilizado e empregou-se a metodologia de formação de óxido de tungstênio via peroxo-complexos (KIM et al., 2010; SAYAMA et al., 2010; BICA et al., 2009).

Assim, uma massa fixa de ácido túngstico (0,2155 g, SIGMA-ALDRICH, 99\%) foi adicionada a $40 \mathrm{~mL}$ de peróxido de hidrogênio 2,5 mol.L - $^{-1}$ (Synth, P.A. 29\%). Após a completa dissolução do ácido e a formação de peroxo-complexos de tungstênio, uma massa variável do $\mathrm{g}-\mathrm{C}_{3} \mathrm{~N}_{4}$ foi adicionada.

Esta suspensão formada foi sonicada (Branson Digital Sonifier 450, 400W, amplitude de $20 \%$ ), por um período de $20 \mathrm{~min}$, em banho de gelo. Após este tratamento, as amostras foram liofilizadas.

Os produtos liofilizados foram colocados em um cadinho de porcelana com tampa (Chiarotti A-45) e calcinados em uma mufla (modelo EDG 7000 acoplado a aquecedor EDG EDGCON 3P). A temperatura de calcinação foi de $400^{\circ} \mathrm{C}$, mantida por $120 \mathrm{~min}$, sendo o cadinho posicionado no centro da mufla durante o tratamento térmico. Estas condições foram 
escolhidas devido à instabilidade de $\mathrm{g}-\mathrm{C}_{3} \mathrm{~N}_{4}$ em temperaturas superiores aos $500^{\circ} \mathrm{C}(\mathrm{SHI}$ et al., 2014; ZHANG et al., 2012) e a maior possibilidade de formação da fase monoclínica (mais ativa) de $\mathrm{WO}_{3}$ (KIM et al., 2010).

Decorrido o tempo de calcinação, a mufla foi desligada e resfriada lentamente até a temperatura ambiente. Após o resfriamento, o cadinho foi colocado em um dessecador, permanecendo nele por aproximadamente $24 \mathrm{~h}$. A massa resultante foi então transferida para um almofariz de ágata, triturada manualmente e armazenada em um frasco limpo de vidro âmbar.

Foram executados cinco experimentos, com diferentes proporções teóricas entre o g- $\mathrm{C}_{3} \mathrm{~N}_{4}$ e o $\mathrm{WO}_{3}$, além de experimentos-controle contendo apenas os semicondutores puros. As proporções foram de 20, 40, 50, 60 e $80 \%$ em massa de $g-\mathrm{C}_{3} \mathrm{~N}_{4}$.

A massa de ácido túngstico foi escolhida levando-se em consideração sua possível total conversão para $\mathrm{WO}_{3}$, gerando teoricamente $0,2000 \mathrm{~g}$ do semicondutor. A Tabela 5 apresenta a massa dos precursores adicionados para a formação das relações desejadas.

\begin{tabular}{|c|c|c|}
\hline $\begin{array}{c}\mathrm{g}-\mathrm{C}_{3} \mathrm{~N}_{4} \\
(\%)\end{array}$ & $\begin{array}{l}\text { Ác. Túng. } \\
\text { (g) }\end{array}$ & $\begin{array}{c}\mathrm{g}-\mathrm{C}_{3} \mathrm{~N}_{4} \\
(\mathrm{~g})\end{array}$ \\
\hline 0 & 0,2155 & 0,0000 \\
\hline 20 & 0,2155 & 0,0500 \\
\hline 40 & 0,2155 & 0,1333 \\
\hline 50 & 0,2155 & 0,2000 \\
\hline 60 & 0,2155 & 0,3000 \\
\hline 80 & 0,2155 & 0,8000 \\
\hline 100 & 0,0000 & 0,2000 \\
\hline
\end{tabular}

Fonte: Autoria própria. 


\section{RESULTADOS E DISCUSSÕES}

\subsection{OTIMIZAÇÃO DA SÍNTESE EM FASE SÓLIDA DO g-C $\mathrm{C}_{3} \mathrm{~N}_{4}$}

\subsubsection{CONSIDERAÇÕES INICIAIS}

O método de síntese utilizado foi o de condensação em fase sólida, o mais tradicionalmente empregado e considerado de referência por autores que trabalham com o g- $\mathrm{C}_{3} \mathrm{~N}_{4}$ (YE et al., 2015). Na realidade, grande parte dos estudos avalia modificações desta metodologia na busca de maiores atividades fotocatalíticas. Há exemplos de estudos de modificação com abordagens sintéticas (BOJDYS et al., 2008; DAI et al., 2013; LIN, L. et al., 2015), morfológicas (HAN et al., 2015), de dopagem (HU et al., 2014; LIN; WANG, 2013), de heterojunção (CHEN et al., 2015; KUANG et al., 2015) e de sensibilização (CHENG et al., 2015).

A metodologia de síntese em fase sólida tende a fornecer resultados relativamente inferiores aos das modificações (YE et al., 2015). Mesmo no procedimento padrão, as condições utilizadas não têm padrão definido, sendo elas arbitrárias para cada autor. Um conjunto de condições amplamente escolhido é o de temperatura final de calcinação de $550^{\circ} \mathrm{C}$, mantida por $4 \mathrm{~h}$ (CHEN et al., 2016; KAILASAM et al., 2015; LU et al., 2014; XING et al., 2014).

Os níveis dos fatores empregados no planejamento de experimentos inicial foram escolhidos com base na literatura, como uma média dos conjuntos de condições mais amplamente utilizados para este precursor.

Nos experimentos de fotocatálise heterogênea, utilizou-se o composto em estado bruto, sem as etapas de esfoliação comumente aplicadas (YE et al., 2015). Esta escolha teve por objetivo evitar uma nova fonte de variabilidade na síntese: diferentes eficiências na esfoliação das amostras.

As condições de fotocatálise como temperatura, tempo de irradiação, grau de agitação, vazão de oxigênio, concentração do fotocatalisador e distância entre a lâmpada e a suspensão 
sendo irradiada também foram fixadas em condições intermediárias às encontradas em literatura.

A lâmpada emite comprimentos de onda tanto na região do ultravioleta quanto na do visível (Figura 18). Os dois picos entre 400 e $500 \mathrm{~nm}$ têm, teoricamente, energia suficiente para promover os elétrons da VB para a CB do g- $\mathrm{C}_{3} \mathrm{~N}_{4}$ (CAO et al., 2015; DONG et al., 2011; WANG et al., 2009). Entretanto, Wang afirma que as condições de síntese via condensação em fase sólida podem gerar modificações nas propriedades eletrônicas e óticas do $g-\mathrm{C}_{3} \mathrm{~N}_{4}$ (WANG et al., 2009). Assim, é interessante a presença do pico de maior irradiância entre 365 $\mathrm{nm}$, capaz de excitar elétrons mesmo de amostras sintetizadas em condições não otimizadas.

Figura 18 - Espectro de emissão de lâmpada de vapor de mercúrio média pressão, modelo Philips HPL-N $250 \mathrm{~W}$

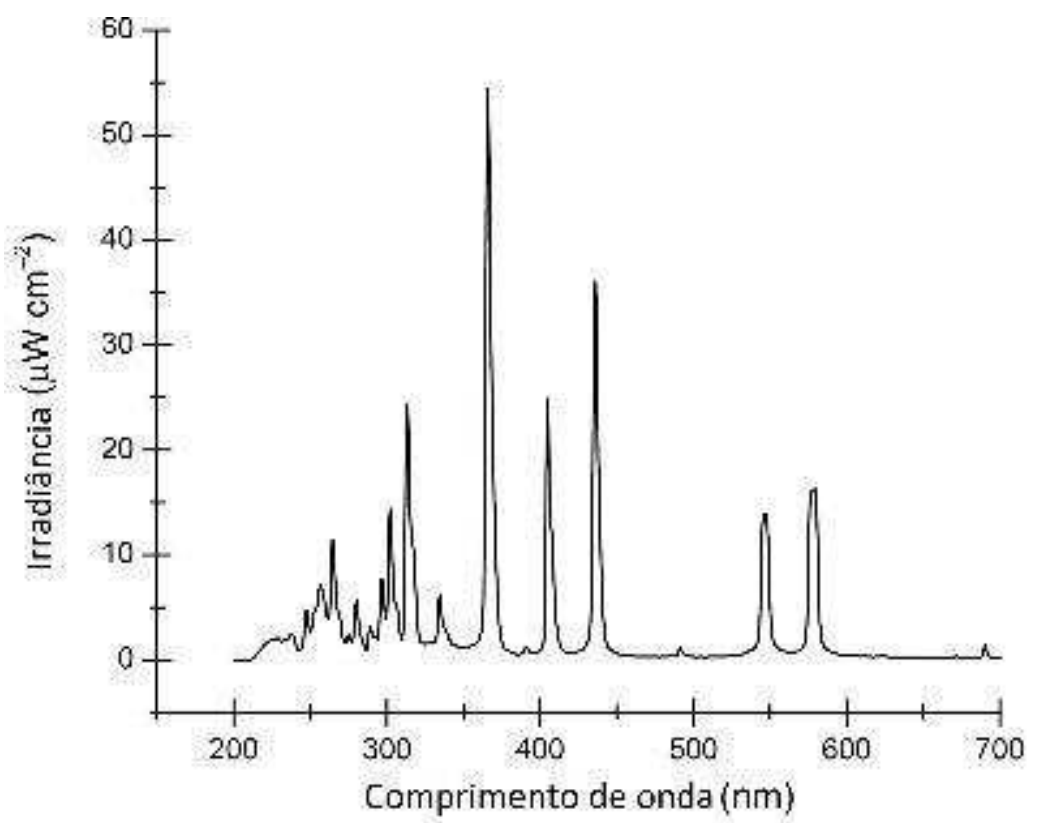

Fonte: Padovan e Azevedo (2015).

A molécula-modelo utilizada como alvo de degradação foi a tartrazina (Acid Yellow 23, Food Yellow 4 ou FD\&C Yellow 5) que se trata de um corante azóico (Figura 19), amplamente utilizado na indústria de fármacos, alimentos e cosméticos. Já foram relatados casos de intolerâncias e alergias em humanos, além do possível agravamento de casos de asma (MOUTINHO; BERTGES; ASSIS, 2007). Países como Suíça, Suécia e Noruega proibiram o seu uso (WÜTHRIC, 1993) e, no Brasil, a Agência Nacional de Vigilância Sanitária (ANVISA) exige nos produtos o aviso da presença de tartrazina (ANVISA, 2002). 
Figura 19 - Estrutura química da tratrazina

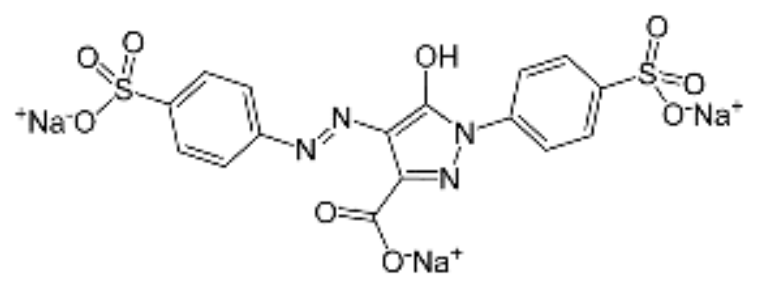

Fonte: Autoria própria.

A Figura 20 apesenta cromatogramas da solução inicial de tartrazina e após sua degradação, com o surgimento de pico positivo e negativo, relacionados à intermediários de degradação, que absorvem no mesmo ou em comprimentos de onda próximos ao analisado, respectivamente.

Figura 20 - Cromatogramas de soluções de tartrazina: (a) inicial e (b) após degradação

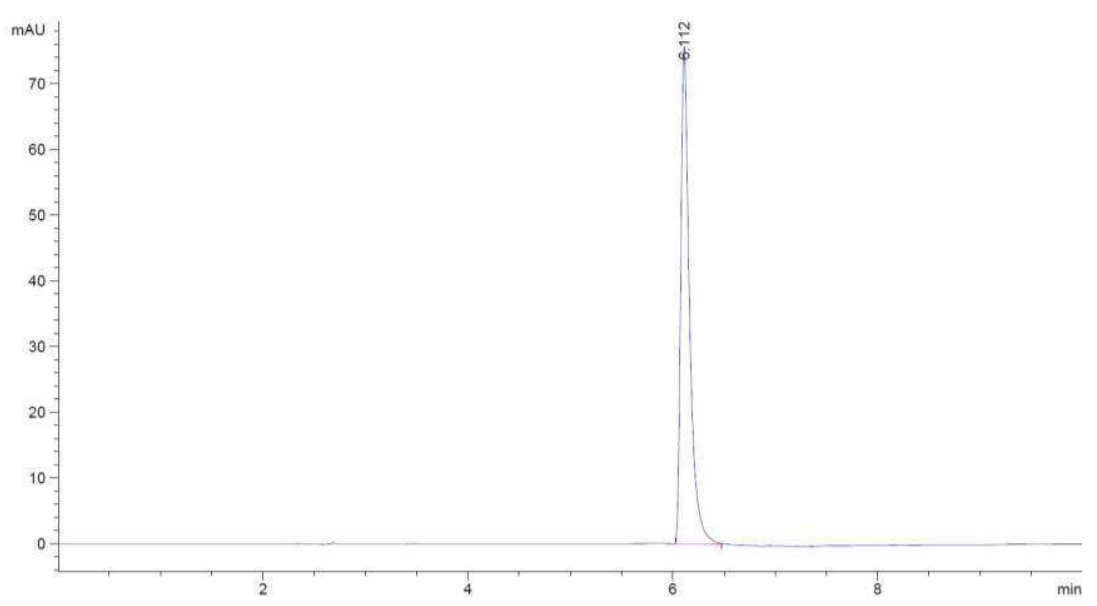

(a)

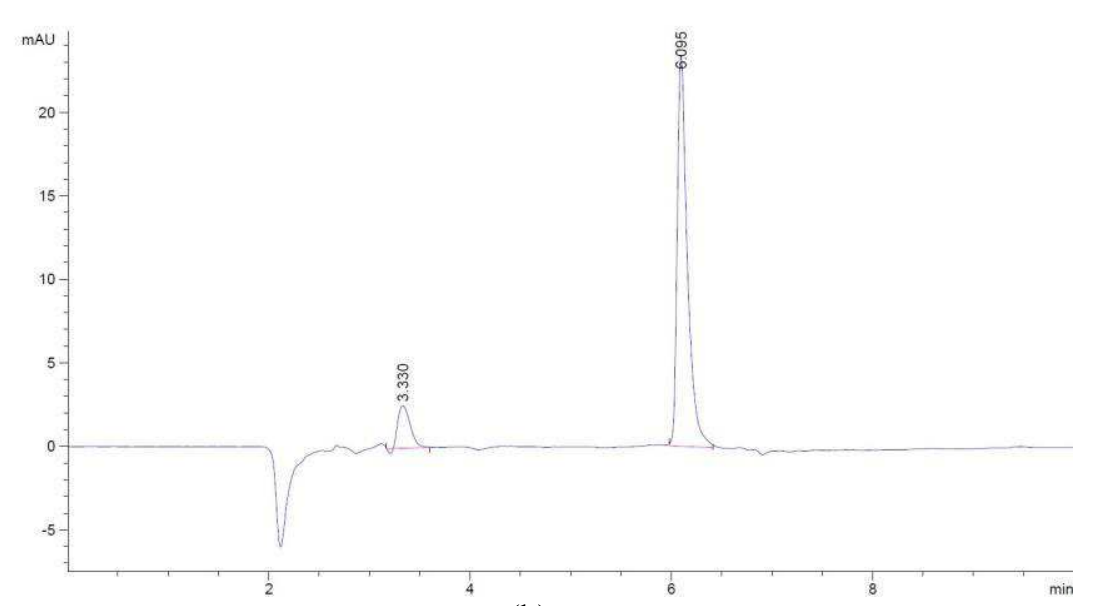

(b)

Fonte: Autoria própria. 


\subsubsection{PLANEJAMENTO EXPERIMENTAL E RESPOSTAS FOTOCATALÍTICAS}

Foram estipulados os níveis dos fatores da matriz de planejamento fatorial como mostrado na Tabela 6. Tais níveis estão entre os limites observados na literatura previamente consultada e apresentam variações significativas nas respostas avaliadas (PAPAILIAS et al., 2015; ZHANG et al., 2012; DONG et al., 2013). Esses níveis, a partir este ponto, foram considerados equivalentes a unidades codificadas destes fatores.

Tabela 6 - Níveis e, portanto, unidades codificadas dos três fatores

\begin{tabular}{cccc}
\hline Níveis & $\begin{array}{c}\text { Taxa de } \\
\text { Aquecimento } \\
\left({ }^{\circ} \mathrm{C} \mathrm{\text {min } ^ { - 1 } )}\right.\end{array}$ & $\begin{array}{c}\text { Temperatura } \\
\text { Final } \\
\left({ }^{\circ} \mathrm{C}\right)\end{array}$ & $\begin{array}{c}\text { Tempo } \\
(\mathrm{h})\end{array}$ \\
\hline+1 & 10 & 600 & 3 \\
-1 & 5 & 500 & 2 \\
\hline
\end{tabular}

Fonte: Autoria própria.

A Tabela 7 apresenta os resultados para o rendimento mássico da síntese e o descoramento da solução de tartrazina, obtidos na execução do planejamento inicial.

Tabela 7 - Respostas obtidas para cada ensaio

\begin{tabular}{ccc}
\hline Ensaio & $\begin{array}{c}\text { Rendimento Mássico } \\
(\%)\end{array}$ & $\begin{array}{c}\text { Remoção de Corante } \\
(\%)\end{array}$ \\
\hline E1 & 24,4 & 42,3 \\
E2 & 42,6 & 35,6 \\
E3 & 34,1 & 44,3 \\
E4 & 43,4 & 39,7 \\
E5 & 30,7 & 52,0 \\
E6 & 44,4 & 36,1 \\
E7 & 38,3 & 31,7 \\
E8 & 39,6 & 24,4 \\
E9 & 33,1 & 41,4 \\
E10 & 37,2 & 31,7 \\
E11 & 22,0 & 51,3 \\
E12 & 39,8 & 23,9 \\
E13 & 28,1 & 33,2 \\
E14 & 42,8 & 34,8 \\
E15 & 29,5 & 36,2 \\
E16 & 28,8 & 63,3 \\
\hline
\end{tabular}

Fonte: Autoria própria. 
Os rendimentos mássicos variaram entre $20 \%$ e $45 \%$, enquanto as degradações entre $25 \%$ e $60 \%$. Os melhores rendimentos foram obtidos nas amostras E4 e E6, ambas réplicas genuínas com as condições: $500^{\circ} \mathrm{C}, 2 \mathrm{~h}$, e $5^{\circ} \mathrm{C} \min ^{-1}$. Já as maiores degradações foram obtidas nas amostras E5 e E16, ambas réplicas genuínas com as condições: $600^{\circ} \mathrm{C}, 3 \mathrm{~h}$ e $\quad 5^{\circ} \mathrm{C}$ $\min ^{-1}$.

Como, a princípio, a atividade fotocatalítica foi considerada mais importante do que o rendimento da síntese, buscou-se então somente a otimização da degradação da tartrazina. Além disso, em condições relativamente brandas de síntese (como as dos experimentos E4 e E6) há indícios da presença de resquícios de precursores ou intermediários da reação (CHU et al., 2014; WU et al., 2014; YE et al., 2015).

Ajustou-se então um modelo empírico linear (Equação 13) aos dados experimentais de degradação, considerando-se apenas os efeitos principais. Nesta equação, $R$ é a rampa de aquecimento, $T$ a temperatura e $t$ o tempo, em unidades codificadas. Todos os cálculos foram realizados no software Statistica ${ }^{\circledR} 10$, utilizando-se um limite de confiança de $95 \%$ e modelos sem interações. O erro padrão estimado foi de 3,9\%. O diagrama de Pareto (Figura 21) apresenta a significância dos fatores na resposta.

$$
\text { Remoção Corante }(\%)=38,87+6,63 \cdot T-4,53 \cdot R+3,97 \cdot t
$$

Figura 21 - Gráfico de Pareto para a \% de degradação de tartrazina (planejamento fatorial, sem interações)

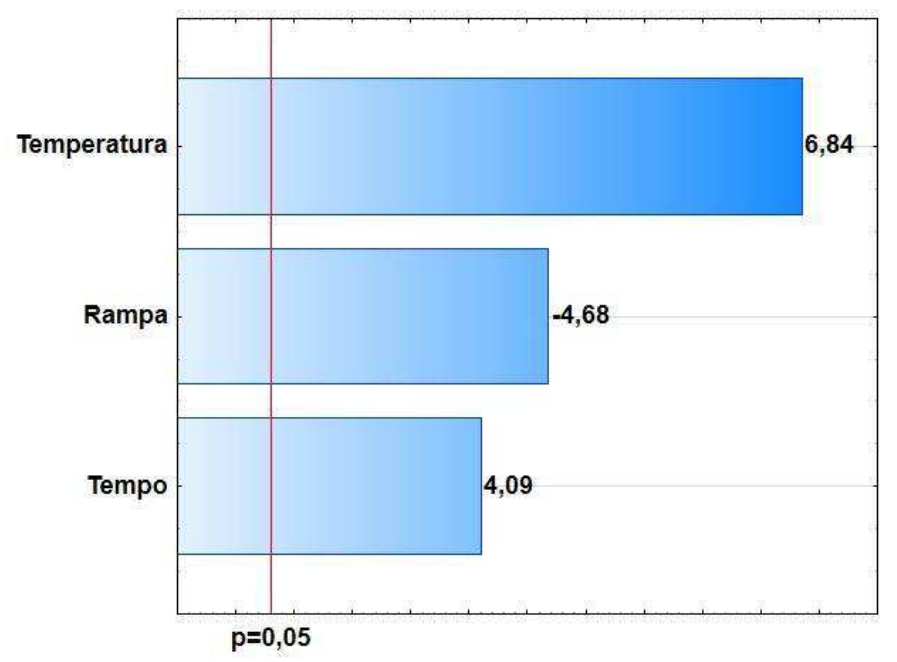

Fonte: Autoria Própria. 
A partir da Figura 21, observa-se que todos os fatores foram significativos para este modelo, com $95 \%$ de confiança. O fator mais significativo foi a temperatura final, seguido da taxa de aquecimento (rampa) e do tempo de permanência na temperatura final. Mais ainda, na busca da região ótima (caminho de máxima inclinação), dever-se-ia aumentar a temperatura final, o tempo de permanência nela e diminuir a rampa de aquecimento.

De acordo com a Equação 2, nos experimentos a serem realizados na busca da região ótima, a variação aplicada à rampa de aquecimento teria de ser de décimos de grau. Como isso não era possível com a mufla utilizada nas sínteses, fixou-se este fator em seu nível inferior $\left(5^{\circ} \mathrm{C} \mathrm{min}^{-1}\right)$, o que garantiria melhores respostas.

Assim, os experimentos realizados foram aqueles mostrados na Tabela 8 (já com as respostas obtidas). Os experimentos foram realizados a partir do ponto central, somando-se a cada passo um valor proporcional aos coeficientes do modelo. Ou seja, foram somados a cada passo $15^{\circ} \mathrm{C}$ na temperatura final e entre 7 a 8 min no tempo.

Tabela 8 - Condições de cada passo do caminho de máxima inclinação e suas respostas $\left(\right.$ rampa $\left.=5^{\circ} \mathrm{C} \min ^{-1}\right)$

\begin{tabular}{cccc}
\hline Ensaio & $\begin{array}{c}\text { Temperatura } \\
\left({ }^{\circ} \mathrm{C}\right)\end{array}$ & $\begin{array}{c}\text { Tempo } \\
(\mathrm{min})\end{array}$ & $\begin{array}{c}\text { Remoção de Corante } \\
(\%)\end{array}$ \\
\hline P0 & 550 & 150 & 38,7 \\
P1 & 565 & 158 & 41,4 \\
P2 & 580 & 165 & 44,1 \\
P3 & 595 & 173 & 48,6 \\
P4 & 610 & 180 & 51,8 \\
P5 & 625 & 188 & 46,8 \\
\hline
\end{tabular}

Fonte: Autoria própria.

A melhor resposta foi obtida no ponto P4 (Tabela 8), ou seja, P4 era um máximo local. Em torno deste ponto foi construído um planejamento composto central para se modelar a possível região de melhor resposta, com níveis (novas unidades codificadas) apresentados na Tabela 9.

Tabela 9 - Níveis dos fatores do planejamento composto central

\begin{tabular}{ccc}
\hline Níveis & $\begin{array}{c}\text { Temperatura Final } \\
\left({ }^{\circ} \mathrm{C}\right)\end{array}$ & $\begin{array}{c}\text { Tempo } \\
(\mathrm{min})\end{array}$ \\
\hline$+1,414$ & 624 & 187 \\
+1 & 620 & 185 \\
0 & 610 & 180 \\
-1 & 600 & 175 \\
$-1,414$ & 596 & 173 \\
\hline
\end{tabular}

Fonte: Autoria própria. 
A matriz dos experimentos do planejamento composto central é apresentada na Tabela 10 , juntamente com as respectivas respostas para a remoção do corante tartrazina.

\begin{tabular}{cccc} 
Tabela $10-$ Condições do planejamento composto central e suas resp \\
\cline { 2 - 4 } Ensaio & $\begin{array}{c}\text { Temperatura } \\
\left({ }^{\circ} \mathrm{C}\right)\end{array}$ & $\begin{array}{c}\text { Tempo } \\
(\mathrm{min})\end{array}$ & $\begin{array}{c}\text { Remoção de Corante } \\
(\%)\end{array}$ \\
\hline CC1 & 600 & 185 & 55,5 \\
CC2 & 610 & 180 & 53,3 \\
CC3 & 610 & 180 & 52,8 \\
CC4 & 610 & 180 & 55,3 \\
CC5 & 596 & 180 & 49,1 \\
CC6 & 610 & 180 & 53,9 \\
CC7 & 610 & 187 & 50,0 \\
CC8 & 610 & 173 & 42,6 \\
CC9 & 600 & 175 & 44,4 \\
CC10 & 610 & 180 & 53,6 \\
CC11 & 620 & 185 & 48,1 \\
CC12 & 620 & 175 & 46,8 \\
CC13 & 624 & 180 & 47,3 \\
\hline
\end{tabular}

Fonte: Autoria própria.

Ajustou-se então um modelo (Equação 14) aos dados experimentais de degradação, considerando os coeficientes lineares, quadráticos e de interação para as variáveis. Nesta equação, $T$ é a temperatura e $t$ o tempo, em unidades codificadas. Todos os cálculos foram realizados no software Statistica ${ }^{\circledR} 10$, utilizando-se um limite de confiança de 95\%. O diagrama de Pareto (Figura 22) apresenta a significância estatística dos fatores na resposta.

$$
\text { Remoção Corante }(\%)=53,74-0,94 \cdot T-2,41 \cdot T^{2}+2,86 \cdot t-3,39 \cdot t^{2}-2,45 . T \cdot t
$$

Figura 22 - Gráfico de Pareto para a \% de degradação de tartrazina (planejamento composto central)

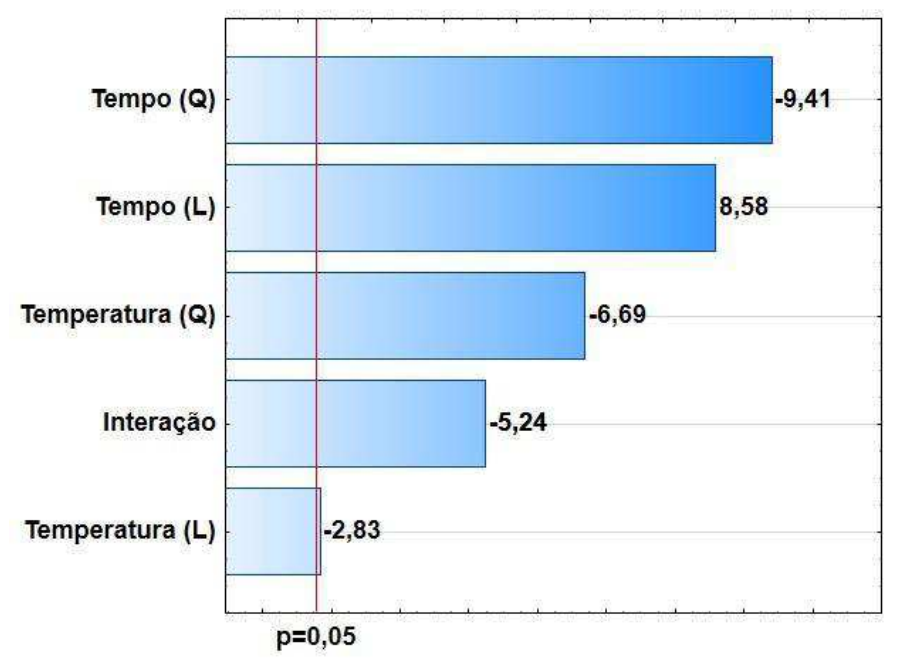

Fonte: Autoria Própria. 
A Tabela 11 apresenta a análise de variância. Para este modelo, o valor de F calculado é de 30,64, aproximadamente 7,72 vezes maior que o tabelado para estes graus de liberdade: 3,97. Sendo assim, como a estatística $\mathrm{F}$ é maior que o $\mathrm{F}$ crítico para estes graus de liberdade, pode-se dizer que o modelo está bem ajustado aos dados experimentais. Porém como a estatística $\mathrm{F}$ não é superior a 10 vezes o $\mathrm{F}$ crítico, o modelo não pode ser utilizado para fins preditivos, sendo necessária a realização de experimentos adicionais para confirmar os valores estimados pelo modelo.

Tabela 11 - ANOVA para o composto central

\begin{tabular}{cccc}
\hline Fonte de variação & SQ & Graus de liberdade & MQ \\
\hline Regressão & 211,0 & 5 & 42,2 \\
Resíduos & 9,64 & 7 & 1,38 \\
Falta de ajuste & 0,002 & 3 & $5,4.10^{-3}$ \\
Erro puro & 3,51 & 4 & 0,88 \\
\hline Total & 220,6 & 12 & \\
\hline $\mathrm{R}^{2}$ & 0,956 & & \\
$\mathrm{R}^{2}$ max & 0,984 & & \\
\hline
\end{tabular}

Fonte: Autoria própria.

Nota-se que os termos relacionados a falta de ajuste são muito pequenos. Isto se deve ao fato que foram realizadas réplicas apenas para o ponto central e a média entre as respostas destes experimentos ser muito próxima da prevista pelo modelo ajustado.

O erro experimental pôde ser estimado a partir das réplicas realizadas no ponto central, valendo-se do desvio-padrão, do valor tabelado da distribuição " $t$ " de Student em função do número de graus de liberdade: $\pm 0,9 \%$.

A Figura 23a apresenta a superfície de respostas, criado a partir do modelo ajustado. Observa-se que o ponto de máxima resposta global se encontra entre os experimentos $\mathrm{CC} 1$ e o ponto central (Figura 23b). Mais especificamente, determinou-se o ponto ótimo do tratamento nas coordenadas codificadas $-0,50$ e $+0,60$, ou seja, $605^{\circ} \mathrm{C}$ e $183 \mathrm{~min}$. 
Figura 23 - Remoção de tartrazina: (a) superfície de resposta e (b) localização do ponto ótimo (azul)

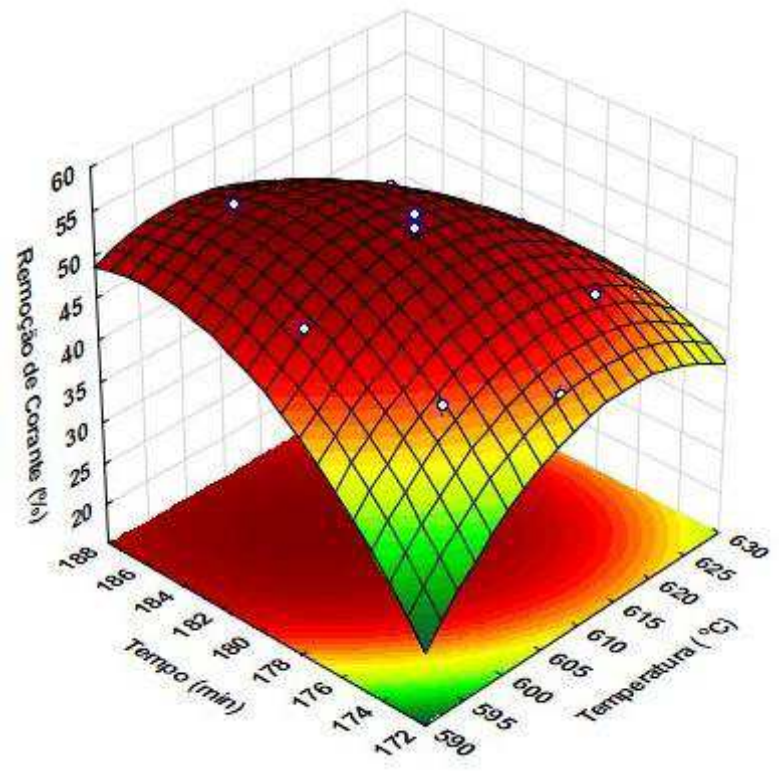

(a)

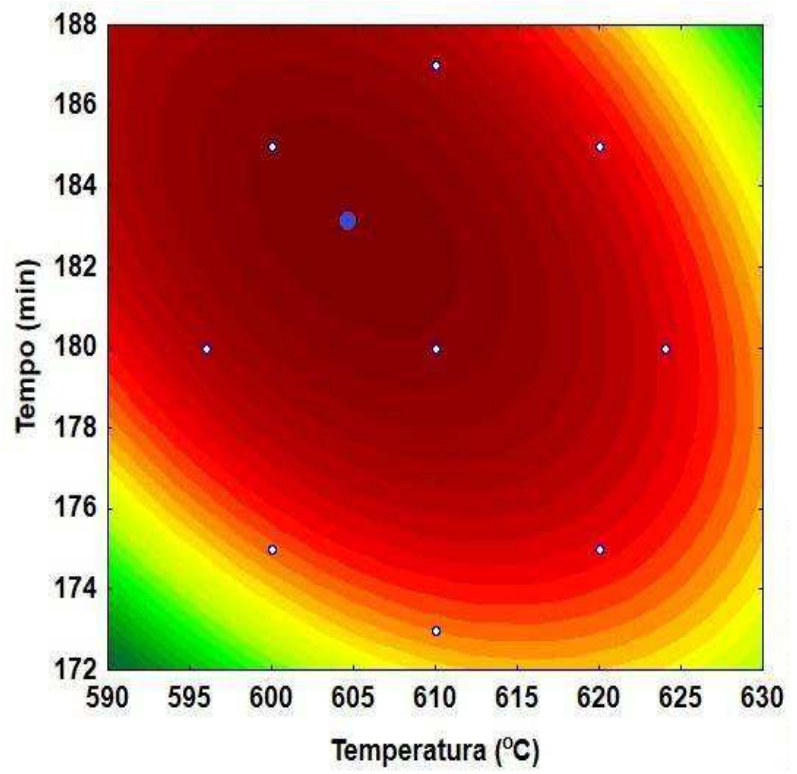

(b)

Fonte: Autoria Própria.

Para confirmar algumas degradações estimadas pelo modelo, foram realizados experimentos em seis condições diferentes. Os resultados obtidos encontram-se apresentados na Tabela 12, juntamente com as respostas estimadas pelo modelo. Estes experimentos incluem o ponto ótimo, o ponto central, a amostra $\mathrm{CC} 1$ e outros três pontos que possuem coordenadas exteriores aos limites do composto central.

Tabela 12 - Experimentos adicionais e suas respostas previstas e experimentais

\begin{tabular}{cccccc}
\hline Ensaio & $\begin{array}{c}\text { Temperatura Final } \\
\left({ }^{\circ} \mathrm{C}\right)\end{array}$ & $\begin{array}{c}\text { Tempo } \\
(\mathrm{min})\end{array}$ & $\begin{array}{c}\text { Remoção de Corante } \\
\text { Estimada } \\
(\%)\end{array}$ & $\begin{array}{c}\text { Remoção de Corante } \\
\text { Experimental } \\
(\%)\end{array}$ & $\begin{array}{c}\text { Desvios do Modelo em } \\
\text { Relação aos } \\
\text { Experimentos }(\%)\end{array}$ \\
\hline CF1 & 590 & 180 & 46,0 & 47,7 & 1,7 \\
CF2 & 590 & 190 & 47,9 & 46,7 & 1,2 \\
CF3 & 600 & 185 & 54,2 & 55,2 & 1,0 \\
CF4 & 610 & 180 & 53,7 & 53,2 & 0,5 \\
CF5 & 610 & 190 & 45,9 & 44,5 & 1,4 \\
OT & 605 & 183 & 54,8 & 56,1 & 1.3 \\
\hline
\end{tabular}

Fonte: Autoria própria.

Os dados experimentais possuem concordância satisfatória com os valores estimados, sendo os desvios observados provavelmente relacionadas à pequenos erros experimentais. 
De posse do ponto de melhor resposta fotocatalítica, obteve-se a cinética de remoção da tartarzina. A Figura 24 apresenta os resultados para a adsorção, a fotólise e a fotocatálise (triplicata). Os pontos representam as degradações obtidas e linha representa os valores estimados para um modelo cinético de primeira ordem (Equação 15). Nesta equação $C$ é a concentração do corante em determinado tempo de reação, $C_{0}$ é a concentração inicial de tartrazina, $k$ é a taxa de remoção e $t$ o tempo transcorrido.

$$
\frac{C}{C_{o}}=e^{-k t}
$$

Observa-se que a remoção por fotocatálise foi superior à fotólise e que não houve adsorção significativa. Por fotocatálise, foi possível remover aproximadamente $90 \%$ da concentração inicial de tartrazina em 90 min. A Tabela 13 apresenta as constantes de taxa de remoção estimadas $\left(\min ^{-1}\right)$ e os respectivos coeficientes de determinação. Percebe-se que a degradação fotocatalítica foi 3 vezes mais rápida que a fotólise.

Figura 24 - Cinética de remoção de tartrazina: (ם) adsorção, $(\bullet)$ fotólise e $(\boldsymbol{\Delta})$ fotocatálise

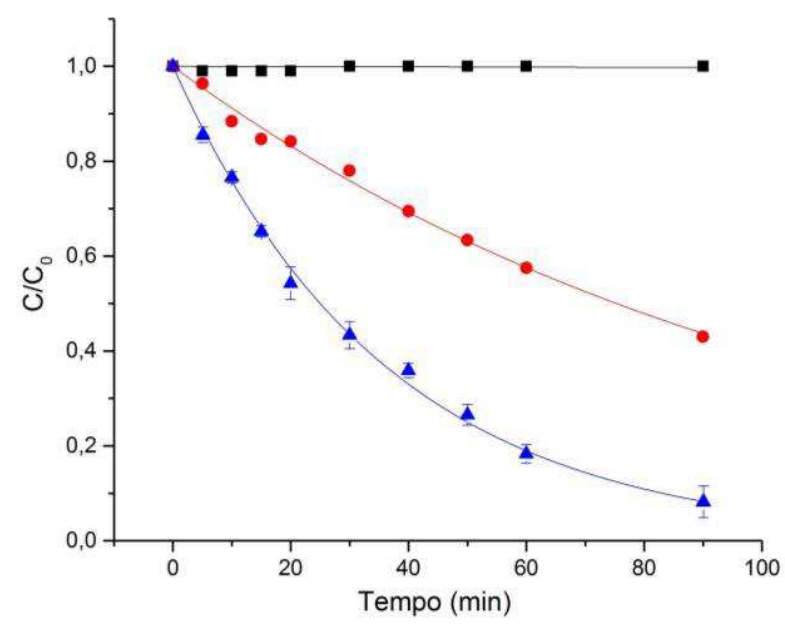

Fonte: Autoria Própria.

Tabela 13 - Taxas de remoção do corante tartrazina por fotólise e fotocatálise $\left(\mathrm{g}-\mathrm{C}_{3} \mathrm{~N}_{4}\right)$

\begin{tabular}{ccc}
\hline Ensaio & $\begin{array}{c}\text { Constantes de Taxa } \\
\text { de Remoção }\left(\mathrm{min}^{-1}\right)\end{array}$ & $\mathrm{R}^{2}$ \\
\hline Fotólise & $0,0092 \pm 0,0002$ & 0,993 \\
Fotocatálise & $0,028 \pm 0,003$ & 0,997 \\
\hline
\end{tabular}

Fonte: Autoria Própria. 
Os resultados das fotocatálises não podem ser considerados como uma soma das contribuições da fotólise e fotocatálise propriamente dita, já que o meio fotocatalítico se torna turvo na presença do fotocatalisador. Ou seja, a contribuição da fotólise é pequena nesses experimentos, sendo os resultados primordialmente referentes à atuação do fotocatalisador.

Por fim, é interessante uma visualização do caminho percorrido durante esta otimização, apresentando a sequência de condições experimentais utilizados para a construção dos modelos propostos (Figura 25). Nesta figura, não é representado o fator taxa de aquecimento.

Figura 25 - Condições experimentais para os pontos: (1) planejamento fatorial, (2) caminho de máxima inclinação, (3) planejamento composto central e (4) ponto ótimo

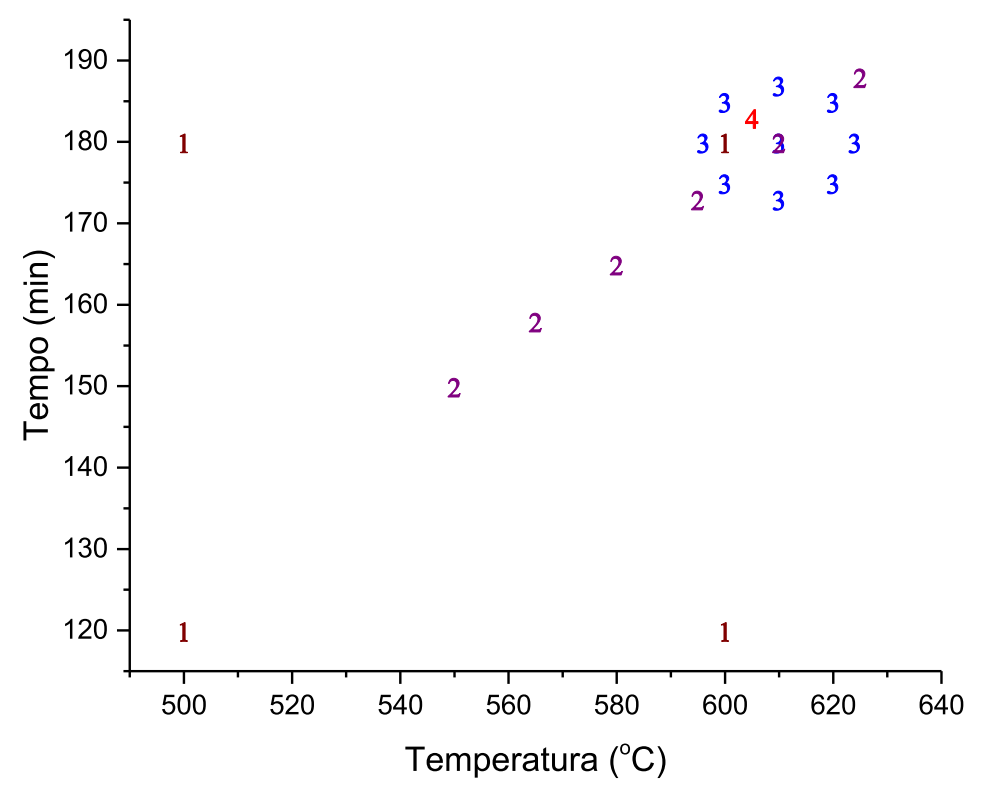

Fonte: Autoria Própria.

\subsection{CARACTERIZAÇÃO DA REGIÃO ÓTIMA}

Uma série de experimentos de caracterização foram executados para elucidar o motivo de a região encontrada pelo planejamento experimental possuir a melhor resposta fotocatalítica, em especial o ponto ótimo estimado.

Esses ensaios têm condições próximas à região de melhor resposta fotocatalítica e, portanto, são ideais para a tentativa de elucidação dos motivos dos melhores resultados. Do 
mesmo modo, a amostra E8, do planejamento inicial, em algumas das caracterizações é utilizada como representativa de condições brandas de síntese. Esta amostra serve de contraponto à região de melhor resposta fotocatalítica, de condições relativamente mais drásticas.

\subsubsection{DIFRAÇÃO DE RAIOS X}

Foram obtidos difratogramas de raios $\mathrm{X}$ de amostras de todas as condições de sínteses. Os resultados obtidos possibilitam o seu agrupamento em dois grupos, conforme a similaridade de seu padrão de difração, como demonstrado na Figura 26. Amostras cujas temperaturas de síntese se aproximam de $600^{\circ} \mathrm{C}$ apresentam o comportamento clássico esperado para o g- $\mathrm{C}_{3} \mathrm{~N}_{4}$ (representadas pela amostra OT) (JCPDS 87-1526, PAPAILIAS et al., 2015; SHI et al., 2014), enquanto as que não atingem este patamar apresentam indícios de interferentes (representadas pela amostra E8) (JÜRGENS et al., 2003).

Figura 26 - Padrão de difração para amostras sintetizadas em condições brandas $\left(500^{\circ} \mathrm{C}\right)$ e drásticas $\left(600^{\circ} \mathrm{C}\right)$ de temperatura

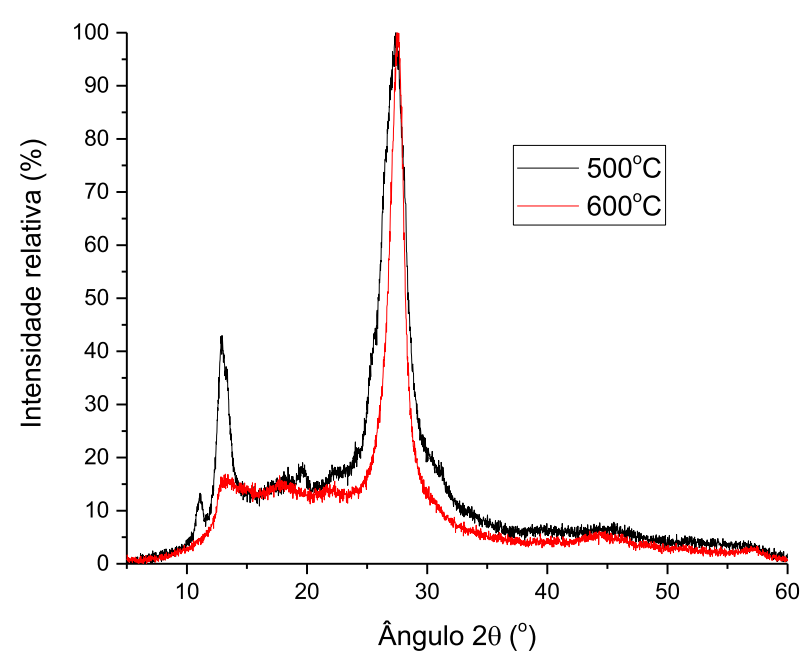

Fonte: Autoria Própria.

Para as amostras do primeiro grupo, sintetizadas em temperaturas de aproximadamente $600^{\circ} \mathrm{C}$, são notados principalmente os picos em torno de $27^{\circ}$ e em torno de $13,1^{\circ}$, sendo estes relacionados ao plano (002) e (100) de $\mathrm{g}-\mathrm{C}_{3} \mathrm{~N}_{4}$, respectivamente. Picos menos característicos podem ser notados em 17,5 e $22^{\circ}$, relacionados à um maior empacotamento entre as lamelas de $\mathrm{g}-\mathrm{C}_{3} \mathrm{~N}_{4}$ (SHI et al., 2014). 
Já amostras sintetizadas em temperaturas de aproximadamente $500^{\circ} \mathrm{C}$, apresentam pico próximo de $12,8^{\circ}$ (e dos de menor intensidade próximos à $19,9^{\circ}, 26^{\circ}$ e $31^{\circ}$ ) que podem estar relacionados a intermediários de condensação, como o melem (2,5,8-triamino-tri-striazina) ou seu dímero (JÜRGENS et al., 2003; PAPAILIAS et al., 2015).

O pico em $13,1^{\circ}$ é referente ao empacotamento estrutural no plano de unidades de tri$s$-triazina (DAI et al., 2013; PAPAILIAS et al., 2015), com distâncias interplanares próximas de $0,684 \mathrm{~nm}\left(\right.$ calculado, para $\left.13^{\circ}\right)$. Este pico é evidência de que o nitreto de carbono é formado por anéis heptazínicos.

O pico em torno de $27^{\circ}$ corresponde à sobreposição entre camadas aromáticas, (DAI et al., 2013; PAPAILIAS et al., 2015), com distâncias interplanares próximas de 0,339 nm (calculado, para $\left.27^{\circ}\right)$. Esta distância é próxima à encontrada no grafite $(0,335 \mathrm{~nm})$ (DATTA et al., 2011), indicando a similaridade das interações entre planos adjacentes (DAI et al., 2013).

Sobre as amostras em que o perfil difratrográfico sugere a presença de melem, um estudo recente sobre o uso da fotocatálise para a evolução de gás hidrogênio demonstrou que este material tem piores resultados que o $\mathrm{g}-\mathrm{C}_{3} \mathrm{~N}_{4}$, sintetizado a partir de melamina, mesmo que em condições diferentes das ótimas calculadas por esta dissertação (CHU et al., 2014).

Portanto, pode-se inferir que a atividade fotocatalítica do grupo de amostras sintetizadas em condições brandas é prejudicada pela presença de intermediários (provavelmente o melem). Neste grupo estão inclusas todas as amostras que em na matriz do planejamento fatorial possuíam unidade codificada de temperatura -1 .

\subsubsection{ESPECTROSCOPIA NA REGIÃO DO INFRAVERMELHO MÉDIO COM TRANSFORMADA DE FOURIER}

Foram realizadas análises FTIR para amostras das condições finais de síntese. Estas amostras apresentam, principalmente, os seguintes picos (Figura 27): o pico em torno de 800 $\mathrm{cm}^{-1}$ pode ser atribuído ao modo de respiração do anel de triazina (WU et al., 2014); as bandas entre 1.570 e $1634 \mathrm{~cm}^{-1}$ e 1.258 e $1.480 \mathrm{~cm}^{-1}$ são atribuídas ao estiramento das ligações 
$\mathrm{C}-\mathrm{N}$ e $\mathrm{C}=\mathrm{N}$, respectivamente, pertencentes ao esqueleto aromático (PAPAILIAS et al., 2015; WU et al., 2014); e os picos entre $3000-3300 \mathrm{~cm}^{-1}$ são relacionados ao estiramento das ligações dos grupamentos $-\mathrm{NH} / \mathrm{NH}_{2}$ (PAPAILIAS et al., 2015).

Figura 27 - Espectro de FTIR típico de amostra relativa aos experimentos finais

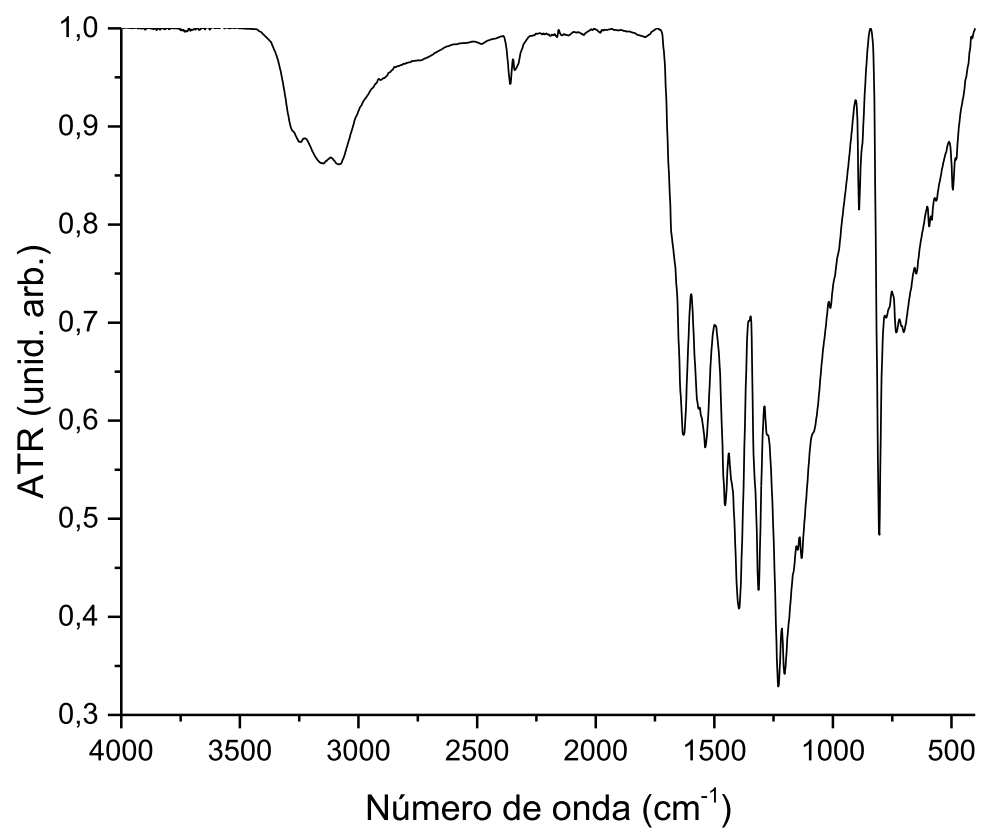

Fonte: Autoria própria.

Para o ciclo final de experimentos esperava-se que a região relacionada ao esqueleto aromático fosse muito similar para todas as amostras. Isto porque, a partir de uma condição limite, os precursores e intermediários deveriam estar já completamente convertidas devido sua condensação. Ou seja, restariam unidades de $\mathrm{g}-\mathrm{C}_{3} \mathrm{~N}_{4}$, com estrutura interior muito similar, formadas pelos heterocíclos C-N (SHI et al., 2014; CHU et al., 2014; DONG et al., 2013).

Assim, os espectros foram normalizados (Figura 28) a partir da região em que se esperava maior similaridade, no sentido de enfatizar suas maiores diferenças. Como pode ser observado, a região na qual a normalização foi baseada é realmente muito similar em todas as amostras. As maiores diferenças foram observadas entre 3.000 e $3.300 \mathrm{~cm}^{-1}$. 
Figura 28 - Espectros FTIR normalizados para amostras da região de melhor resposta

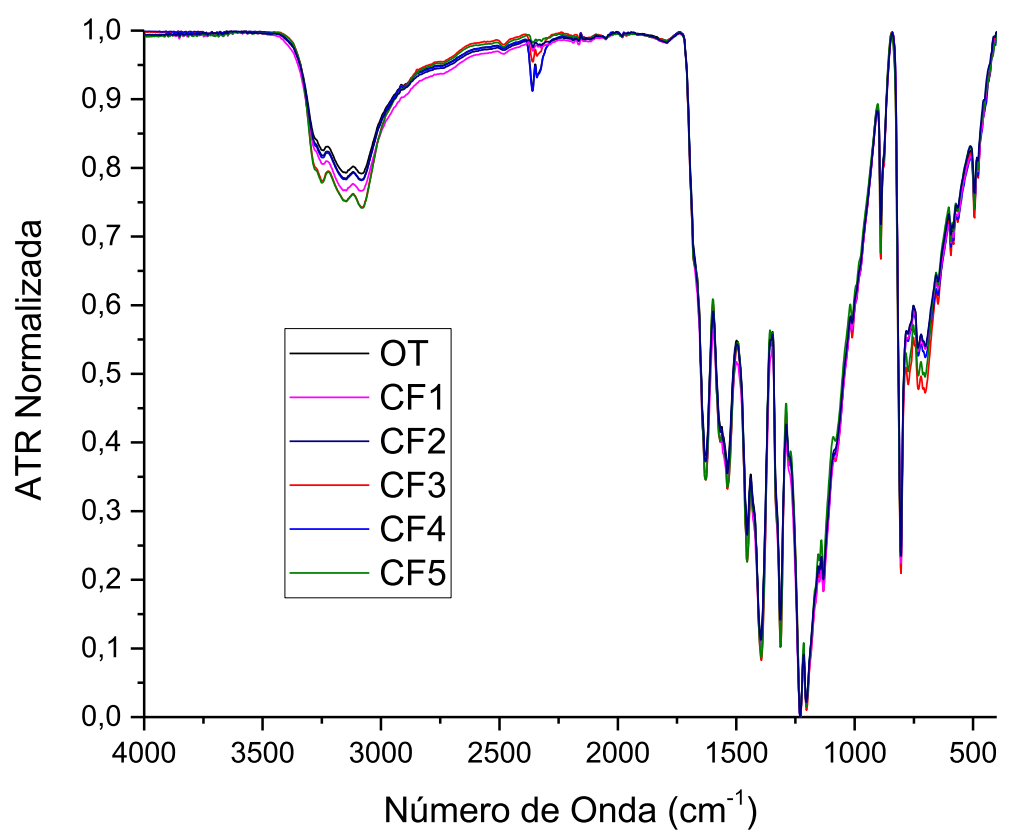

Fonte: Autoria Própria.

Esta região é relacionada à terminações amina oriundas dos anéis heptazínicos (Figura 29), ou seja, pela presença de segmentos pequenos ou mal formados de $\mathrm{g}-\mathrm{C}_{3} \mathrm{~N}_{4}$ (WU et al., 2014).

Figura 29 - Localização de grupos aminas terciárias (negrito), secundárias (azul) e primárias (vermelho) em um segmento hipotético com cinco unidades de heptazina

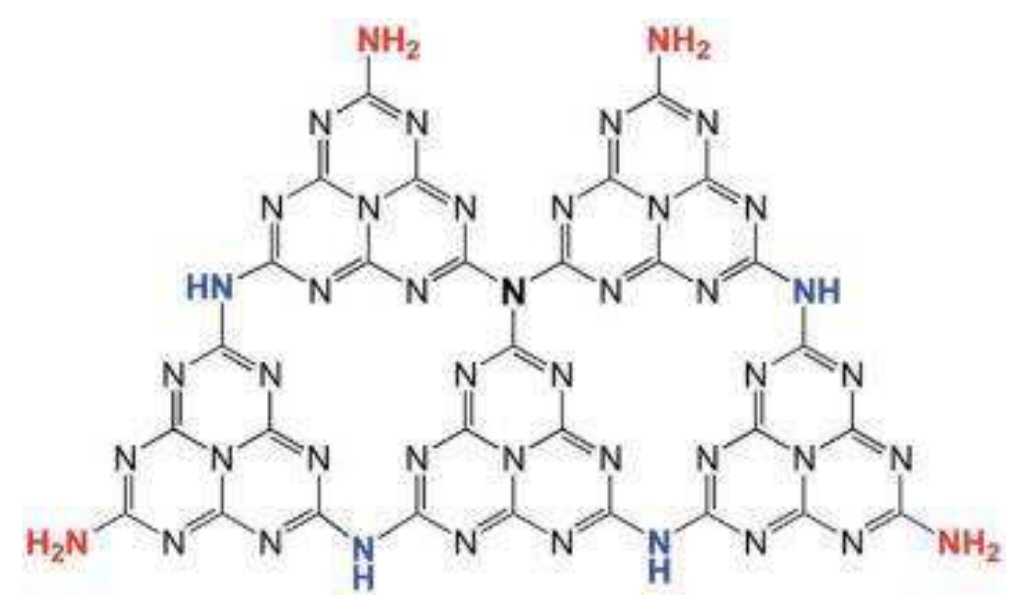

Fonte: Wu et al. (2014).

A permanência destes grupamentos amina pode reduzir parcialmente a característica inerte da superfície do $\mathrm{g}-\mathrm{C}_{3} \mathrm{~N}_{4}$ e promover sua interação com determinadas espécies (CAO et 
al., 2015). Além disso, um excesso de defeitos ou segmentos incompletos 3 podem alterar significativamente a migração e a separação de cargas (CAO et al., 2015).

Portanto, a melhor condição de síntese gera um material com maior eficiência de condensação e de formação de cadeias de heterociclos, já que é a que apresenta a menor intensidade na região de picos relacionados à presença de aminas primárias e secundárias.

Entretanto, pode parecer estranho que a amostra CF5, obtida com alta temperatura e tempo prolongado, possa não ter atingido um grau suficiente de condensação, sendo esta a que possui maior intensidade de picos relacionados a ligações NH. Porém estudos termogravimétricos do $\mathrm{g}-\mathrm{C}_{3} \mathrm{~N}_{4}$ apresentam claramente um perfil de decomposição à altas temperaturas (SHI et al., 2014; ZHANG et al., 2012). Sendo assim, supõe-se que simultaneamente à sua condensação, possa ocorrer quebras e falhas na estrutura heterocíclica que, em contato com a atmosfera não inerte, direcionam o produto à reformação de terminais amina.

\subsection{3 ÁREA SUPERFICIAL ESPECÍFICA (VIA METODOLOGIA BET)}

As determinações de ASE foram realizados apenas nas amostras obtidas nos experimentos finais da síntese. A Figura 30 apresenta estes resultados.

Os resultados mostraram que a amostra da melhor condição de síntese possui a maior ASE, 29,54 $\mathrm{m}^{2} \mathrm{~g}^{-1}$, seguida das amostras CF4 e CF3. As amostras CF1, CF2 e CF5 possuem, comparativamente, uma ASE menor.

Esses resultados são condizentes com os resultados de atividade fotocatalítica das amostras. A região de melhor atividade fotocatalítica é exatamente a mesma da região com maior ASE. Este fato confirma que a ASE impacta positivamente, e de forma significativa, a resposta fotocatalítica. 
Figura 30 - Ciclo final de síntese e suas respostas em área superficial BET, em $\mathrm{m}^{2} \cdot \mathrm{g}^{-1}$

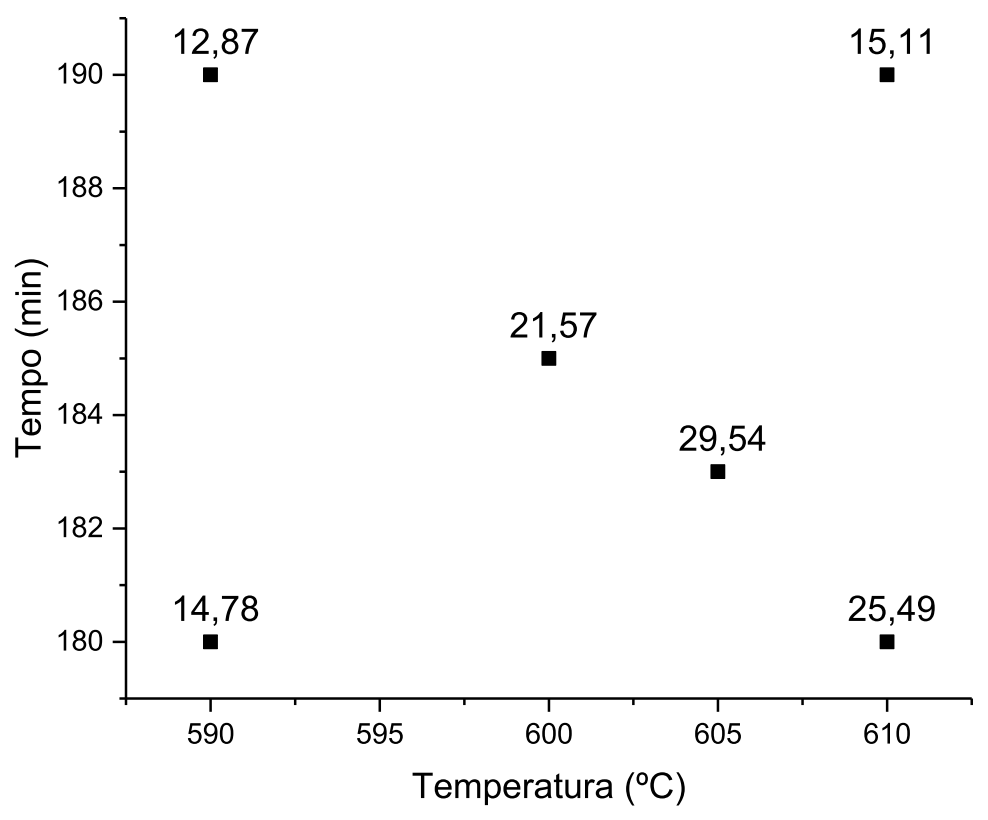

Fonte: Autoria própria.

A importância da ASE em fotocatálise se deve à maior disponibilidade de sítios ativos (MARTÍN-RAMOS et al., 2015). Além disso, uma maior área superficial pode estar relacionada a menores espessuras de lamelas. Yang et al. (2013) relacionam esta qualidade a uma menor resistência à transferência de elétrons, promovendo uma melhor separação de cargas (YANG et al., 2013).

Como comparação, a ASE de amostras de g- $\mathrm{C}_{3} \mathrm{~N}_{4}$ em estado bruto, a partir da melamina, varia muito dependendo da preparação. Entretanto, em condições similares ao do estudo, podem ser encontrados resultados de até $20 \mathrm{~m}^{2} \mathrm{~g}^{-1}$ (CAO et al., 2013; CHEN et al., 2015; SHI et al., 2014).

\subsubsection{MICROSCOPIA ELETRÔNICA}

Os estudos de microscopia foram realizados apenas com as amostras dos experimentos finais da síntese. $\mathrm{O}$ intuito destes experimentos foi a tentativa de observação de estruturas morfológicas diferenciadas entre estes pontos, que pudessem ajudar a elucidar suas diferen- 
ças. Porém, provavelmente devido à proximidade das condições, uma mudança morfológica grande o suficiente para ser notada não foi observada.

Entretanto, as características gerais da morfologia na região de melhor resposta fotocatalítica podem ser observadas (Figura 31).

A Figura 31 mostra claramente que todas as amostras apresentam morfologia muito similar. São visíveis tanto grandes placas planas, quanto pequenas partículas retorcidas de estruturas não específicas, muito similares às encontradas por outros pesquisadores (GIBOT; SCHNELL; SPITZER, 2016).

Para melhor elucidar as pequenas estruturas não específicas, foram realizadas micrografias SEM-FEG, capazes de maior magnificação (Figura 32).

Novamente, as amostras se mostraram muito similares entre si. É possível notar que as partículas são formadas por uma aglomeração de estruturas lamelares. É interessante observar também que a aglomeração vista nestas partículas de escala nanométrica permanecem mesmo após a preparação para este tipo de microscopia, que é muito similar às estratégias de esfoliação (ZHANG; CHEN; WANG, 2015). 
Figura 31 - SEM das amostras dos experimentos finais da síntese: (a) melhor condição, (b) CF1, (c) CF2, (d) CF3, (e) CF4 e (f) CF5

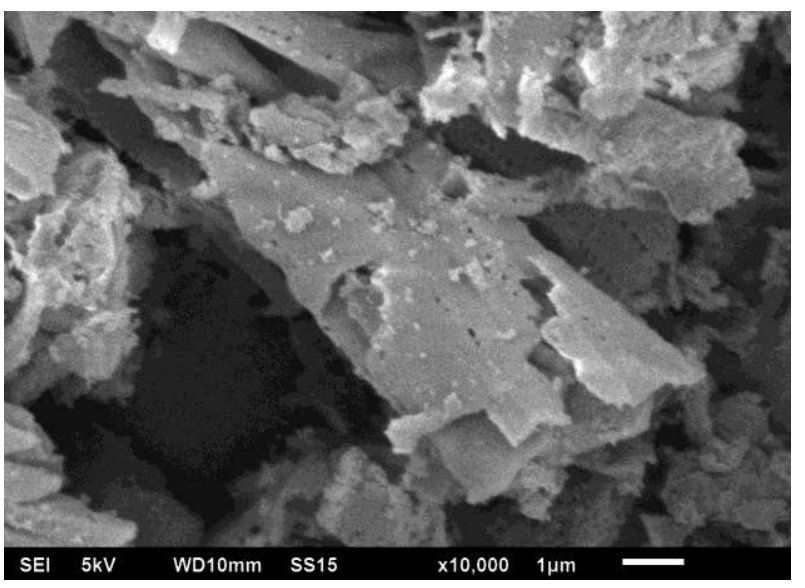

(a)

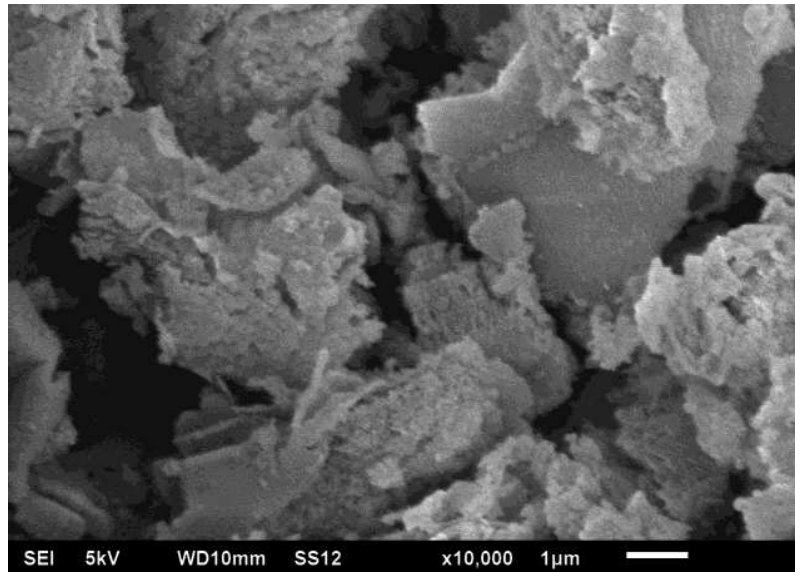

(c)

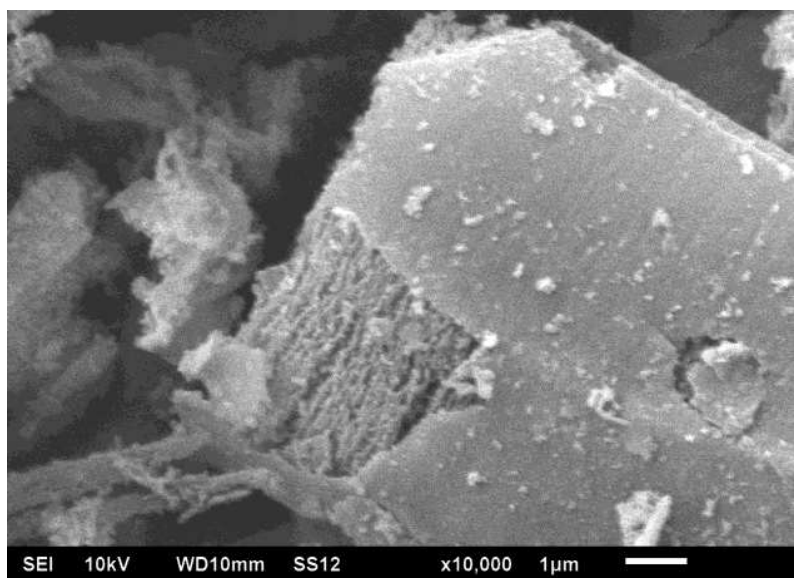

(e)

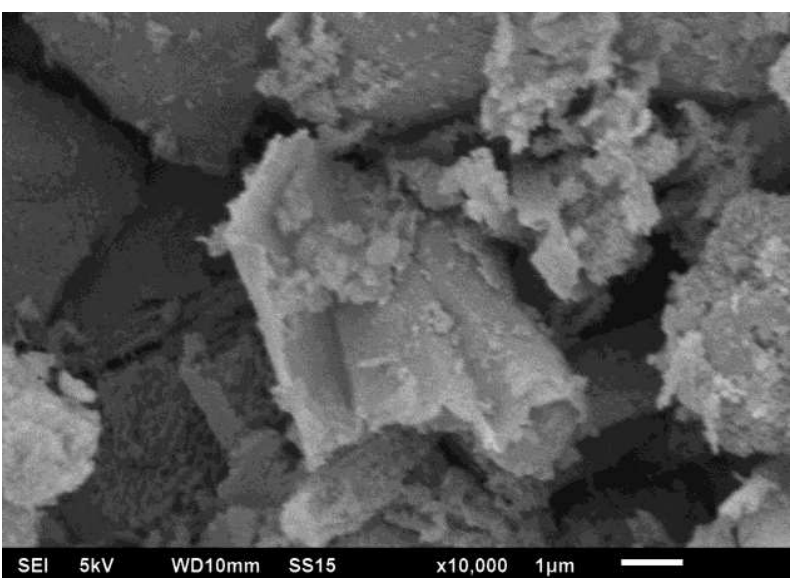

(b)

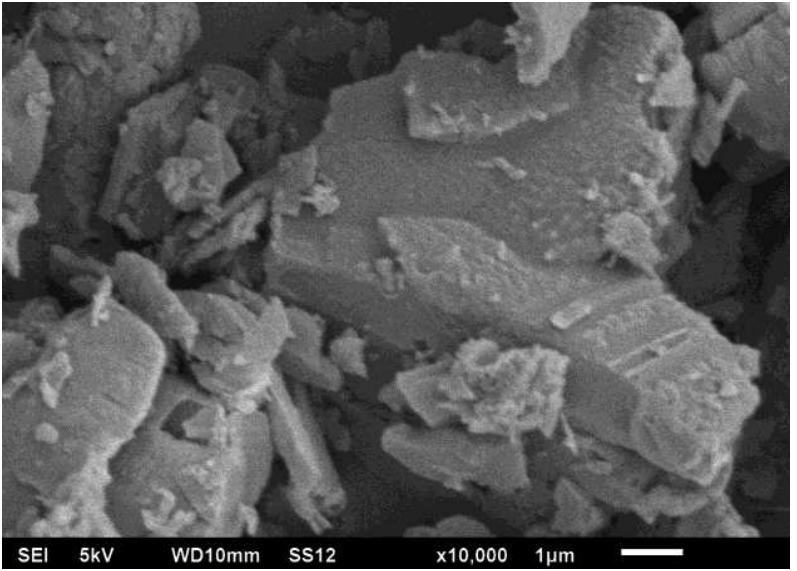

(d)

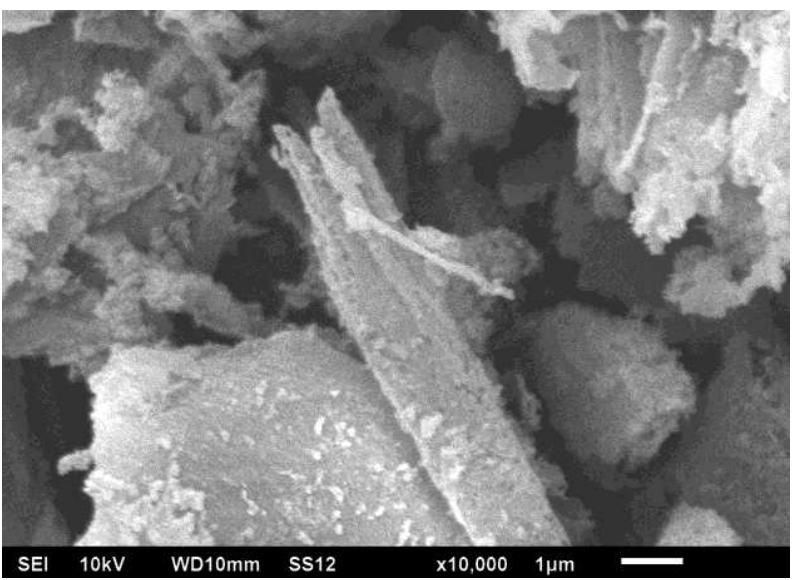

(f)

Fonte: Autoria própria. 
Figura 32 - SEM- FEG das amostras dos experimentos finais da síntese: (a) melhor condição, (b) CF1, (c) CF2, (d) CF3, (e) CF4 e (f) CF5

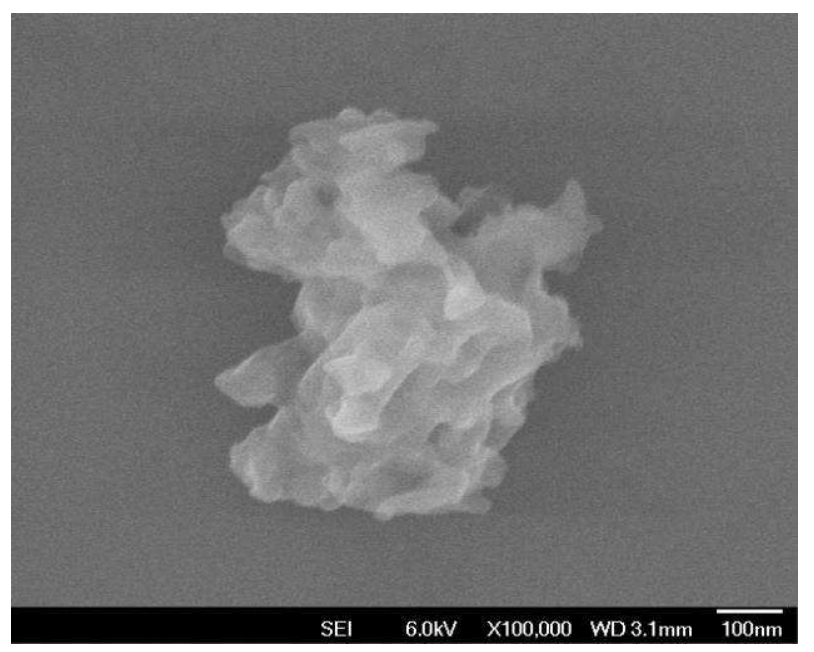

(a)

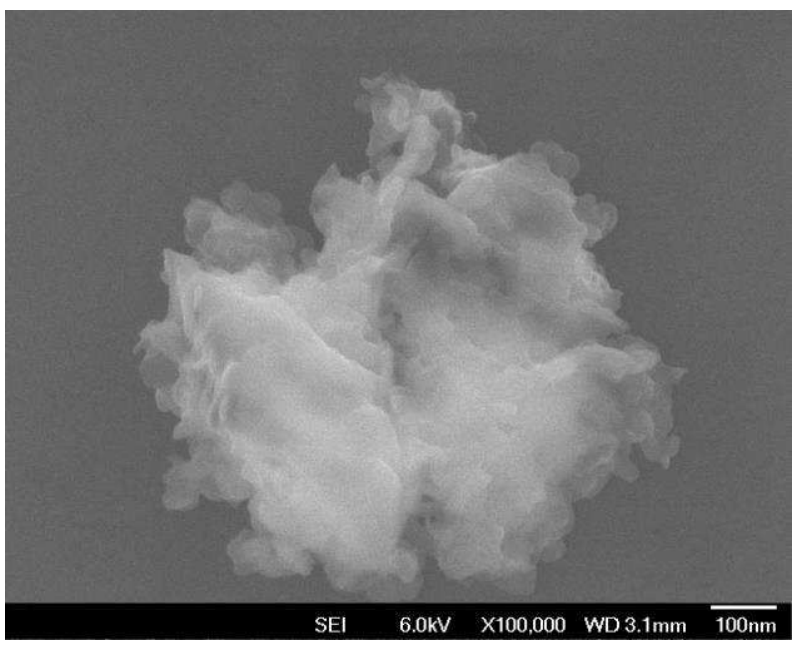

(c)

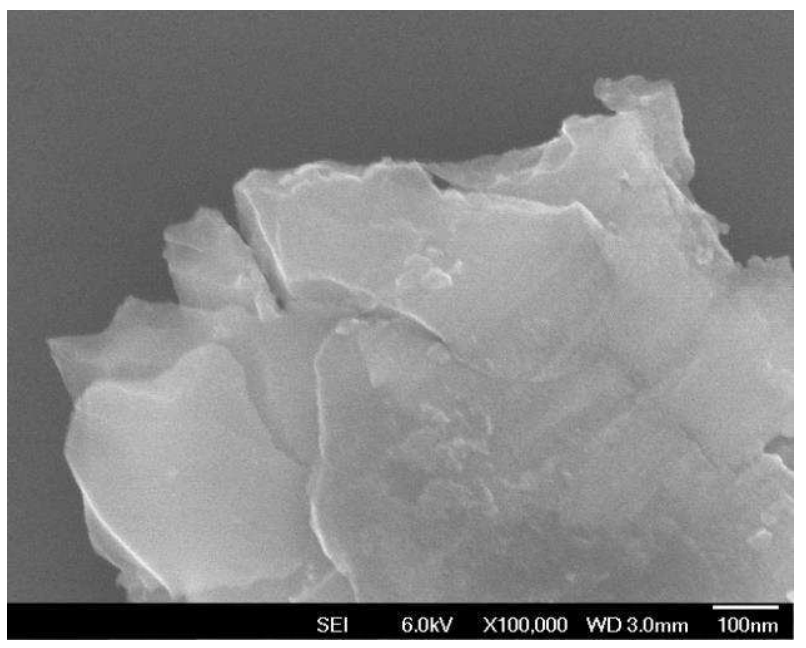

(e)

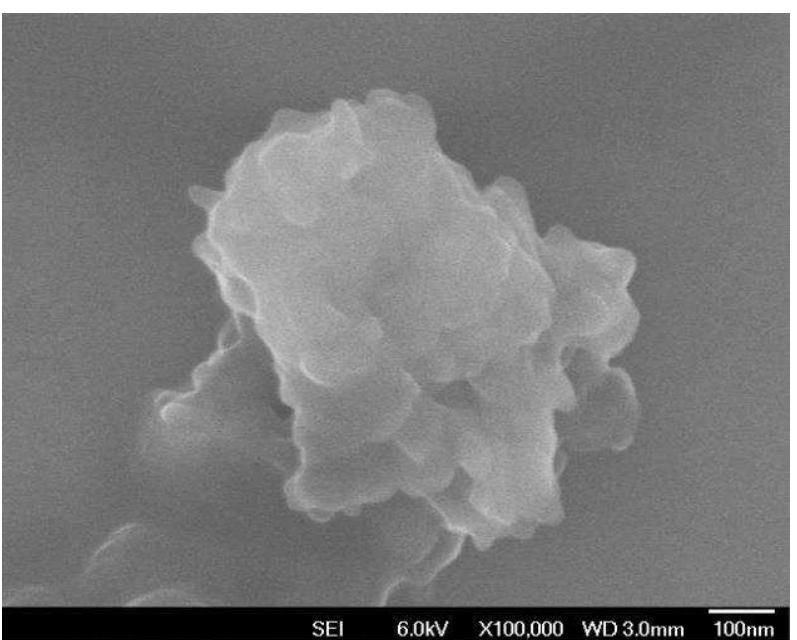

(b)

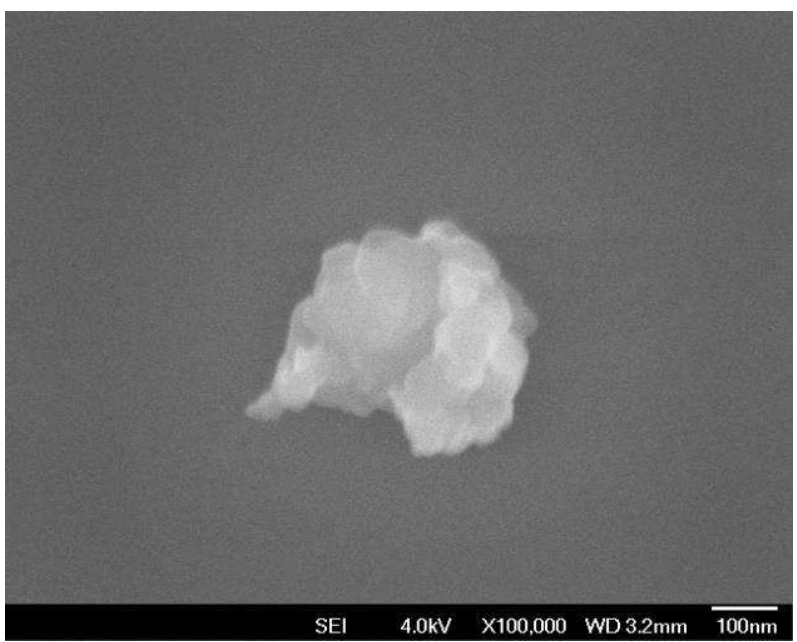

(d)

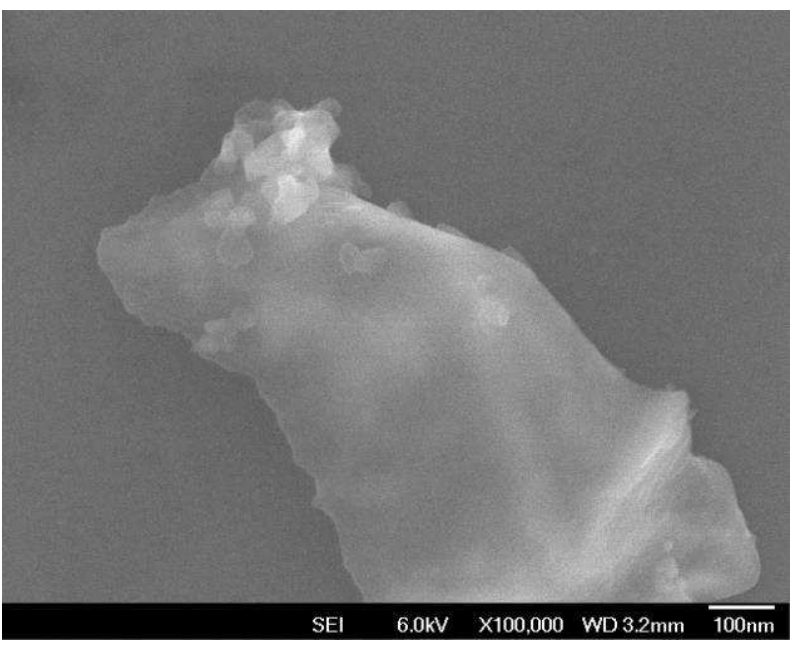

(f)

Fonte: Autoria própria. 


\subsubsection{POTENCIAL ZETA}

A Figura 33 apresenta os potenciais zeta medidos em vários $\mathrm{pH}$, com várias amostras, sendo possível a visualização do ponto isoelétrico das amostras. Ele é definido como " $\mathrm{O} \mathrm{pH}$ no qual a carga elétrica líquida de uma entidade elementar [de uma partícula] é zero. O símbolo pI é comumente usado para este tipo de grandeza. Ele deve ser substituído por pH(I) porque é um pH determinado sob aquela condição particular.” (IUPAC, 2017).

Figura 33 - Variação do potencial zeta em relação ao $\mathrm{pH}$ da suspensão

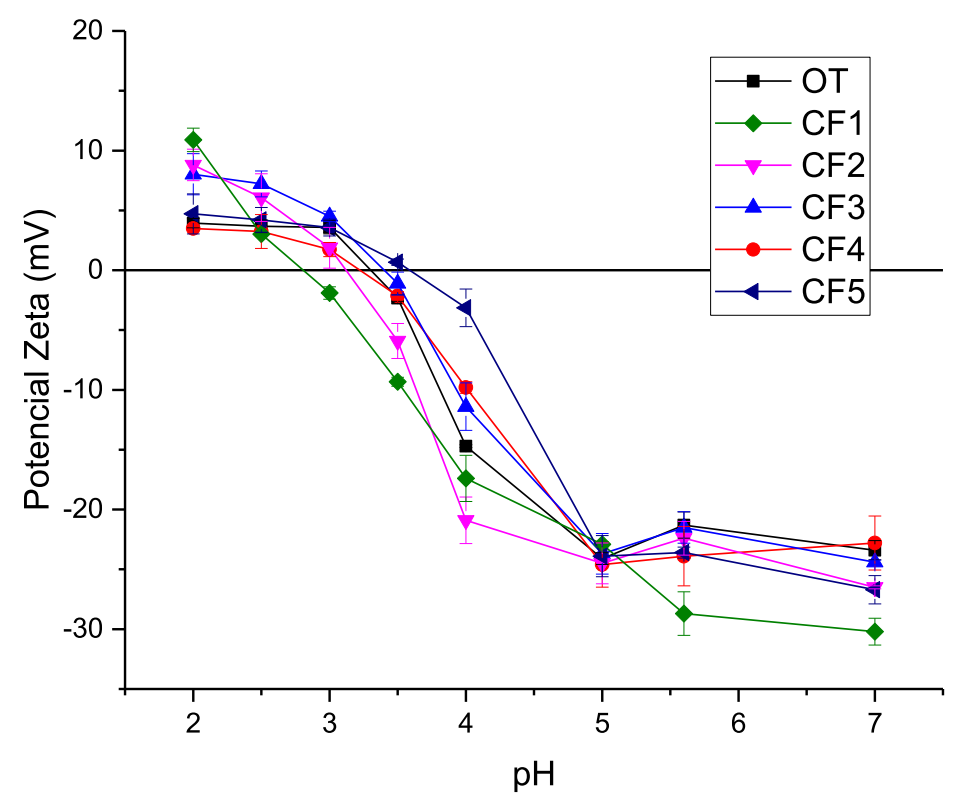

Fonte: Autoria própria.

Num primeiro momento, pode ser observado que no intervalo de $\mathrm{pH}$ em que foi realizada a fotocatálise (entre 5,5 e 6) todas as amostras possuem carga superficial muito próximas. Isto permite concluir que as diferentes atividades fotocatalíticas dessas amostras não estão relacionadas pura e simplesmente à uma possível melhor interação entre o fotocatalisador e o corante-alvo.

De fato, era esperado que a interação fotocatalisador-corante fosse relativamente reduzida, sabendo-se que ambos possuem superfície com cargas negativas em meios neutros ou levemente ácidos (ASADPOUR-ZEYNALI; ALESHI, 2014; ZHU et al., 2015). Na curva de adsorção para a melhor amostra (Figura 24) pode-se verificar isto claramente. 
As diferenças nos pontos isoelétricos das amostras podem ser explicadas em função dos grupos superficiais presentes nessas amostras. Como discutido no item destinado a análises de FTIR, há a presença de aminas (Figura 29).

As aminas terciárias são capazes de atuar como aceptores de prótons, devido a presença de um par de elétrons não ligantes, e adquirir carga superficial positiva (ZHU et al., 2015). Ao mesmo tempo, aminas primárias e secundárias podem sofrer uma série de reações, tendo por fim uma superfície carregada negativamente (ZHU et al., 2015). A Figura 34 apresenta um esquema das respectivas reações.

Figura 34 - Possíveis reações dos grupamentos amina na superfície do $g-\mathrm{C}_{3} \mathrm{~N}_{4}$ : (a) terciárias e (b) primárias e secundárias

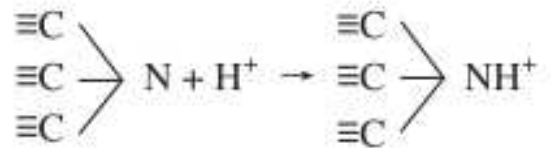

(a)

$$
\begin{aligned}
& \equiv \mathrm{C}-\mathrm{NH}_{2}+\mathrm{H}_{2} \mathrm{O} \rightarrow \equiv \mathrm{C}-\mathrm{OH}+\mathrm{NH}_{3} \\
& \equiv \mathrm{C}-\mathrm{OH}+\mathrm{H}^{+} \rightarrow \equiv \mathrm{C}-\mathrm{OH}_{2}^{+} \\
& \equiv \mathrm{C}-\mathrm{OH}+\mathrm{OH}^{-} \rightarrow \equiv \mathrm{C}-\mathrm{O}^{-}+\mathrm{H}_{2} \mathrm{O}
\end{aligned}
$$

(b)

Fonte: Zhu et al. (2015).

Assim, a carga de superfície e, consequentemente, o $\mathrm{pH}(\mathrm{I})$ dependem intimamente da presença de grupamentos amina na superfície do catalisador e de seu equilíbrio no meio.

A amostra CF1, com condições de síntese mais brandas, provavelmente possui um maior número de aminas primárias e secundárias expostas na superfície, devido à permanência dessas aminas em segmentos pequenos ou malformados de $\mathrm{g}-\mathrm{C}_{3} \mathrm{~N}_{4}$. Ou seja, o ponto isoelétrico nessa amostra ocorre em condições mais ácidas porque uma concentração maior de íons hidrônio é necessária para contrabalancar a carga dos ânions gerados.

$\mathrm{Na}$ amostra CF5, devido as condições mais drásticas de síntese, a presença de aminas terciárias deve ser elevada, devido ao alto grau de condensação possivelmente atingido. $\mathrm{Ou}$ seja, grupos aceptores de carga positiva estariam presentes em alto teor. Assim, uma concentração menor de íons hidrônio seria necessária para a equalização das cargas de superfície. 
As demais amostras, agrupadas entre as duas amostras-limite, possuem provavelmente uma disponibilidade intermediária de grupamentos amina passíveis de interferência na carga superficial do semicondutor.

Os pH(I) encontrados são menores que o de outros estudos, entre 4 e 5 (HUANG et al., 2015; XU et al., 2015; ZHU et al., 2015). Entretanto, vale ressaltar que, por ser esta uma análise intimamente ligada aos grupos presentes na superfície, as diferenças estruturais geradas pelas diversas condições de síntese, modificações e precursores podem gerar superfícies muito diferentes, o que poderia impossibilitar uma comparação.

\subsubsection{ESPECTROSCOPIA NA REGIÃO ULTRAVIOLETA-VISÍVEL}

A determinação da $E_{g}$ de materiais semicondutores é de grande importância para a caracterização e interpretação dos resultados fotocatalíticos, uma vez que este parâmetro está diretamente relacionado à quantidade necessária de energia em forma de luz a ser absorvida pelo semicondutor para a excitação eletrônica (PAPAILIAS et al., 2015).

Figura 35 - Espectros de reflectância para todas amostras do ciclo final de experimentos

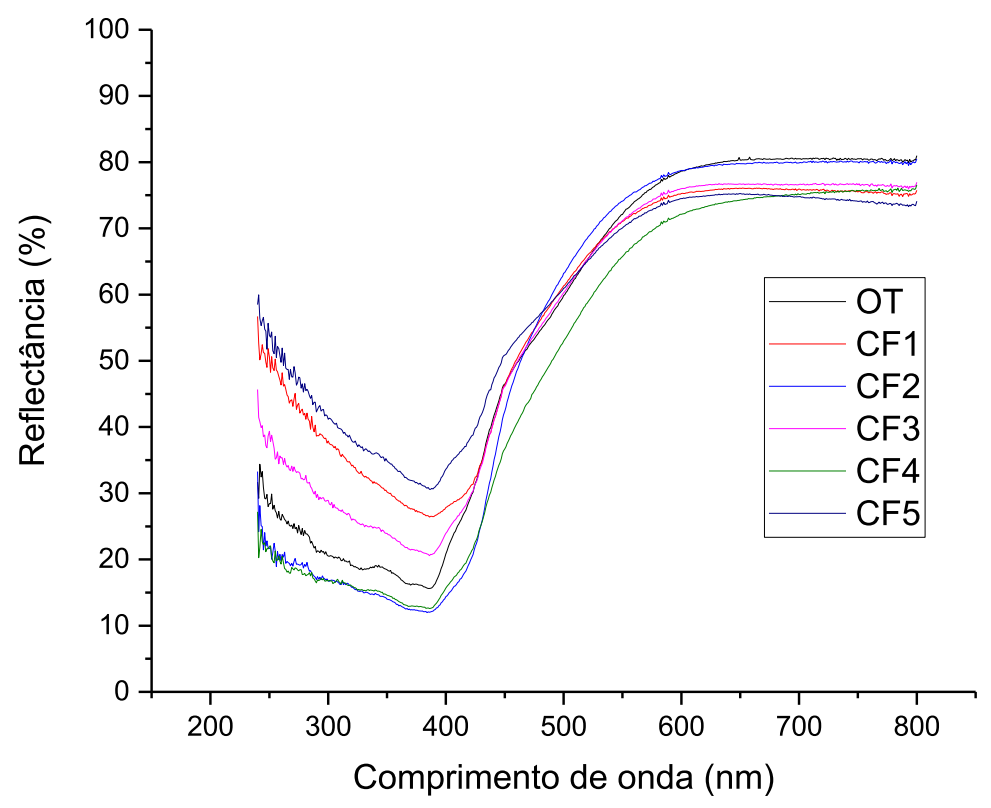

Fonte: Autoria própria. 
A Figura 35 apresenta os espectros de refletância para todas as amostras resultantes dos experimentos finais da síntese. Os resultados de reflectância não permitem conclusões claras, mas a Figura 36 apresenta os gráficos gerados pela abordagem descrita para a aproximação de $E_{\mathrm{g}}$ a partir destes dados.

Os valores de $E_{\mathrm{g}}$, segundo a literatura (IWANO et al., 2008; PAPAILIAS et al., 2015; SUN et al., 2015), são reduzidos conforme aumenta-se a temperatura final de condensação, sendo este um efeito da extensão de cadeia polimérica pela conexão de mais unidades triazínicas e consequente extensão de conjugados $\mathrm{C}-\mathrm{N}$ em sp².

Assim, pode-se inferir que, apesar de não ser possível uma comparação entre amostras, elas possuem uma cadeia de heterociclos mais extensa e melhor conjugada, quando comparadas a grande parte dos estudos com $\mathrm{g}-\mathrm{C}_{3} \mathrm{~N}_{4}$ em estado bruto. Estes estudos apresentam energias de band gap em torno de $2,7 \mathrm{eV}$, mesmo em preparações a partir de precursores diferentes (CAO et al., 2015). Cao et al. (2015) propõem que a variação do band gap em relação à temperatura seja parabólica, com mínimo em torno de $2,58 \mathrm{eV}$, valor muito próximo do alcançado. 
Figura 36 - Valores estimados de $E_{\mathrm{g}}$ para as amostras: (a) OT, (b) CF1, (c) CF2, (d) CF3, (e) CF4 e (f) CF5 (Continua)

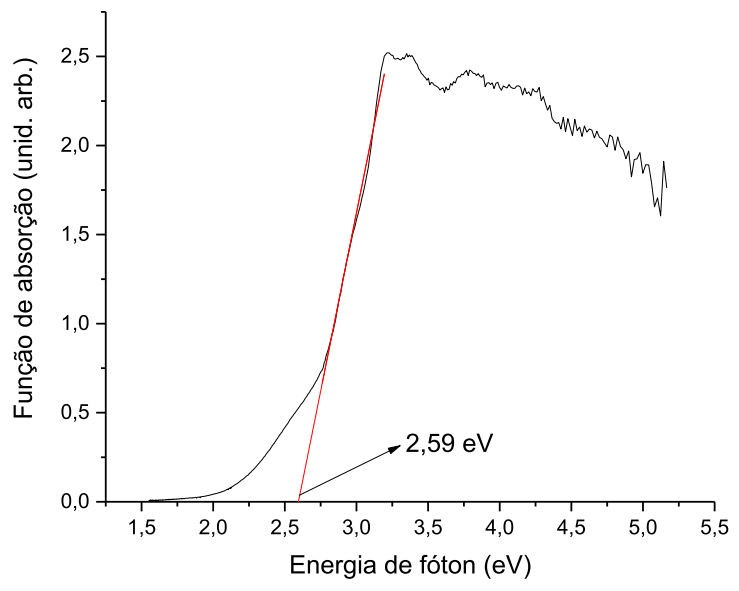

(a)

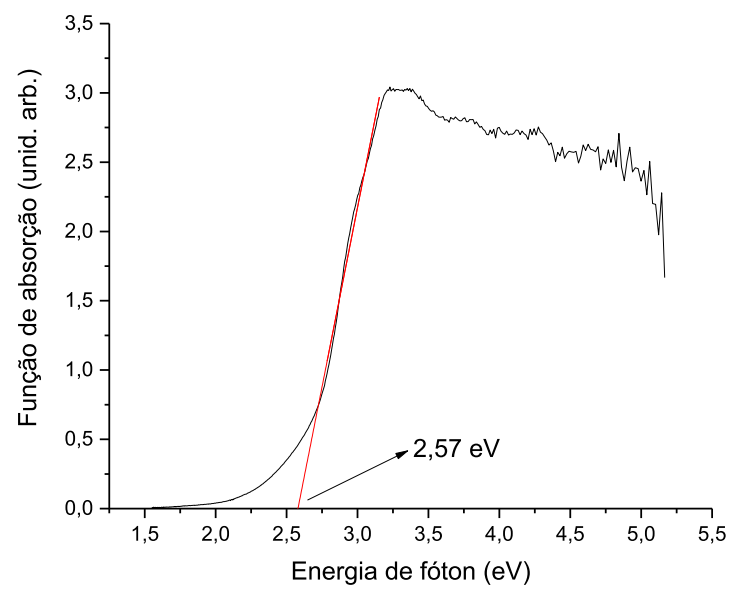

(c)

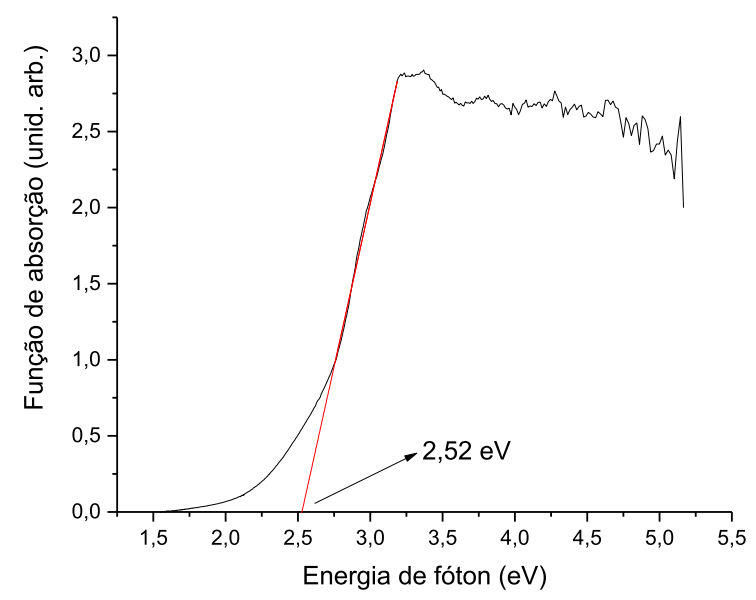

(e)

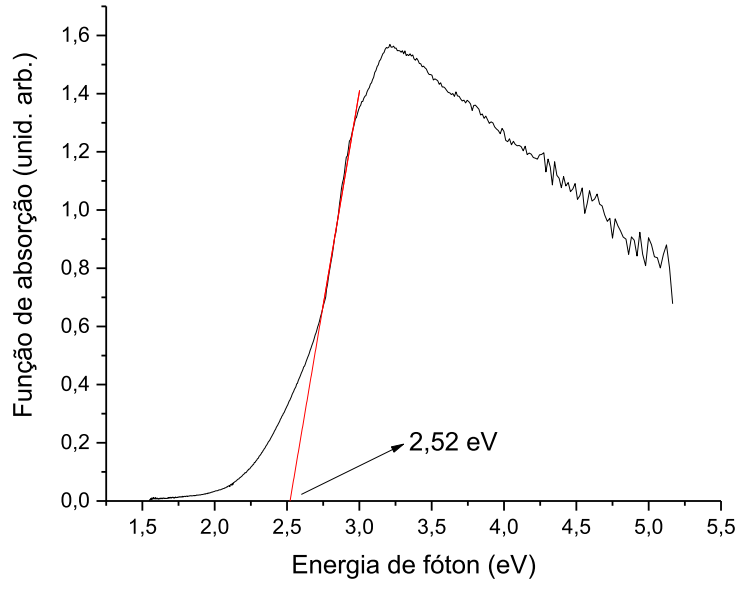

(b)

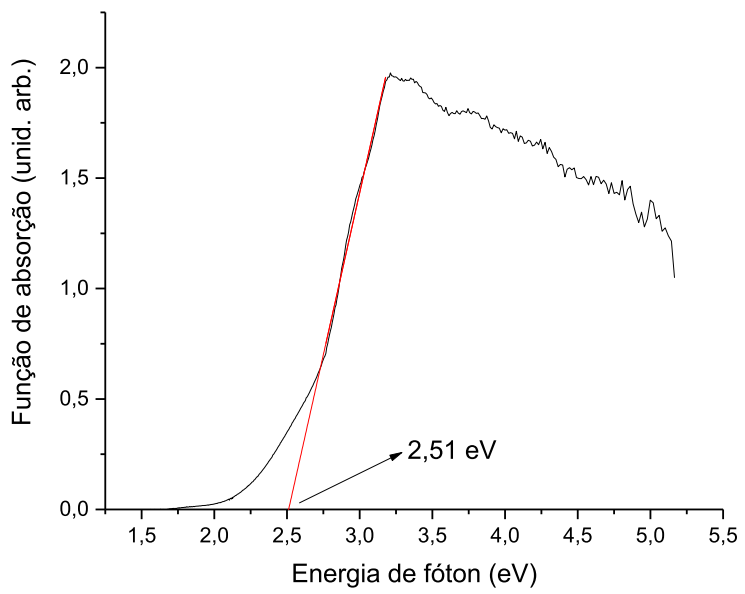

(d)

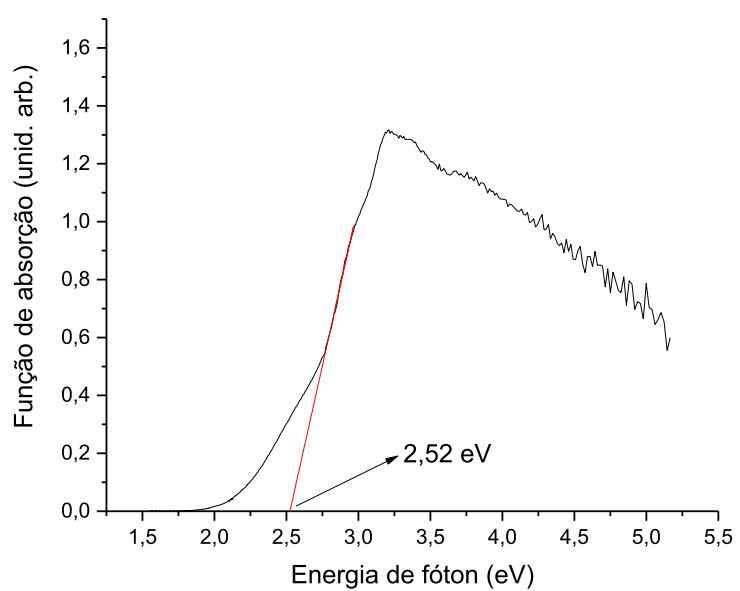

(f)

Fonte: Autoria própria.

De todo modo, a $E_{g}$ é estreita o suficiente para esses materiais atuarem também sob radiação visível, um aspecto muito desejável. 


\subsubsection{CONSIDERAÇÕES FINAIS SOBRE OS PRINCIPAIS RESULTADOS DA OTIMIZAÇÃO}

Dentre os experimentos de caracterização, foram realizadas análises com o intuito tanto de observar diferenças entre as amostras sintetizadas em condições próximas à ótima, quanto de elucidar os motivos de incremento da atividade fotocatalítica nesta região.

As análises de estrutura, morfologia e cristalinidade apontaram similaridades entre as amostras, em relação a si próprias e em relação à literatura. Entretanto, dois experimentos se destacaram no sentido de terem apresentado comportamentos diferenciados: ASE e Eg.

Estes fatores estão relacionados à atividade fotocatalítica do $\mathrm{g}-\mathrm{C}_{3} \mathrm{~N}_{4}$, proporcionando uma maior concentração de sítios ativos (MARTÍN-RAMOS et al., 2015) e uma maior facilidade em ter-se a excitação de elétrons sob radiação visível (CAO et al., 2015), respectivamente. Além disso, estudos relacionam estes fatores à uma melhor formação da estrutura de g$\mathrm{C}_{3} \mathrm{~N}_{4}$ (IWANO et al., 2008; PAPAILIAS et al., 2015; YANG et al., 2013).

Sendo assim, considerando-se estas análises como parâmetros-chave para a qualidade do material, compararam-se os resultados obtidos nesta otimização com os relatados na literatura. A Tabela 14 apresenta uma série de condições de síntese, os resultados do estado bruto e as suas referências. A Figura 37 apresenta um gráfico de ASE vs E $E_{g}$ para estas condições.

Como se observa, o material sintetizado possui maior ASE e menor band gap do que os trabalhos selecionados na literatura (últimos 3 anos). Dessa forma, percebe-se a importância do uso de metodologias de otimização multivariada para a obtenção de materiais de qualidade superior. 
Tabela 14 - ASE e E $\mathrm{g}_{\mathrm{g}}$ relatadas na literatura para materiais obtidos sob diversas condições de temperatura, tempo e taxa de aquecimento

\begin{tabular}{cccccc}
\hline $\begin{array}{c}\text { Temperatura } \\
\left({ }^{\circ} \mathrm{C}\right)\end{array}$ & $\begin{array}{c}\text { Tempo } \\
(\mathrm{min})\end{array}$ & $\begin{array}{c}\text { Taxa } \\
\left({ }^{\circ} \mathrm{C} \mathrm{min}^{-1}\right)\end{array}$ & $\begin{array}{c}\mathrm{E}_{\mathrm{g}} \\
(\mathrm{eV})\end{array}$ & $\begin{array}{c}\text { ASE } \\
\left(\mathrm{m}^{2} \mathrm{~g}^{-1}\right)\end{array}$ & Referências \\
\hline 550 & 240 & 5,0 & 2,66 & 10,6 & LIU et al., 2017 \\
620 & 180 & 15 & 3,08 & 27,0 & KOČ́́ et al., 2017 \\
520 & 120 & - & 2,73 & 7,00 & KRIVTSOV et al., 2017 \\
500 & 240 & - & 2,80 & 4,80 & HERNÁNDEZ-URESTI et al., 2016 \\
550 & 120 & 5,0 & 2,65 & 14,0 & LIU; QIN; FAN, 2016 \\
550 & 240 & 15 & 2,60 & 18,0 & MA; WANG; HE, 2016 \\
500 & 120 & - & 2,70 & 7,36 & QU et al., 2016 \\
550 & 180 & 3,0 & 2,75 & 6,71 & SHAN et al., 2016 \\
550 & 240 & 2,5 & 2,71 & 10,0 & WANG et al., 2016 \\
550 & 120 & 8,0 & 2,67 & 9,42 & ZOU et al., 2016 \\
550 & 240 & 5,0 & 2,72 & 13,8 & HO et al., 2015 \\
520 & 120 & - & 2,72 & 6,31 & PI et al., 2015 \\
460 & 120 & 20 & 2,75 & 7,26 & XU et al., 2015 \\
500 & 120 & 20 & 2,71 & 23,2 & XU et al., 2015 \\
540 & 120 & 20 & 2,62 & 23,5 & XU et al., 2015 \\
580 & 120 & 20 & 2,60 & 26,0 & XU et al., 2015 \\
520 & 240 & 10 & 2,70 & 9,00 & ZHANG, L. et al., 2015 \\
550 & 240 & 4,0 & 2,52 & 8,53 & ZHANG, Y. et al., 2015 \\
605 & 183 & 5,0 & 2,59 & 29,5 & Este trabalho \\
\hline
\end{tabular}

Fonte: Autoria própria.

Figura 37 - Comparação entre a ASE e a $E_{g}$ de diversos materiais: (ם) relatados na literatura e (•) deste trabalho

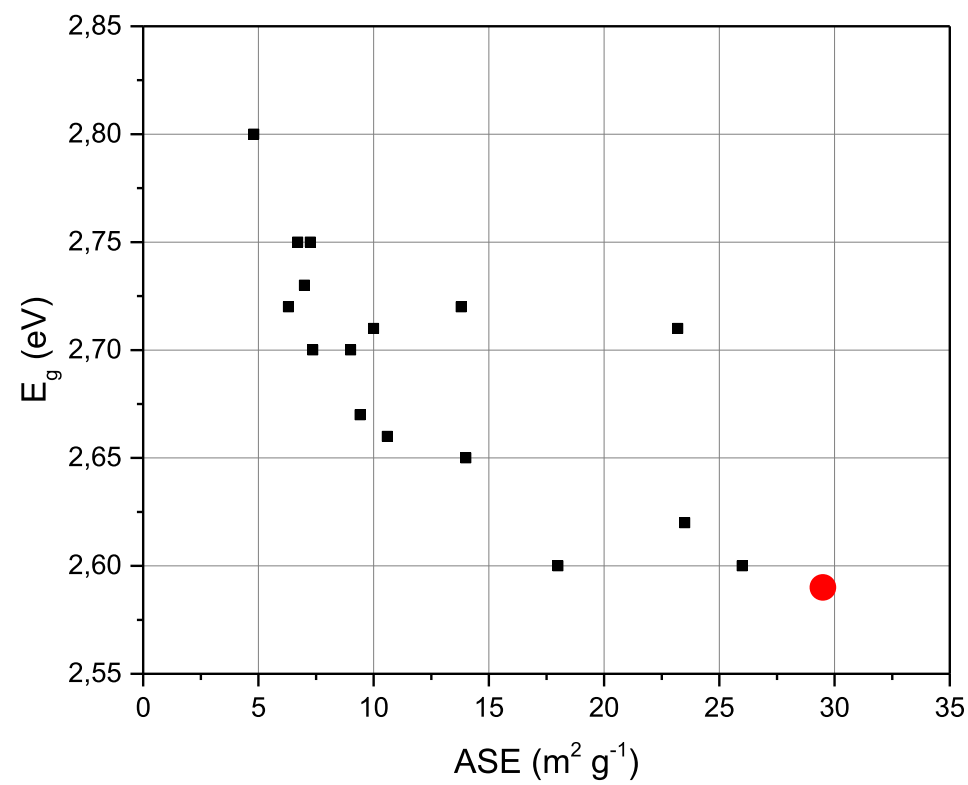

Fonte: Autoria própria. 


\subsection{FORMAÇÃO DE HETEROESTRUTURAS g-C ${ }_{3} \mathrm{~N}_{4} / \mathrm{WO}_{3}$}

\subsubsection{CONSIDERAÇÕES INICIAIS}

Dentre as diversas metodologias disponíveis para a síntese do $\mathrm{WO}_{3}$, escolheu-se a metodologia de síntese via peroxo-complexos (GIANNOULI; LEFTHERIOTIS, 2011; KIM et al., 2010). A metodologia foi escolhida devido à experiência do grupo de pesquisa, relativa simplicidade e possibilidade de incorporação de $\mathrm{g}-\mathrm{C}_{3} \mathrm{~N}_{4}$ diretamente em etapas de formação de $\mathrm{WO}_{3}$.

Ainda, em vista do acoplamento e formação de heteroestruturas com o g- $\mathrm{C}_{3} \mathrm{~N}_{4}$ préformado, uma pequena modificação para a síntese clássica via peroxo-complexos foi proposta.

A modificação foi a sonicação da solução dos peroxo-complexos, já na presença do g$\mathrm{C}_{3} \mathrm{~N}_{4}$ e posterior secagem via liofilização. Esta etapa foi realizada por três motivos principais: (a) uma possível esfoliação do g- $\mathrm{C}_{3} \mathrm{~N}_{4}$ e aumento de sua ASE na etapa de sonicação; (b) melhor homogeneização, na fase de sonicação; (c) aprisionamento de tungstênio na superfície de $\mathrm{g}-\mathrm{C}_{3} \mathrm{~N}_{4}$ durante a liofilização .

Quanto à esfoliação, sua eficiência depende da proximidade das tensões superficiais do fotocatalisador e da solução (LIN, Q. et al., 2015; YANG et al., 2013). Não foram realizados ensaios no sentido de avaliar este parâmetro. Porém, a literatura possui estudos em que este tipo de esfoliação foi realizado em meios muito ácidos, como o atingido neste caso pela solubilização de ácido túngstico (TONG et al., 2015). Os resultados demonstram melhores eficiências de esfoliação nestes meios.

Neste processo de calcinação, dependendo da temperatura escolhida, poderia ocorrer o início de decomposição térmica do $\mathrm{g}_{-} \mathrm{C}_{3} \mathrm{~N}_{4}$. Em condições muito drásticas, poderia inclusive não restar o polímero (SHI et al., 2014; ZHANG et al., 2012). Assim, foi e escolhida uma temperatura suficiente para a formação do $\mathrm{WO}_{3}\left(400^{\circ} \mathrm{C}\right)$, mas incapaz de gerar alterações no g- $\mathrm{C}_{3} \mathrm{~N}_{4}$. 


\subsubsection{CARACTERIZAÇÃO SIMPLIFICADA}

Uma série de experimentos de caracterização foram realizados na tentativa de elucidar se houvera a formação de heteroestruturas $\mathrm{g}-\mathrm{C}_{3} \mathrm{~N}_{4} / \mathrm{WO}_{3}$. As condições de análise são análogas às empregadas com o g- $\mathrm{C}_{3} \mathrm{~N}_{4}$. Entretanto, foi realizado um conjunto simplificado de análises.

As amostras foram analisadas termogravimetricamente para se determinar as proporções reais de $\mathrm{g}-\mathrm{C}_{3} \mathrm{~N}_{4}$ e $\mathrm{WO}_{3}$ nelas. A Figura 38 apresenta todas estas análises.

Figura 38 - TGA das amostras de heteroestruturas

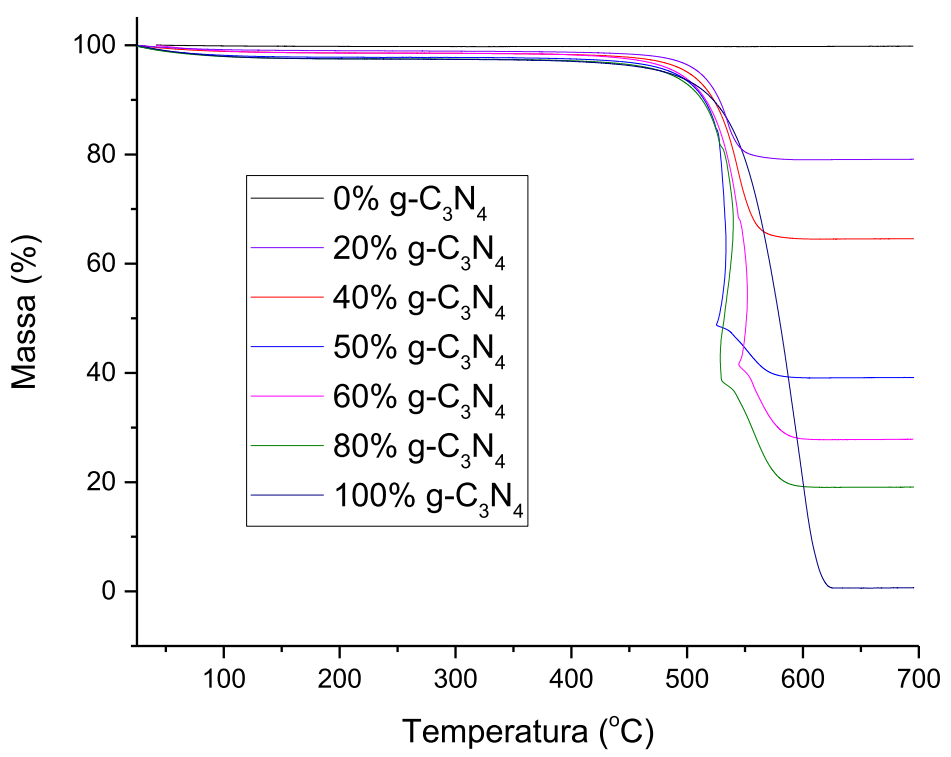

Fonte: Autoria própria.

Nesta análise, é de fácil visualização os diferentes comportamentos dos compostos puros. $\mathrm{O} \mathrm{WO}_{3}$ resiste a temperaturas de até $700^{\circ} \mathrm{C}$, enquanto o $\mathrm{g}-\mathrm{C}_{3} \mathrm{~N}_{4}$ inicia sua degradação térmica próximo aos $500^{\circ} \mathrm{C}$. Na literatura, relata-se a temperatura inicial de decomposição do g- $\mathrm{C}_{3} \mathrm{~N}_{4}$ como superior aos $550^{\circ} \mathrm{C}$ (SHI et al., 2014; ZHANG et al., 2012).

Pode-se calcular a proporção entre os componentes das heteroestruturas a partir da estabilização da massa ocorrida ao final de cada análise. A Tabela 15 apresenta estes valores, assim como os teoricamente planejados para cada ensaio. 
Tabela 15 - Proporções planejadas, reais e sua nomeação

\begin{tabular}{ccc}
\hline $\begin{array}{c}\text { Proporção } \\
\text { Planejada } \\
(\%)\end{array}$ & $\begin{array}{c}\text { Proporção Real } \\
(\%)\end{array}$ & Ensaio \\
\hline 0,00 & 0,0 & CN0 \\
20,0 & 19,8 & CN20 \\
40,0 & 35,5 & CN35 \\
50,0 & 59,8 & CN60 \\
60,0 & 71,7 & CN72 \\
80,0 & 80,4 & CN80 \\
100 & 100 & CN100 \\
\hline
\end{tabular}

Fonte: Autoria própria.

Os resultados mostram uma diferença entre as proporções reais e as planejadas. Entretanto, as primeiras apresentam também uma boa distribuição, sendo ainda possível uma avaliação geral das possíveis heteroestruturas.

Quanto às características cristalinas das amostras, é necessária uma averiguação inicial do padrão cristalino da amostra $\mathrm{CN} 0$, de $\mathrm{WO}_{3}$ puro, para uma melhor comparação e discussão sobre suas características. Esta análise é apresentada na Figura 39.

Este padrão de difração é condizente com a fase cristalina monoclínica do $\mathrm{WO}_{3}$ (JCPDS 89-4476). Os principais picos, de maior intensidade, são observados em torno de $23,1^{\circ} ; 23,6^{\circ}$ e $24,3^{\circ}$. Estes picos correspondem aos planos cristalinos (002), (020) e (200), respectivamente (KWONG; SAVVIDES; SORRELL, 2012). A fase cristalina monoclínica é considerada a de melhor atividade fotocatalítica (BAMWENDA; ARAKAWA, 2001; KAILASAM et al., 2015; LUEVANO-HIPOLITO et al., 2014). 
Figura 39 - Padrão de difração para o $\mathrm{WO}_{3}$ monoclínico (JCPDS 89-4476) e para a amostra CN0

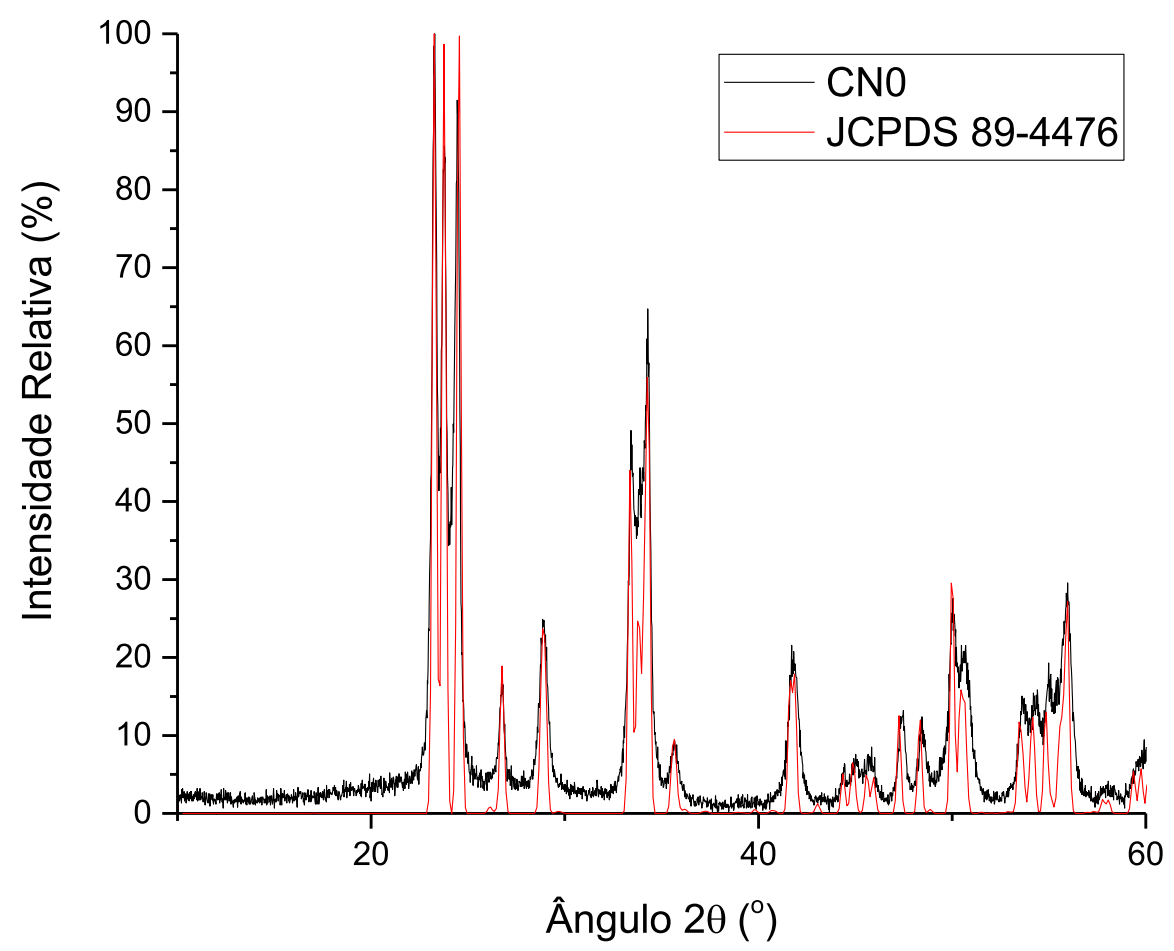

Fonte: Autoria Própria.

Em estudos de heterojunções com o g- $\mathrm{C}_{3} \mathrm{~N}_{4} / \mathrm{WO}_{3}$, podem ser observadas as fases de $\mathrm{WO}_{3}$ monoclínicas (CHEN et al., 2015), ortorrômbicas (KAILASAM et al., 2015) e hexagonais (ZHAO et al., 2015). São observadas as formações principalmente destas três fases ao se utilizar a metodologia de peroxo-complexos, porém é comumente observada a formação da fase monoclínica quando em altas temperaturas ou tempos de calcinação. Os difratogramas das demais amostras de heteroestruturas são mostrados na Figura 40.

Como esperado, é notado um acréscimo na intensidade do pico característico de g- $\mathrm{C}_{3} \mathrm{~N}_{4}$ conforme é aumentada a sua proporção. Mesmo em CN20 é possível notar uma leve alteração na região $2 \theta$ característica. Para os picos referentes ao $\mathrm{WO}_{3}$, desde suas menores proporções (como em CN80), eles se apresentam em alta intensidade. Nota-se ainda uma distorção e pior definição dos seus picos característicos. Isto pode estar relacionado a interferências na cristalização de $\mathrm{WO}_{3}$, na presença de lamelas de $\mathrm{g}-\mathrm{C}_{3} \mathrm{~N}_{4}$. 
Figura 40 - Difratogramas das amostras CN0, CN20, CN35, CN72, CN80 e CN100

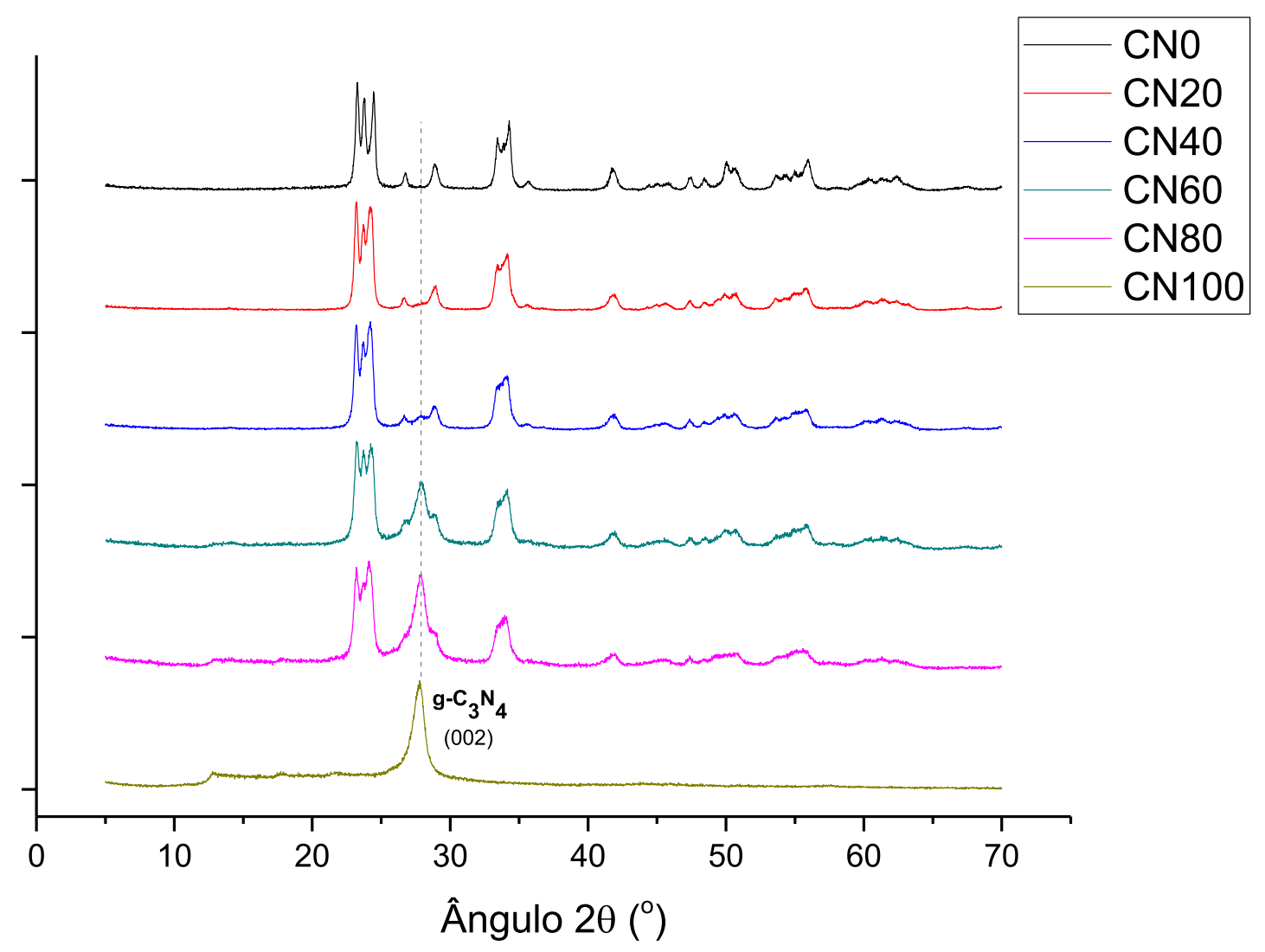

Fonte: Autoria Própria.

Foram obtidas micrografias com o intuito de se observar a morfologia das estruturas e compará-las com a literatura. Também foram obtidas micrografias com detecção de elétrons retroespalhados. Esta analise permite uma melhor visualização de heteroestruturas, gerando uma diferenciação dos compostos a partir do número atômico dos elementos que os compõem (Figura 41).

As amostras CN0 e CN100 apresentaram a morfologia esperada. A CN100 apresentou uma estrutura formada pela aglomeração de lamelas. A amostra CN0 apresentou uma estrutura granular, típica do $\mathrm{WO}_{3}$ monoclínico (LI et al., 2010; NOGUEIRA et al., 2004; XIE et al., 2012). 
Figura 41 - MEV-FEG das amostras: (a) CN0, (b) CN20, (c) CN20 com elétrons retroespalhados, (d) CN35, (e) CN35 com elétrons retroespalhados, (f) CN72, (g) CN72 com elétrons retroespalhados, (h) CN80, (i) $\mathrm{CN} 80$ com elétrons retroespalhados e (j) CN100 (Continua)

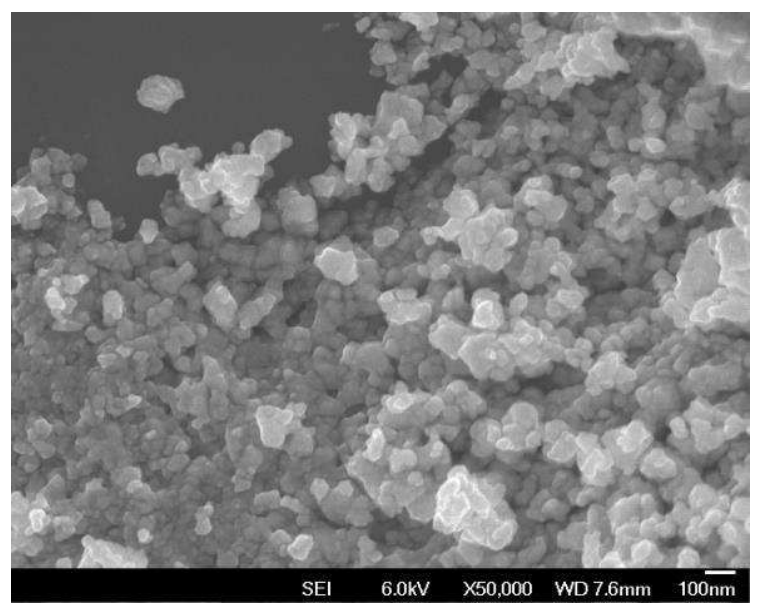

(a)

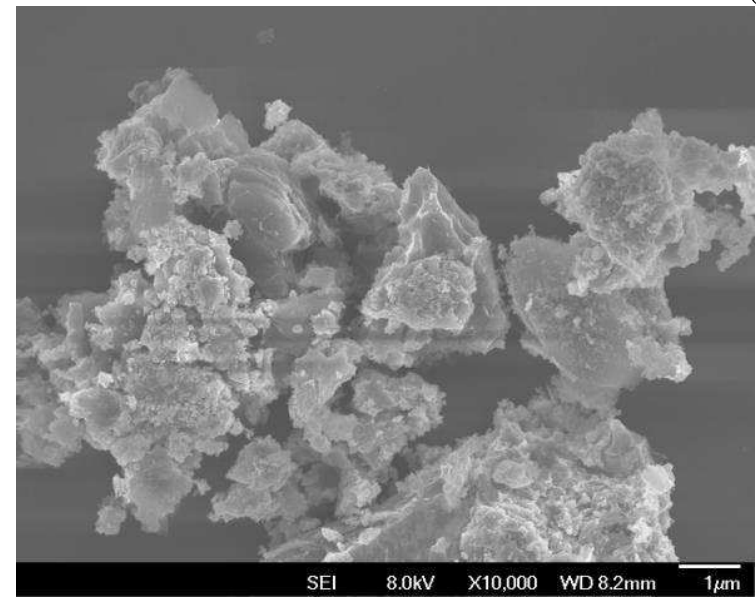

(b)

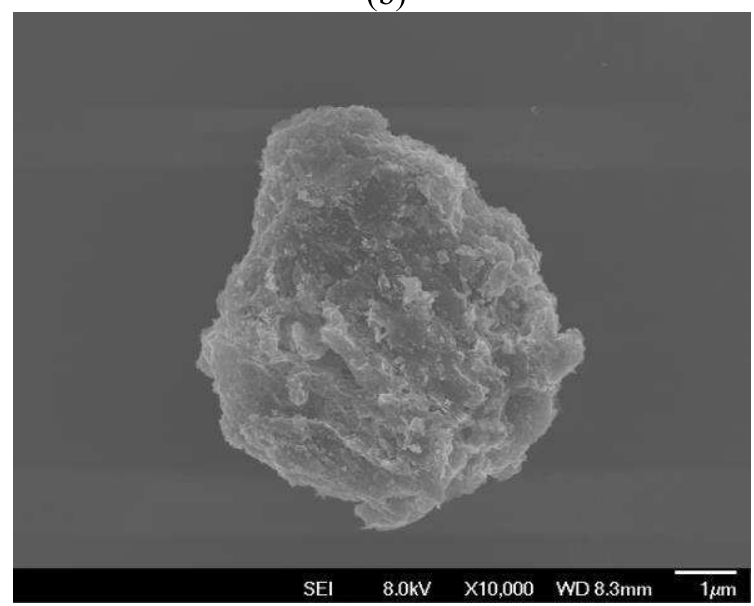

(d)

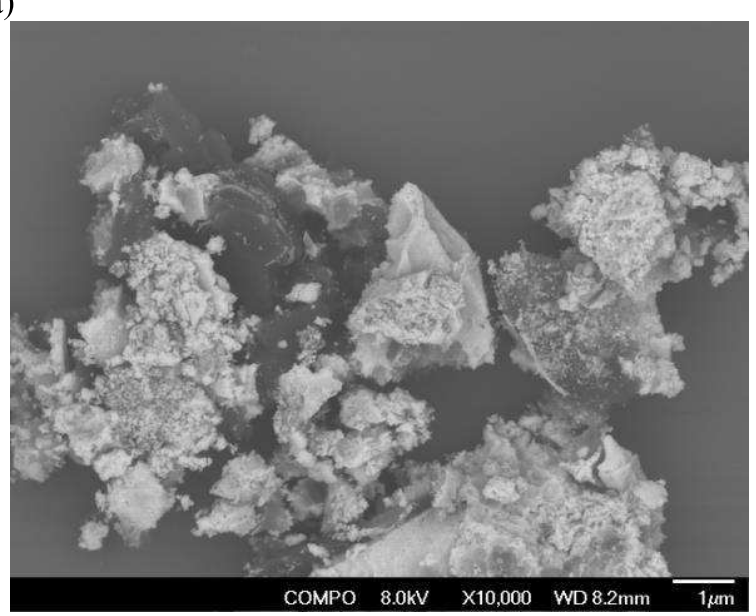

(c)

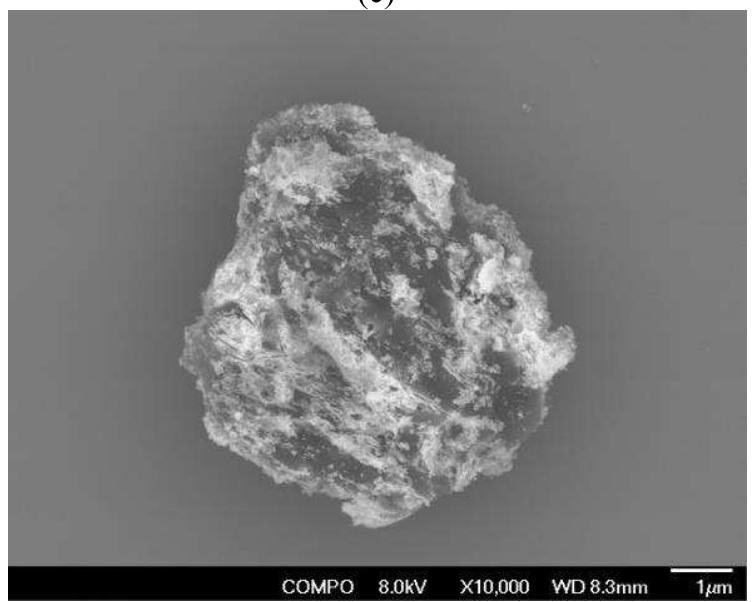

(e) 
Figura 41 - MEV-FEG das amostras: (a) CN0, (b) CN20, (c) CN20 com elétrons retroespalhados, (d) CN35, (e) CN35 com elétrons retroespalhados, (f) CN72, (g) CN72 com elétrons retroespalhados, (h) CN80, (i) CN80 com elétrons retroespalhados e (j) CN100 (Conclusão)

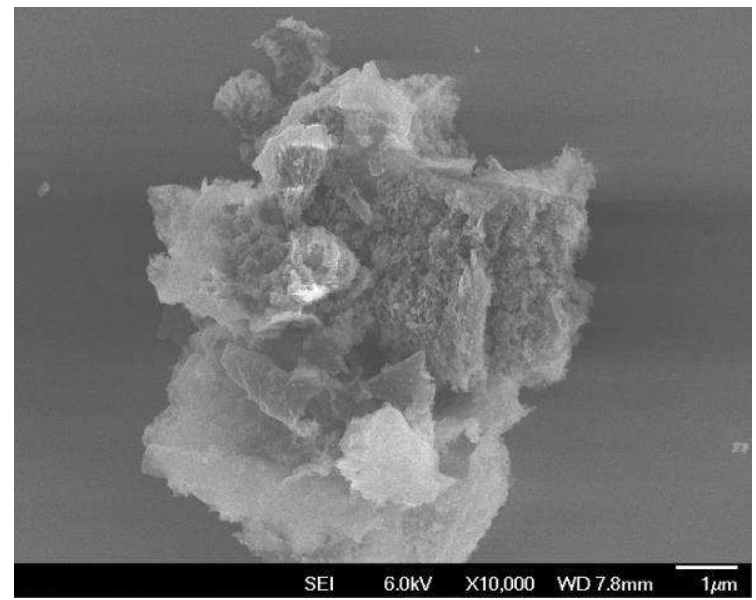

(f)

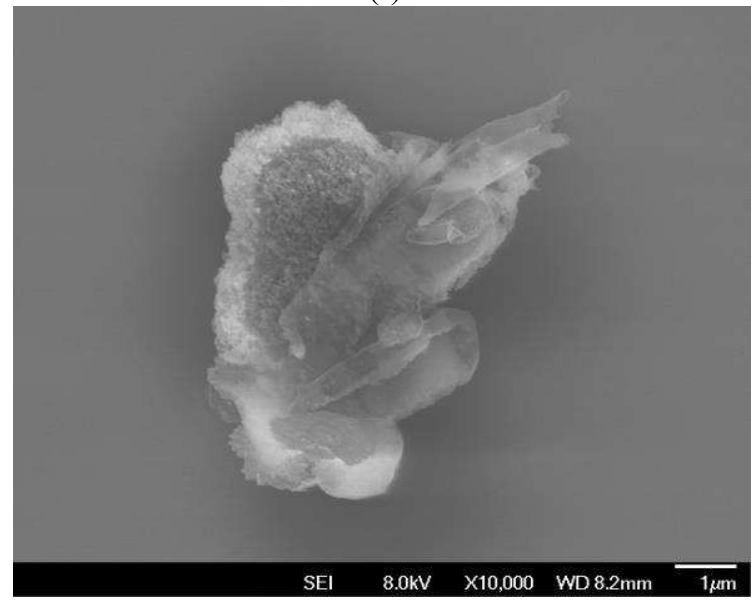

(h)

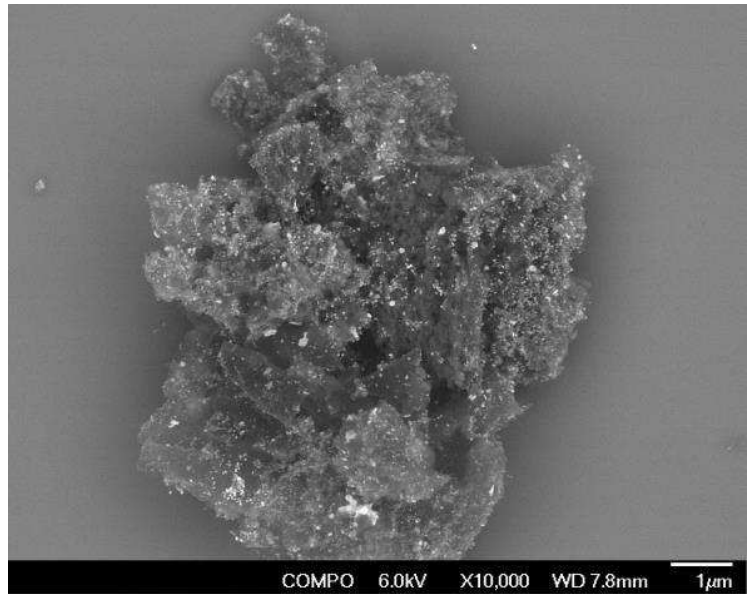

(g)

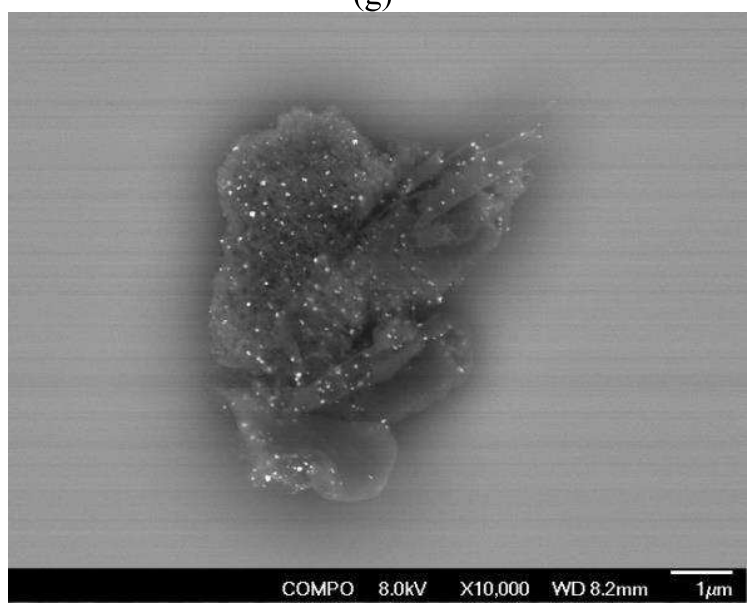

(i)

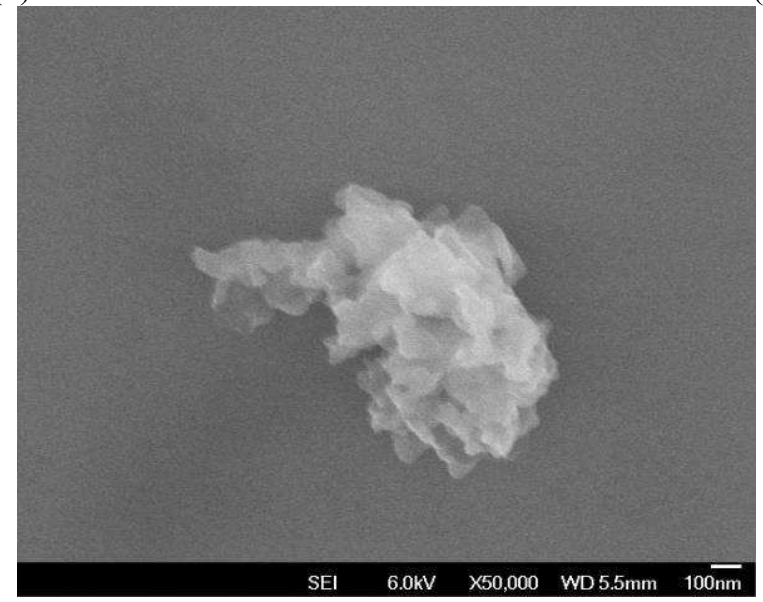

(j)

Fonte: Autoria Própria.

As regiões mais claras destas imagens apresentam a localização do $\mathrm{WO}_{3}$. Assim, pode-se notar uma deposição homogênea sobre uma base de $\mathrm{g}_{-} \mathrm{C}_{3} \mathrm{~N}_{4}$ nas amostras com menor 
porcentagem de $\mathrm{WO}_{3}(\mathrm{CN} 72$ e CN80). Do mesmo modo, pode-se observar boa incorporação do g- $\mathrm{C}_{3} \mathrm{~N}_{4}$ em estruturas maiores frações de $\mathrm{WO}_{3} \mathrm{~g}-\mathrm{C}_{3} \mathrm{~N}_{4}(\mathrm{CN} 20$ e CN35).

Para se ter uma melhor visualização da interface entre os dois fotocatalisadores, foram obtidas imagens de HRTEM (Figura 42). As amostras analisadas foram: CN100 e CN0, como controle; e CN80, como representativa das heteroestruturas.

Novamente, nas amostras puras pôde-se observar as estruturas esperadas. A amostra CN100 apresenta uma estrutura lamelar e a CN0 uma granular. A imagem de HRTEM claramente mostra seus planos cristalinos, destacados na Figura 42c, referentes ao plano 022, com distância interplanar de 0,27 nm (JCPDS 89-4476).

Já a amostra CN80, representante das heteroestruturas, apresentou características dos dois fotocatalisadores. A Figura 42d, em baixa resolução, apresenta lamelas de baixa espessura (claras) sobrepostas por grânulos escuros bem dispersos. As lamelas são características do g- $\mathrm{C}_{3} \mathrm{~N}_{4}$, enquanto os grânulos o são do $\mathrm{WO}_{3}$.

Apesar da difícil observação em alta resolução do $\mathrm{g}-\mathrm{C}_{3} \mathrm{~N}_{4}$, a Figura $42 \mathrm{e}$ indica uma possível interface entre os dois fotocatalisadores. Há regiões de presença de planos cristalográficos sobre estruturas que não os apresentam. Estes planos têm distância de 0,38 nm, sendo relativos aos índices 020 (JCPDS 89-4476).

Com intuito de confirmar a boa dispersão de grânulos de $\mathrm{WO}_{3}$ e sua boa homogeneidade na amostra representativa de heteroestruturas, foi realizado uma análise de EDX (Figura 43), acoplado ao HRTEM.

Observam-se boas homogeneidade e dispersão dos fotocatalisadores na heteroestrutura. Pode-se notar que os pontos mais claros na imagem original são os de maior concentração de tungstênio e oxigênio. 
Figura 42 - Imagens de TEM das amostras: (a) CN100, (b) CN0, (c) CN0 em alta resolução, (d) CN80, (e) CN80 em alta resolução.

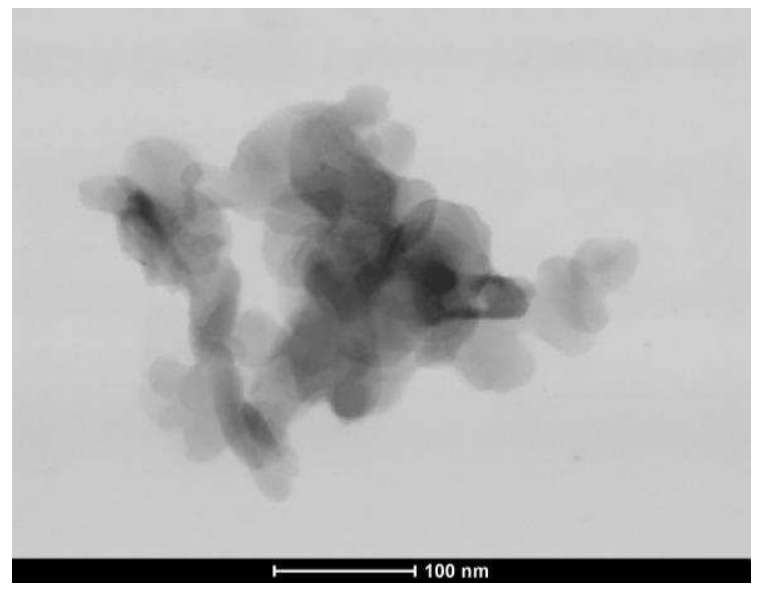

(a)

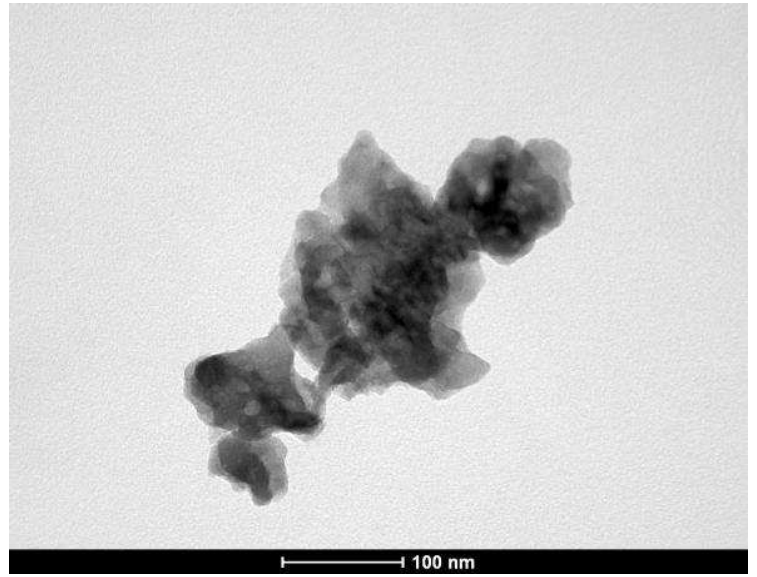

(b)

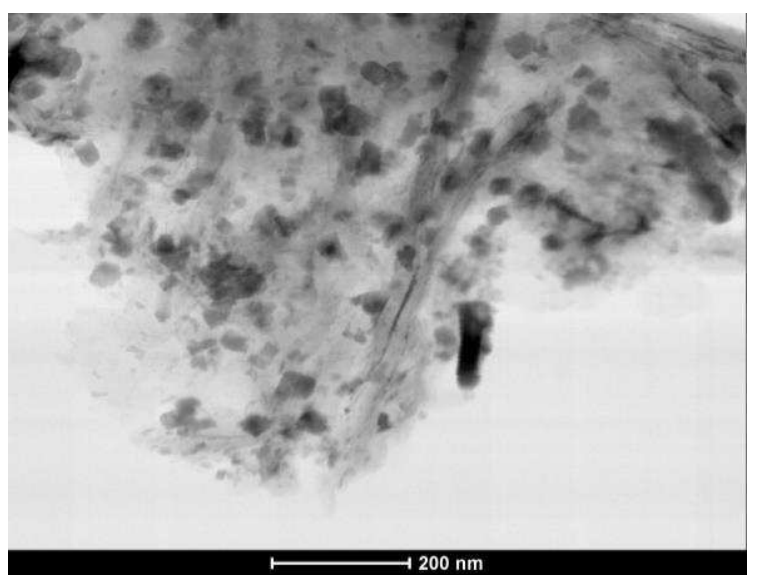

(d)

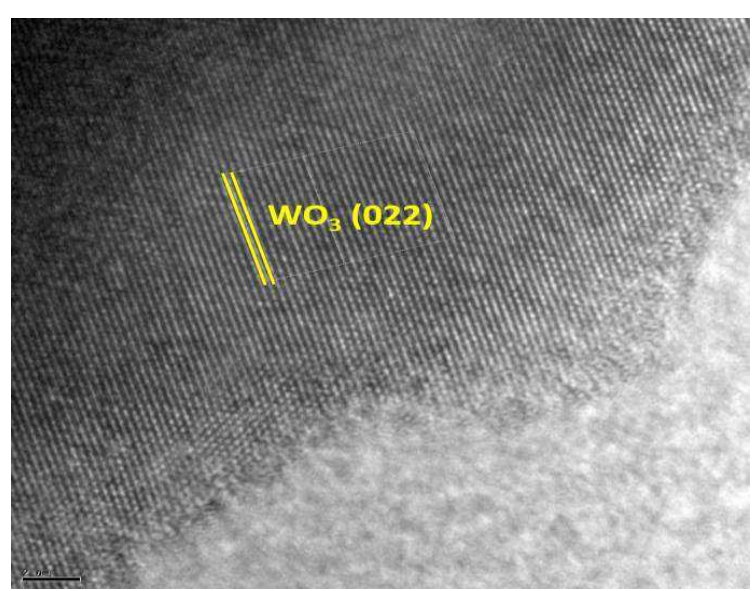

(c)

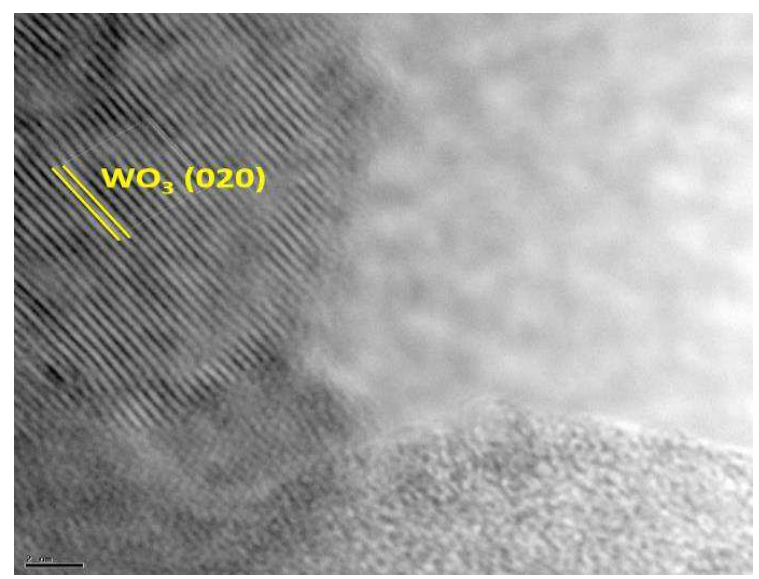

(e)

Fonte: Autoria própria. 
Figura 43 - Região original e mapeamento dos elementos: C (amarelo), N (lilás), W (azul) e O (verde)
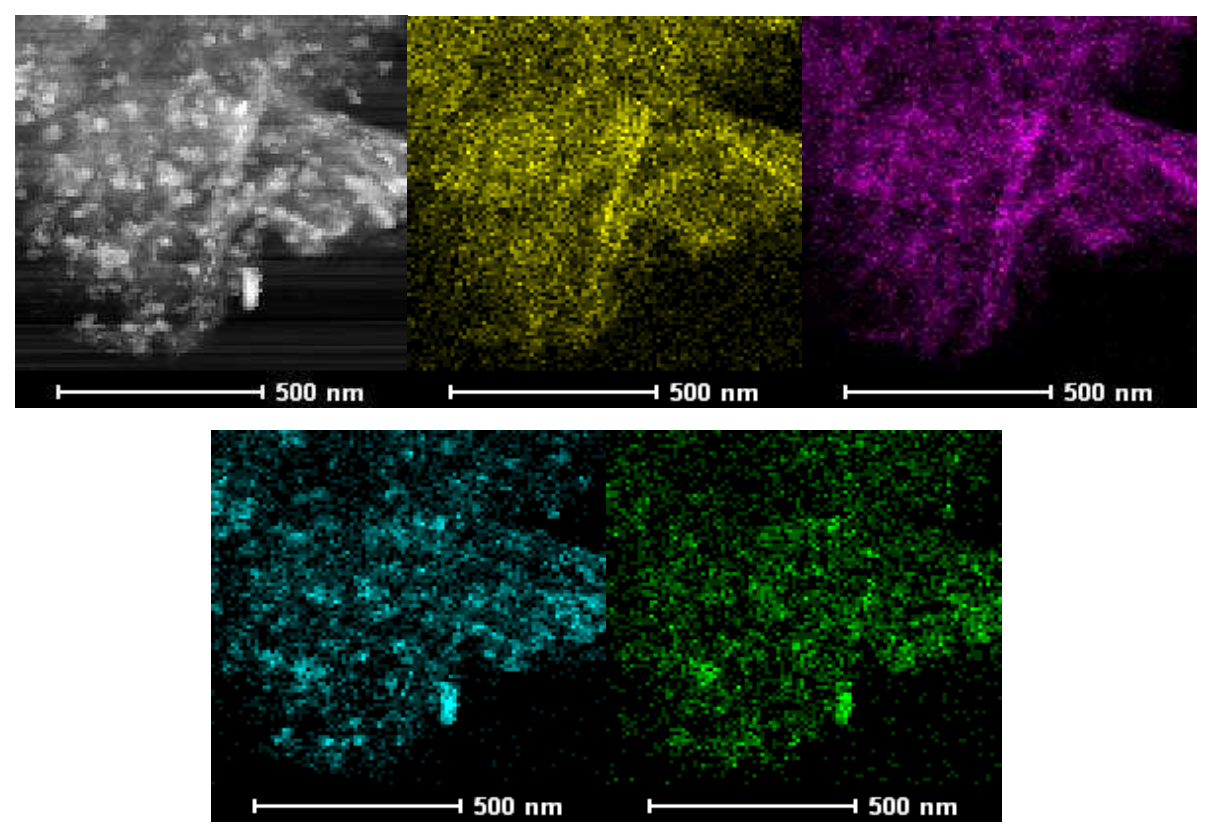

Fonte: Autoria Própria.

Enfim, foi realizada a determinação da $E_{g}$ via espectroscopia de reflectância difusa. A Figura 44 apresenta os resultados de reflectância, enquanto a Figura 45 apresenta as estimativas dos band gaps.

Figura 44 - Espectros de reflectância das amostras de heteroestruturas

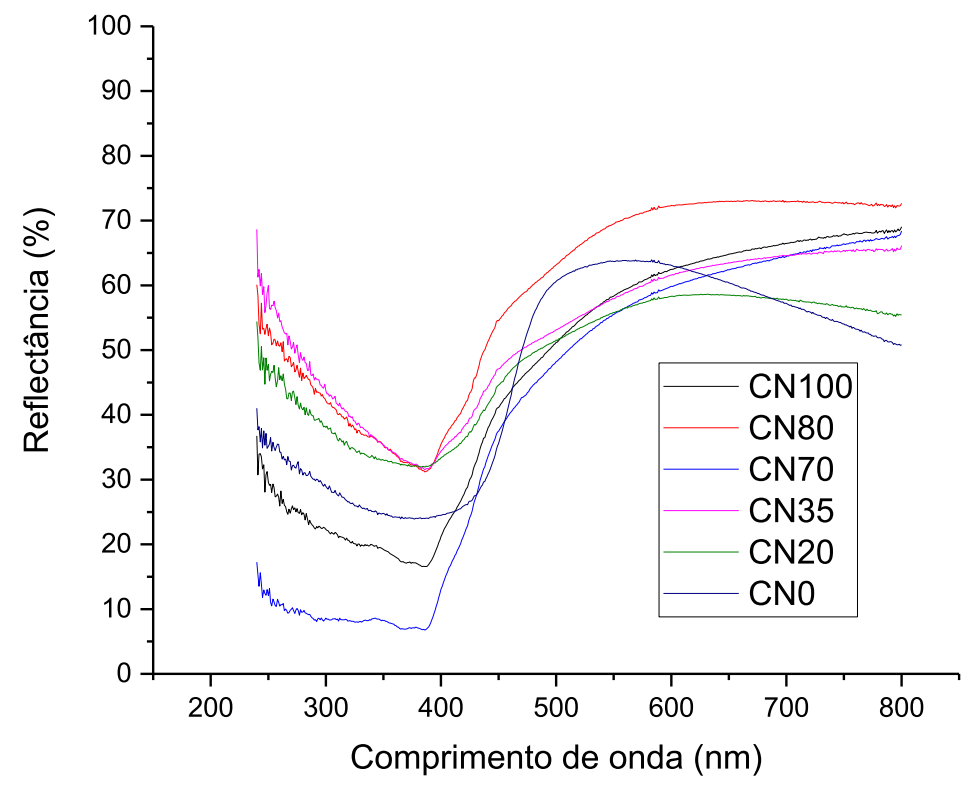

Fonte: Autoria própria. 
Figura 45 - Valores estimados de Eg para as amostras: (a) CN100, (b) CN80, (c) CN71, (d) CN35, (e) CN20 e (f) $\mathrm{CN} 0$

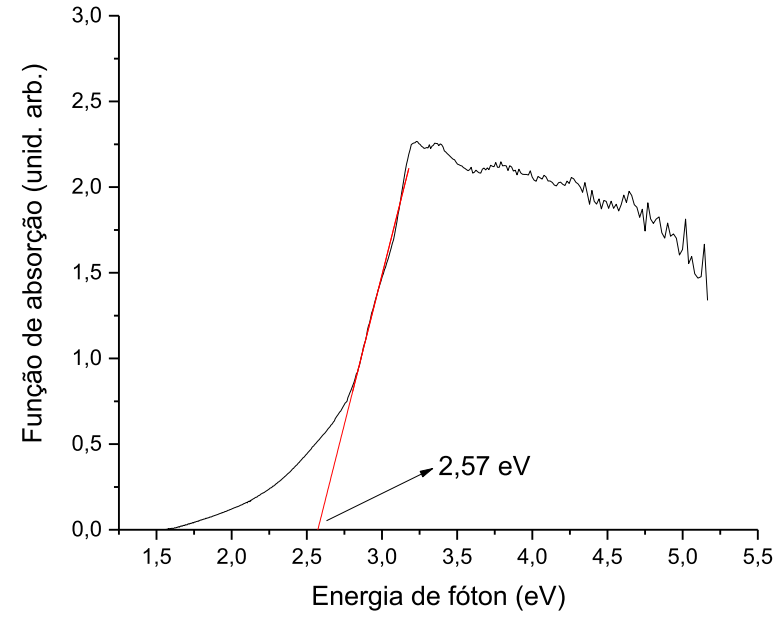

(a)

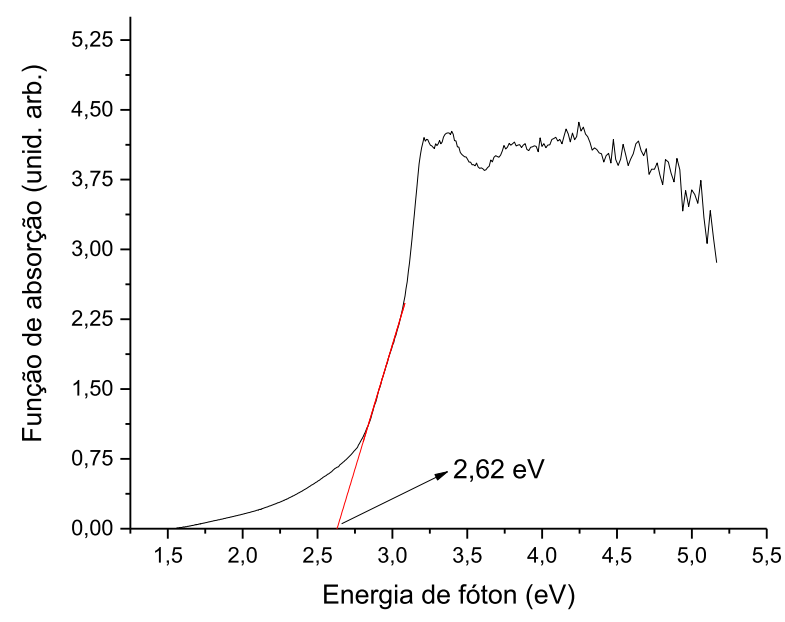

(c)

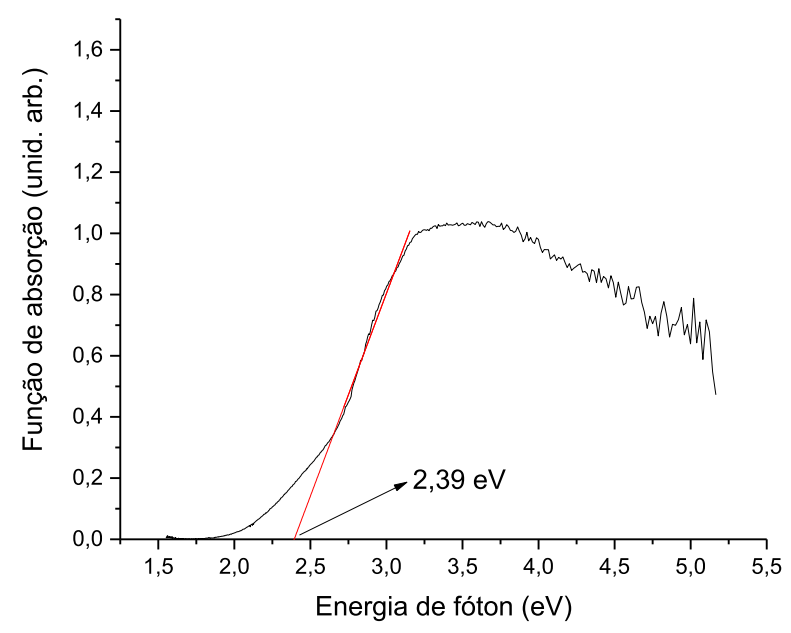

(e)

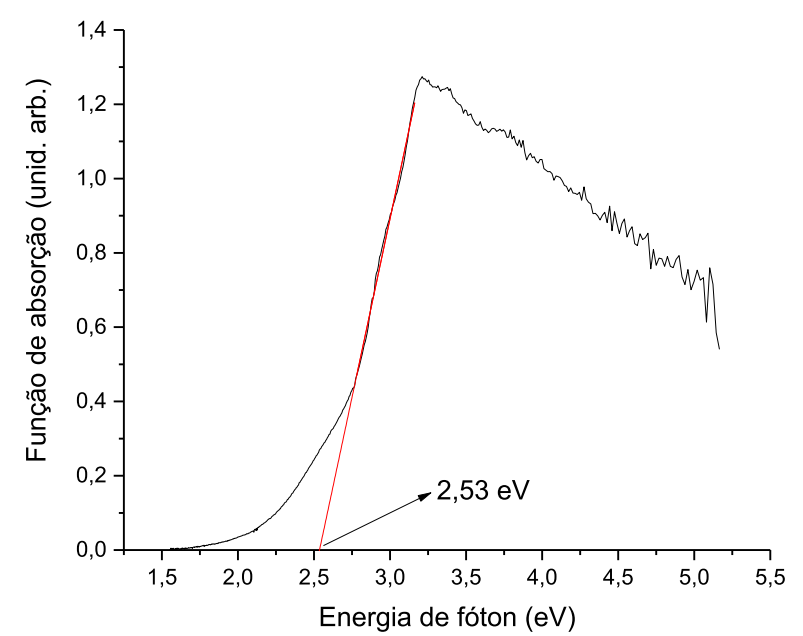

(b)

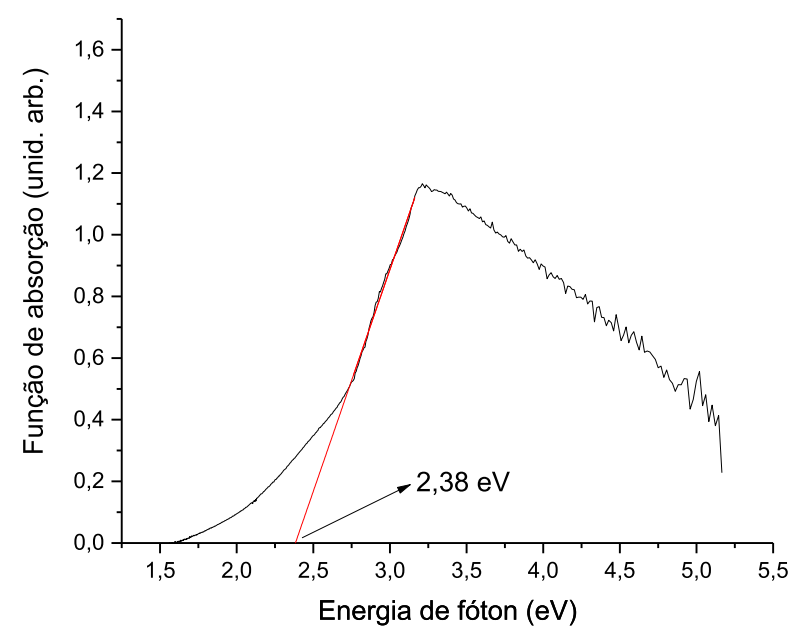

(d)

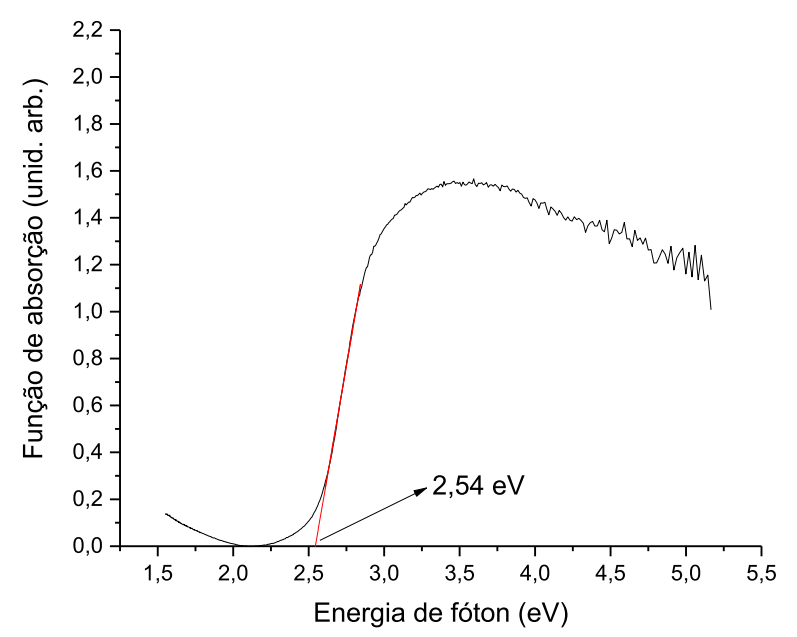

(f)

Fonte: Autoria própria. 
Como pode ser observado, as amostras que possuem massa maior de $\mathrm{g}-\mathrm{C}_{3} \mathrm{~N}_{4}$ possuem $E_{\mathrm{g}}$ próximo ao encontrado para o $\mathrm{g}_{-} \mathrm{C}_{3} \mathrm{~N}_{4}$ puro, origem das heteroestruturas, em torno de 2,6 eV. Já as amostras CN35 e CN20 apresentaram menor $E_{\mathrm{g}}$, em torno de 2,4 eV. A amostra CN0, composta de $\mathrm{WO}_{3}$ puro, apresenta novamente $E_{\mathrm{g}}$ levemente superior, em torno de $2,5 \mathrm{eV}$.

Segundo a literatura, o $\mathrm{WO}_{3}$ tem $\mathrm{E}_{\mathrm{g}}$ entre 2,4 e 2,8 eV (BAMWENDA; ARAKAWA, 2001; GRANQVIST, 2000; KWONG; SAVVIDES; SORRELL, 2012). Sendo assim, as amostras que possuem em sua composição uma maior porcentagem de $\mathrm{WO}_{3}$ possuem $E_{\mathrm{g}}$ nessa faixa.

A redução das energias em composições intermediárias e consequente maior absorção de luz visível (deslocamento para o vermelho), pode indicar uma superior interação dos fotocatalisadores nas heteroestruturas formadas.

\subsubsection{ATIVIDADE FOTOCATALÍTICA}

Com o intuito de se avaliar uma possível melhora na atividade fotocatalítica após a formação das heteroestruturas, foram realizados experimentos de fotocatálise com estas amostras. A fotocatálise foi realizada nas mesmas condições que as do $g-\mathrm{C}_{3} \mathrm{~N}_{4}$ bruto, exceto pelo tempo de irradiação, 20 min. Os resultados são apresentados na Tabela 16.

Tabela 16 - Remoção de tartrazina por fotocatálise com as heteroestruturas

\begin{tabular}{cc}
\hline Ensaio & $\begin{array}{c}\text { Remoção de Corante } \\
(\%)\end{array}$ \\
\hline CN0 & 20,2 \\
CN20 & 26,4 \\
CN35 & 31,2 \\
CN60 & 62,8 \\
CN72 & 84,2 \\
CN80 & 95,0 \\
CN100 & 39,0 \\
\hline
\end{tabular}

Fonte: Autoria própria.

Comparando-se com os resultados do $\mathrm{g}-\mathrm{C}_{3} \mathrm{~N}_{4}$ puro (CN100), pode-se observar que as amostras CN0, CN20 e CN35 são inferiores em atividade fotocatalítica. Por outro lado, a 
amostra CN60 é levemente superior e as amostras CN72 e CN80 se mostraram muito superiores, principalmente a $\mathrm{CN} 80$.

Interessante notar que, mesmo possuindo $E_{\mathrm{g}}$ menores, as amostras $\mathrm{CN} 20$ e CN35 não possuem os melhores resultados fotocatalíticos. Isto pode ser devido a uma maior recombinação de cargas. Em contrapartida, as amostras CN60, CN72 e CN80, apesar de não possuírem $E_{\mathrm{g}}$ menor que o do $\mathrm{g}-\mathrm{C}_{3} \mathrm{~N}_{4}$ bruto, as cargas geradas devem ter maior dificuldade de se recombinarem.

Estudos de outros autores que abordaram a heteroestrutura $\mathrm{g}-\mathrm{C}_{3} \mathrm{~N}_{4}$ apresentam uma faixa de melhor resposta fotocatalítica para proporções mássicas entre 70 e $90 \%$ de $\mathrm{g}_{-} \mathrm{C}_{3} \mathrm{~N}_{4}$ (ASLAM, 2014; CHEN et al., 2015; KAILASAM et al., 2015; KATSUMATA et al., 2013; ZHAO et al., 2015). Os resultados obtidos neste trabalho estão condizentes tais autores.

A Figura 46 apresenta a cinética de remoção da tartrazina a partir de fotocatálise com a amostra CN80 (triplicata). Novamente, os pontos representam as degradações obtidas e as linhas os valores estimados por modelos cinéticos de primeira ordem (Equação 15).

Figura 46 - Cinética de remoção da tartrazina: (ם) fotólise, $(\bullet)$ fotocatálise com $g-\mathrm{C}_{3} \mathrm{~N}_{4} \mathrm{e}$ $(\Delta)$ fotocatálise com $\mathrm{g}-\mathrm{C}_{3} \mathrm{~N}_{4} / \mathrm{WO}_{3}(\mathrm{CN} 80)$

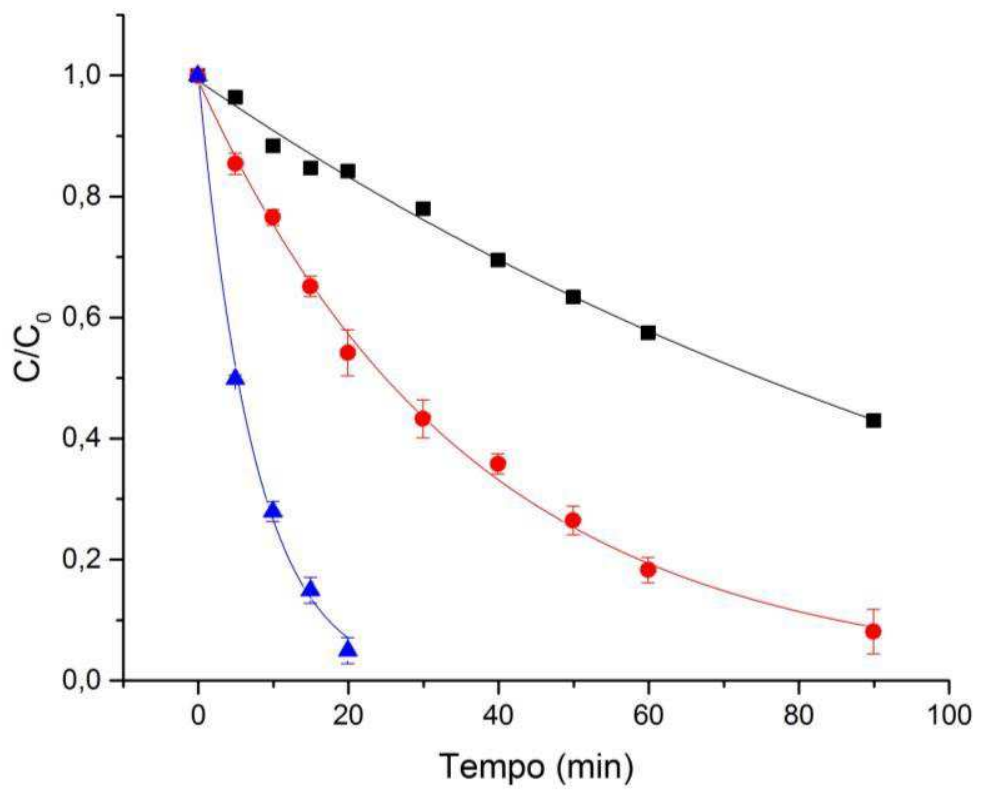

Fonte: Autoria Própria. 
Pode-se notar que a amostra CN80 (heteroestrutura $\mathrm{g}-\mathrm{C}_{3} \mathrm{~N}_{4} / \mathrm{WO}_{3}$ ) é bem mais ativa do que o g- $\mathrm{C}_{3} \mathrm{~N}_{4}$. A Tabela 17 apresentam os valores calculados para a taxa de degradação.

Tabela 17 - Taxas de remoção do corante tartrazina por fotólise e fotocatálise $\left(\mathrm{g}-\mathrm{C}_{3} \mathrm{~N}_{4}\right.$ e $\left.\mathrm{g}-\mathrm{C}_{3} \mathrm{~N}_{4} / \mathrm{WO}_{3}\right)$

\begin{tabular}{cccc}
\hline Ensaio & Material & $\begin{array}{c}\text { Constantes de Taxa } \\
\text { de Remoção }\left(\min ^{-1}\right)\end{array}$ & $\mathrm{R}^{2}$ \\
\hline Fotólise & - & $0,0092 \pm 0,0002$ & 0,993 \\
Fotocatálise & $\mathrm{g}_{-} \mathrm{C}_{3} \mathrm{~N}_{4}$ & $0,028 \pm 0,003$ & 0,997 \\
& $\mathrm{~g}-\mathrm{C}_{3} \mathrm{~N}_{4} / \mathrm{WO}_{3}$ & $0,133 \pm 0,003$ & 0,998 \\
\hline
\end{tabular}

Fonte: Autoria própria.

Observa-se, então, que a taxa de degradação fotocatalítica usando-se o g- $\mathrm{C}_{3} \mathrm{~N}_{4} / \mathrm{WO}_{3}$ é aproximadamente quatorze vezes maior que a fotólise e cinco vezes maior que o g- $\mathrm{C}_{3} \mathrm{~N}_{4}$. 


\section{CONCLUSÕES}

A utilização da metodologia de superfícies de resposta (via planejamentos experimentais) foi capaz de definir as melhores condições de síntese do $\mathrm{g}-\mathrm{C}_{3} \mathrm{~N}_{4}$ (dentro das faixas estudadas para cada variável), utilizando a degradação da tartrazina como variável-resposta.

As análises de difração de raios $\mathrm{X}$ deram indícios importantes da presença de interferentes em amostras sintetizadas em condições brandas (não ótimas). Os sinais observados estão provavelmente relacionados ao melem e/ou outros intermediários da condensação em fase sólida e podem ter prejudicado a atividade fotocatalítica destas condições.

$\mathrm{O}$ material assim formado apresentou ASE e $\mathrm{E}_{\mathrm{g}}$ mais favoráveis do que àqueles relatados na literatura.

A taxa de degradação fotocatalítica da tartrazina, usando-se o material sintetizado, foi aproximadamente três vezes maior que a fotolítica. O fotocatalisador mostrou-se capaz de remover $90 \%$ do corante, inicialmente a $20 \mathrm{mg} \mathrm{L}^{-1}$, em 90 min de irradiação.

As análises realizadas confirmaram a formação de heteroestruturas entre o $g-\mathrm{C}_{3} \mathrm{~N}_{4}$, previamente sintetizado, e o $\mathrm{WO}_{3}$. Outro indício da formação das heteroestruturas, foi o aumento significativo da atividade fotocatalítica.

A heteroestrutura formada aumentou aproximadamente cinco vezes a taxa de degradação da tartrazina. Comparativamente ao $\mathrm{g}-\mathrm{C}_{3} \mathrm{~N}_{4}$, a mesma remoção foi obtida em 20 min de irradiação. 


\section{TRABALHOS FUTUROS}

- Realizar experimentos de degradação na presença de sequestrantes de elétrons, lacunas e radicais, com o objetivo de entender melhor o mecanismo de degradação;

- Utilizar o fotocatalisador sintetizado para a degradação de compostos de interesse recente;

- Aplicar diferentes estratégias de esfoliação do fotocatalisador sintetizado;

- Utilizar outras técnicas de caracterização complementares: fotoluminescência, fotoluminescência resolvida no tempo, tamanho de poros, espectroscopia de fotoelétrons excitados por raios X e espectroscopia Raman;

- Otimizar a formação de heteroestruturas com o trióxido de tungstênio;

- Melhorar a caracterização das heteroestruturas. 


\section{REFERENCIAS}

ASADPOUR-ZEYNALI, K.; ALESHI, M. Electrochemical modification of glassy carbon electrode by bismuth-chitosan nanosheets for electrocatalytic reduction and determination of tartrazine. Portugaliae Electrochimica Acta, v. 32, n. 6, p. 369-379, 2014.

ASLAM, I. The synergistic effect between $\mathrm{WO}_{3}$ and $\mathrm{g}-\mathrm{C}_{3} \mathrm{~N}_{4}$ towards efficient visible-lightdriven photocatalytic performance. New Journal of Chemistry, v. 38, p. 5462-5469, 2014.

BAMWENDA, G. R.; ARAKAWA, H. The visible light induced photocatalytic activity of tungsten trioxide powders. Applied Catalysis A: General, v. 210, n. 1-2, p. 181-191, 2001.

BARBENI, M.; MINERO, C.; PELIZZETTI, E. Chemical degradation of chlorophenols with fenton's reagent. Chemosphere, v. 16, p. 2225-2237, 1987.

BARROS NETO, B.; SCARMINIO, I.; BRUNS, R. Como fazer experimentos: aplicações na ciência e na indústria. 3. ed. Campinas: Editora da UNICAMP, 2007. 480 p.

BEZERRA, M. A.; SANTELI, R. E.; OLIVEIRA, E. P.; VILLAR, L. S.; ESCALEIRA L. A. Response surface methodology (RMS) as a tool for optimization in analytical chemistry. Talanta, v. 76, n. 5, p. 965-977, 2008.

BICA, E.; STEFAN, M.; MURESAN, L. E.; INDREA, E.; POPESCU, I. C.; POPOVICI, E. J. Characterization of some tugsten trioxide thin films obtained by dip-coating. Journal of Optoeletronics and Advanced Materials, v. 1, n. 6, p. 1011-1014, 2009.

BOJDYS, M. J.; MÜLLER, J.; ANTONIETTI, M.; THOMAS, A. Ionothermal synthesis of crystalline, condensed, graphitic carbon nitride. Chemistry - A European Journal, v. 14, n. 27 , p. 8177-8182, 2008.

BOONPRAKOB, N.; WTTCHAKUN, N.; PHANICHPHANT, S.; WAXLER, D.; SHERRELL, A. N.; CHEN, J.; INCEESUNGVORN, B. Enhanced visible-light photocatalytic activity of $\mathrm{g}-\mathrm{C}_{3} \mathrm{~N}_{4} / \mathrm{TiO}_{2}$ films. Journal of Colloid and Interface Science, v. 417, p. 402-409, 2014.

BRASIL, Agência Nacional de Vigilância Sanitária (ANVISA), 2002. Resolução n. 572, 5 de abril de 2002. Diário Oficial da União, Brasília, DF, 5 abril 2002. Seção 1, p. 243.

BYRNE, J. A.; DUNLOP, P. S. M.; HAMILTON, J. W. J.; FERNÁNDEZ-IBÁÑES, P.; POLO-LÓPEZ, I.; SHARMA, P. K.; VENNARD, A. S. M. A review of heterogeneous photocatalysis for water and surface disinfection. Molecules, v. 20, n. 4, p. 5574-5615, 2015.

CALOW, J. T.; DEASLEY, P. J.; OWEN, S. J. T.; WEBB, P. W. A review of semiconductor heterojunctions. Journal of Materials Science, v. 2, n. 1, p. 88-96, 1967. 
CAO, S.; YUAN, Y.; FANG, J.; SHAHJAMALI, M. M.; BOEY, F. Y. C.; BARBER, J.; LOO, S. C. J.; XUE, C. In-situ growth of CdS quantum dots on $\mathrm{g}-\mathrm{C}_{3} \mathrm{~N}_{4}$ nanosheets for highly efficient photocatalytic hydrogen generation under visible light irradiation. International Journal of Hydrogen Energy, v. 38, n. 3, p. 1258-1266, 2013.

CAO, S.; LOW, J.; YU, J.; JARONIEC, M. Polymeric photocatalysts based on graphitic carbon nitride. Advanced Materials, v. 27, n. 13, p. 2150-2176, 2015.

CHANG, F.; XIE, Y.; LI, C.; CHEN, J.; LUO, J.; HU, X. A facile modification of g-C ${ }_{3} \mathrm{~N}_{4}$ with enhanced photocatalytic activity for degradation of methylene blue. Applied Surface Science, v. 280, p. 967-974, 2013.

CHEN, S.; HU, Y.; JIANG, X.; MENG, S.; FU, X. Fabrication and characterization of novel Z-scheme photocatalyst $\mathrm{WO}_{3} / \mathrm{g}-\mathrm{C}_{3} \mathrm{~N}_{4}$ with high efficient visible light photocatalytic activity. Materials Chemistry and Physics, v. 149, p. 512-521, 2015.

CHEN, X.; LIU, Q.; WU, Q.; DU, P.; ZHU, J.; DAI, S.; YANG, S. Incorporating graphitic carbon nitride $\left(\mathrm{g}-\mathrm{C}_{3} \mathrm{~N}_{4}\right)$ quantum dots into bulk-heterojunction polymer solar cells leads to efficiency enhancement. Advanced Functional Materials, v. 26, p. 1719-1728, 2016.

CHENG, E.; YIN, W.; BAI, S.; QIAO, R.; ZHONG, Y.; LI, Z. Synthesis of vis/NIR-driven hybrid photocatalysts by electrostatic assembly of $\mathrm{NaYF}_{4}: \mathrm{Yb}$, Tm nanocrystals on $\mathrm{g}^{-\mathrm{C}_{3} \mathrm{~N}_{4}}$ nanosheets. Materials Letters, v. 146, p. 87-90, 2015.

CHU, S.; WANG, C.; FENG, J.; WANG, Y.; ZOU, Z. Melem: a metal-free unit for photocatalytic hydrogen evolution. International Journal of Hydrogen Energy, v. 39, n. 25, p. 13519-13526, 2014.

DAI, H.; GAO, X.; LIU, E.; YANG, Y.; HOU, W.; KANG, L.; FAN, J.; HU, X. Synthesis and characterization of graphitic carbon nitride sub-microspheres using microwave method under mild condition. Diamond and Related Materials, v. 38, p. 109-117, 2013.

DATTA, K. K. R.; BALASUBRAMANIAN, V. V.; ARIGA, K.; MORI, T.; VINU, A. Highly crystalline and conductive nitrogen-doped mesoporous carbon with graphitic walls and its electrochemical performance. Chemistry - A European Journal, v. 17, n. 12, p. 3390-3397, 2011.

DEJAEGHER, B.; HEYDEN, Y. VANDER. Experimental designs and their recent advances in set-up, data interpretation, and analytical applications. Journal of Pharmaceutical and Biomedical Analysis, v. 56, n. 2, p. 141-158, 2011.

DING, J.; LIU, Q.; ZHANG, Z.; LIU, X.; ZHAO, J.; CHENG, S.; ZONG, B.; DAI, W. Carbon nitride nanosheets decorated with $\mathrm{WO}_{3}$ nanorods: ultrasonic-assisted facile synthesis and catalytic application in the green manufacture of dialdehydes. Applied Catalysis B: Environmental, v. 165, p. 511-518, 2015.

DONG, F.; WU, L.; SUN, Y.; FU, M.; WU, Z.; LEE, S. C. Efficient synthesis of polymeric g- $\mathrm{C}_{3} \mathrm{~N}_{4}$ layered materials as novel efficient visible light driven photocatalysts. Journal of Materials Chemistry, v. 21, p. 15171-15174, 2011. 
DONG, F.; WANG, Z.; SUN, Y.; HO, W.; ZHANG, H. Engineering the nanoarchitecture and texture of polymeric carbon nitride semiconductor for enhanced visible light photocatalytic activity. Journal of Colloid and Interface Science, v. 401, p. 70-79, 2013.

DONG, P.; HOU, G.; XI, X.; SHAO, R.; DONG, F. WO-based photocatalysts: morphology control, activity enhancement and multifunctional applications. Environmental Science: Nano, v. 4, p. 539-557, 2017.

FAGERLUND, G. Determination of specific surface by the BET method. Matériaux et Contruction, v. 6, n. 3, p. 239-245, 1973.

FLORES-MENA, J. E.; DÍAZ-REYES, J.; BALDERAS-LÓPEZ, J. A. Structural propertiies of $\mathrm{WO}_{3}$ dependent of annealing temperature deposited by hot-filament metal oxide deposition. Revista Mexicana de Física, v. 58, p. 504-509, 2012.

FRACCA, M. P. Acoplamento das micro-ondas ao processo oxidativo avançado $\mathrm{UV} / \mathrm{H}_{2} \mathrm{O}_{2}$ para a degradação de corantes ácidos. 2014. 83 f. Dissertação (Mestrado em Ciências) Instituto de Química de São Carlos, Universidade de São Paulo, São Carlos, 2014.

FU, M.; LIAO, J.; DONG, F.; LI, H.; LIU, H. Growth of g-C $\mathrm{C}_{3} \mathrm{~N}_{4}$ layer on commercial $\mathrm{TiO}_{2}$ for enhanced visible light photocatalytic activity. Journal of Nanomaterials, v. 2014, n. 44, p. 1-8, 2014.

GAO, H.; YAN, S.; WANG, J.; HUANG, Y. A.; WANG, P.; LI, Z.; ZOU, Z. Towards efficient solar hydrogen production by intercalated carbon nitride photocatalyst. Physical Chemistry Chemical Physics, v. 15, n. 41, p. 18077-18084, 2013.

GEORGAKI, I. V. I.; KENANAKIS, D. V. G.; KATSARAKIS, N. Synthesis of $\mathrm{WO}_{3}$ catalytic powders : evaluation of photocatalytic activity under NUV/visible light irradiation and alkaline reaction ph. Journal of Sol-Gel Science and Technology, v. 1, p. 120-128, 2015.

GIANNOULI, M.; LEFTHERIOTIS, G. The effect of precursor aging on the morphology and electrochromic performance of electrodeposited tungsten oxide films. Solar Energy Materials and Solar Cells, v. 95, n. 7, p. 1932-1939, 2011.

GIBOT, P.; SCHNELL, F.; SPITZER, D. Enhancement of the graphitic carbon nitride surface properties from calcium salts as templates. Microporous and Mesoporous Materials, v. 219, p. 42-47, 2016.

GONZALEZ, M. G.; OLIVEROS, E.; WÖRNER, M.; BRAUN, A. M. Vacuum-ultraviolet photolysis of aqueous reaction systems. Journal of Photochemistry and Photobiology C: Photochemistry Reviews, v. 5, n. 3, p. 225-246, 2004.

GONZÁlEZ-BORRERO, P. P.; SATO, F.; MEDINA, A. N.; BAESSO, M. L.; BENTO, A.C. Optical band-gap determination of nanostructured $\mathrm{WO}_{3}$ film. Applied Physics Letters, v. 96, p. $1-4,2010$.

GRANQVIST, C. G. Electrochromic tungsten oxide: review of progress 1993-1998. Solar Energy Materials and Solar Cells, v. 60, p. 201-262, 2000. 
HAN, Q.; WANG, B.; ZHAO Y.; HU, C.; QU, L. A graphitic- $\mathrm{C}_{3} \mathrm{~N}_{4}$ "seaweed" architecture for enhanced hydrogen evolution. Angewandte Chemie - International Edition, v. 54, n. 39, p. 11433-11437, 2015.

HAN, Q.; ZHAO, F.; HU, C.; LV, L.; ZHANG, Z.; CHEN, N.; QU, L. Facile production of ultrathin graphitic carbon nitride nanoplatelets for efficient visible-light water splitting. Nano Research, v. 8, n. 5, p. 1718-1728, 2015.

HERNÁNDEZ-URESTI, D. B.; VÁZQUEZ, A.; SANCHEZ-MARTINEZ, D.; OBRÉGON, $\mathrm{S}$. Performance of the polymeric $\mathrm{g}-\mathrm{C}_{3} \mathrm{~N}_{4}$ photocatalyst through the degradation of pharmaceutical pollutants under UV-vis irradiation. Journal of Photochemistry and Photobiology A: Chemistry, v. 324, p. 47-52, 2016.

HO, W.; ZHANG, Z.; XU, M.; ZHANG, X.; WANG, X. Enhanced visible-light-driven photocatalytic removal of NO: effect on layer distortion on $\mathrm{g}_{-} \mathrm{C}_{3} \mathrm{~N}_{4}$ by $\mathrm{H}_{2}$ heating. Applied Catalysis B: Environmental, v. 179, p. 106-112, 2015.

HOFFMANN, M. R.; MARTIN, S. T.; CHOI, W.; BAHNEMANN, D. W. Environmental Applications of Semiconductor Photocatalysis. Chemical Reviews, v. 95, p. 69-96, 1995.

HOSMANE, R. S.; ROSSMAN, M. A.; LEONARD, N. J. Synthesis and structure of tri-striazine. Journal of the American Chemical Society, v. 104, n. 20, p. 5497-5499, 1982.

HU, S.; MA, L.; YOU, J.; LI, F.; FAN, Z.; LU, G.; LIU, D.; GUI, J. Enhanced visible light photocatalytic performance of $\mathrm{g}-\mathrm{C}_{3} \mathrm{~N}_{4}$ photocatalysts co-doped with iron and phosphorus. Applied Surface Science, v. 311, p. 164-171, 2014.

HUANG, Q.; YU, J.; CAO, S.; CUI, C.; CHENG, B. Efficient photocatalytic reduction of $\mathrm{CO}_{2}$ by amine-functionalized g- $\mathrm{C}_{3} \mathrm{~N}_{4}$. Applied Surface Science, v. 358, p. 350-355, 2015.

HUANG, Z. F.; SONG, J.; PAN, L.; ZHANG, X.; WANG, L.; ZOU, J. Tungsten oxides for photocatalysis, electrochemistry, and phototherapy. Advanced Materials, v. 27, n. 36, p. 5309-5327, 2015.

IUPAC. Compendium of Chemical Terminology. 2. ed. Oxford, 1997. Disponível em: < http://goldbook.iupac.org/I03275.html>. Acesso em: 29 abr. 2017.

IWANO, Y.; KITTAKA, T.; TANUCHI, H.; SOUKAWA, M.; KUNITSUGU, S.; TAKARABE, K.; ITOH, K. Study of amorphous carbon nitride films aiming at white light emitting devices. Japanese Journal of Applied Physics, v. 47, n. 10, p. 7842-7844, 2008.

JANÁKY, C.; RAJESHWAR, K.; TACCONI, N. R.; CHANMANEE, W.; HUDA, M. N. Tungsten-based oxide semiconductors for solar hydrogen generation. Catalysis Today, v. 199, n. 1, p. 53-64, 2013.

JÜRGENS, B.; IRRAN, E.; SENKER, J.; KROLL, P.; MÜLLER, H.; SCNICK, W. Melem (2,5,8-triamino-tri-s-triazine), an important intermediate during condensation of melamine rings to graphitic carbon nitride: synthesis, structure determination by X-ray powder diffractometry, solid-state NMR, and theoretical studies. Journal of the American Chemical Society, v. 125, n. 34, p. 10288-10300, 2003. 
KAILASAM, K.; FISHER, A.; ZHANG, G.; ZHANG, J.; SCWARZE, M.; SCHRÖDER, M.; WANG, X.; SCHOMÄCKER, R.; THOMAS, A. Mesoporous carbon nitride-tungsten oxide composites for enhanced photocatalytic hydrogen evolution. Chemsuschem, v. 8, n. 8 , p. 1404-1410, 2015.

KATSUMATA, K.; MOTOYOSHI, R.; MATSUSHITA, N.; OKADA, K. Preparation of graphitic carbon nitride $\left(\mathrm{g}-\mathrm{C}_{3} \mathrm{~N}_{4}\right) / \mathrm{WO}_{3}$ composites and enhanced visible-light-driven photodegradation of acetaldehyde gas. Journal of Hazardous Materials, v. 260, p. 475-482, 2013.

KIM, C. Y.; LEE, M.; HUH, S.; KIM, E. $\mathrm{WO}_{3}$ thin film coating from $\mathrm{H}_{2} \mathrm{O}$-controlled peroxotungstic acid and its electrochromic properties. Journal of Sol-Gel Science and Technology, v. 53, n. 2, p. 176-183, 2010.

KOČÍ, K.; RELI, M.; TROPPOVÁ, I.; SIHOR, M.; KUPKOVÁ, J.; KUSTROWSKI, P.; PRAUS, P. Photocatalytic decomposition of $\mathrm{N}_{2} \mathrm{O}$ over $\mathrm{TiO}_{2} / \mathrm{g}-\mathrm{C}_{3} \mathrm{~N}_{4}$ photocatalysts heterojunction. Applied Surface Science, v. 396, p. 1685-1695, 2017.

KRIVTSOV, I.; GARCÍA-LOPEZ, E.; MARCÌ, G.; PALMISANO, L.; AMGHOUZ, Z.; GRACÍA, J. R.; ORDÓÑES, S.; DÍAZ, E. Selective photocatalytic oxidation of 5-hydroxymethyl-2-furfural to 2,5-furandicarboxyaldehyde in aqueous suspension of $\mathrm{g}_{-} \mathrm{C}_{3} \mathrm{~N}_{4}$. Applied Catalysis B: Environmental, v. 204, p. 430-439, 2017.

KUANG, P. Y.; SU, Y.; CHEN, G.; LUO, Z.; XING, S.; LI, N.; LIU, Z. g-C ${ }_{3} \mathrm{~N}_{4}$ decorated $\mathrm{ZnO}$ nanorod arrays for enhanced photoelectrocatalytic performance. Applied Surface Science, v. 358, p. 296-303, 2015.

KWONG, W. L.; SAVVIDES, N.; SORRELL, C. C. Electrodeposited nanostructured $\mathrm{WO}_{3}$ thin films for photoelectrochemical applications. Electrochimica Acta, v. 75, p. 371-380, 2012.

LEGRINI, O.; OLIVEROS, E.; BRAUN, A. M. Photochemical processes for water treatment. Chemical Reviews, v. 93, n. 2, p. 671-698, 1993.

LI, J.; ZHAO, Q.; ZHANG, G.; CHEN, J.; ZHONG, L.; LI, L.; HUANG, J.; MA, Z. Synthesis of monoclinic $\mathrm{WO}_{3}$ nanosphere hydrogen gasochromic film via a sol-gel approach using PS-b-PAA diblock copolymer as template. Solid State Sciences, v. 12, n. 8, p. 1393-1398, 2010.

LIN, B.; XUE, C.; YAN, X.; YANG, G.; YANG, G.; YANG, B. Facile fabrication of novel $\mathrm{SiO}_{2} / \mathrm{g}-\mathrm{C}_{3} \mathrm{~N}_{4}$ core-shell nanosphere photocatalysts with enhanced visible light activity. Applied Surface Science, v. 357, p. 346-355, 2015.

LIN, L.; YE, P.; CAO, C.; JIN, Q.; XU, G.; SHEN, Y.; YUAN, Y. Rapid microwave-assisted green production of a crystalline polyimide for enhanced visible-light-induced photocatalytic hydrogen production. Journal of Materials Chemistry A: Materials for Energy and Sustainability, v. 3, p. 10250-10208, 2015. 
LIN, Q.; LI, L.; LIANG, S.; LIU, M.; BI, J.; WU, L. Efficient synthesis of monolayer carbon nitride 2D nanosheet with tunable concentration and enhanced visible-light photocatalytic activities. Applied Catalysis B: Environmental, v. 163, p. 135-142, 2015.

LIN, Z.; WANG, X. Nanostructure engineering and doping of conjugated carbon nitride semiconductors for hydrogen photosynthesis. Angewandte Chemie - International Edition, v. 52, n. 6, p. 1735-1738, 2013.

LINSEBIGLER, A. L.; LU, G.; YATES, J. Photocatalysis on $\mathrm{TiO}_{2}$ surfaces: principles, mechanisms, and selected results. Chemical Reviews, v. 95, n. 3, p. 735-758, 1995.

LIU, H.; CHEN, D.; WANG, Z.; JING, H.; ZHANG, R. Microwave-assisted molten-salt rapid synthesis of isotype triazine-/heptazine based $\mathrm{g}_{-} \mathrm{C}_{3} \mathrm{~N}_{4}$ heterojunctions with highly enhanced photocatalytic hydrogen evolution performance. Applied Catalysis B: Environmental, v. 203, p. 300-313, 2017.

LIU, X.; QIN, H.; FAN, W. Enhanced visible-light photocatalytic activity of a g- $\mathrm{C}_{3} \mathrm{~N}_{4} /$ m-LaVO 4 heterojunction: band offset determination. Science Bulletin, v. 61, n. 8, p. 645$655,2016$.

LOPES, O. F.; MENDONÇA, V. R.; SILVA, F. B. F.; PARIS, E. C.; RIBEIRO, C. Niobium oxides: an overview of the synthesis of $\mathrm{Nb}_{2} \mathrm{O}_{5}$ and its application in heterogeneous photocatalysis. Química Nova, v. 38, n. 1, p. 106-117, 2014.

LU, X.; XU, K.; CHEN, P.; JIA, K.; LIU, S.; WU, C. Facile one step method realizing scalable production of $\mathrm{g}-\mathrm{C}_{3} \mathrm{~N}_{4}$ nanosheets and study of their photocatalytic $\mathrm{H}_{2}$ evolution activity.

Journal of Materials Chemistry A, v. 2, n. 44, p. 18924-18928, 2014.

LUÉVANO-HIPÓLITO, E.; CRUZ.; A. M.; YU, Q. L.; BROUWERS, H. J. H. Precipitation synthesis of $\mathrm{WO}_{3}$ for $\mathrm{NO}_{x}$ removal using PEG as template. Ceramics International, v. 40, n. 8, part A, p. 12123-12128, 2014.

MA, J.; WANG, C.; HE, H. Enhanced photocatalytic oxidation of no over g- $\mathrm{C}_{3} \mathrm{~N}_{4}-\mathrm{TiO}_{2}$ under UV and visible light. Applied Catalysis B: Environmental, v. 184, p. 28-34, 2016.

MARQUES, A. C.; SANTOS, L.; COSTA, M. N.; DANTAS, J. M.; DUARTE, P.; GONÇALVES, A.; MARTINS, R.; SLAGUEIRO, C. A.; FORTUNATO, E. Office paper platform for bioelectrochromic detection of electrochemically active bacteria using tungsten trioxide nanoprobes. Scientific Reports, v. 3, n. 5, p. 1-7, 2015.

MARTÍN-RAMOS, P.; MARTÍN-GIL, J.; DANTE, R. C.; VAQUERO, F.; NAVARRO, R. M.; FIERRO, J. L. C. A simple approach to synthesize $g-\mathrm{C}_{3} \mathrm{~N}_{4}$ with high visible light photoactivity for hydrogen production. International Journal of Hydrogen Energy, v. 40, n. 23, p. 7273-7281, 2015.

MILLS, A.; DAVIES, R. H.; WORSLEY, D. Water purification by semiconductor photocatalysis. Chemical Society Reviews, v. 22, n. 6, p. 417-425, 1993. 
MOURÃO, H. A. J. L.; MENDONÇA, V. R.; MALAGUTTI, A. R.; RIBEIRO, C. Nanoestruturas em fotocatálise: uma revisão sobre estratégias de síntese de fotocatalisadores em escala nanométrica. Quimica Nova, v. 32, n. 8, p. 2181-2190, 2009.

MOUTINHO, I. L. D.; BERTGES, L. C.; ASSIS, R. V. C. Prolonged use of the food dye tartrazine (FD\&C yellow $\mathrm{n}^{\circ} 5$ ) and its effects on the gastric mucosa of wistar rats. Brazilian Journal of Biology, v. 67, n. 1, p. 141-145, 2007.

NOGUEIRA, H. I. S.; CAVALEIRO, A. M. V.; ROCHA, J.; TRINDADE, T.; DE JESUS, J. D. P. Synthesis and characterization of tungsten trioxide powders prepared from tungstic acids. Materials Research Bulletin, v. 39, n. 4-5, p. 683-693, 2004.

OVCHAROV, M.; SCHERBAN, N.; FILONENKO, S.; MISHURA, A.; SKORYK, M.; SHVALAGIN, V.; GRANCHAK, V. Hard template synthesis of porous carbon nitride materials with improved efficiency for photocatalytic $\mathrm{CO}_{2}$ utilization. Materials Science and Engineering: B, v. 202, p. 1-7, 2015.

PADOVAN, R. N.; AZEVEDO, E. B. Combining a sequencing batch reactor with heterogeneous photocatalysis $\left(\mathrm{TiO}_{2} / \mathrm{UV}\right)$ for treating a pencil manufacturer's wastewater. Brazilian Journal of Chemical Engineering, v. 32, n. 1, p. 99-106, 2015.

PAPAILIAS, I.; GIANNAKOPOULOU, T.; TODOROVA, N.; DEMOTIKALI, D.; VAIMAKIS, T.; TRAPALIS. Effect of processing temperature on structure and photocatalytic properties of $\mathrm{g}-\mathrm{C}_{3} \mathrm{~N}_{4}$. Applied Surface Science, v. 358, p. 278-286, 2015.

PI, L.; JIANG, R.; ZHOU, W.; ZHU, H.; XIAO, W.; WANG, D.; MAO, X. g-C $3 \mathrm{~N}_{4}$ modified biochar as an adsorptive and photocatalytic material for decontamination of aqueous organic pollutants. Applied Surface Science, v. 358, p. 231-239, 2015.

QU, A.; XU, X.; XIE, H.; ZHANG, Y.; LI, Y.; WANG, J. Effects of calcining temperature on photocatalysis of $\mathrm{g}-\mathrm{C}_{3} \mathrm{~N}_{4} / \mathrm{TiO}_{2}$ composites for hydrogen evolution from water. Materials Research Bulletin, v. 80, p. 167-176, 2016.

SAYAMA, K.; HAYASHI, H.; ARAI, T.; YANAGIDA.; GUNJI, T.; SUGIHARA, H. Highly active $\mathrm{WO}_{3}$ semiconductor photocatalyst prepared from amorphous peroxo-tungstic acid for the degradation of various organic compounds. Applied Catalysis B: Environmental, v. 94, n. 1-2, p. 150-157, 2010.

SENGUPTA, R.; BHATTACHARYA, M.; BANDYOPADHYAY, S.; BHOWMICK, A. K. A review on the mechanical and electrical properties of graphite and modified graphite reinforced polymer composites. Progress in Polymer Science, v. 36, n. 5, p. 638-670, 2011.

SHAN, W.; HU, Y.; BAI, Z.; ZHENG, M.; WEI, C. In situ preparation of g-C $\mathrm{C}_{3} \mathrm{~N}_{4} /$ bismuthbased oxide nanocomposites with enhanced photocatalytic activity. Applied Catalysis B: Environmental, v. 188, p. 1-12, 2016.

SHI, L.; LIANG, L.; WANG, F.; MA, J.; SUN, J. Polycondensation of guanidine hydrochloride into a graphitic carbon nitride semiconductor with a large surface area as a visible light photocatalyst. Catalysis Science \& Technology, v. 4, p. 3235-3243, 2014. 
SHI, L.; LIANG, T.; LIANG, L.; WANG, F.; LIU, M.; SUN, J. High temperature promoted synthesis of graphitic carbon nitride with porous structure and enhanced photocatalytic activity. Journal of Porous Materials, v. 22, n. 5, p. 1393-1399, 2015.

SHU, T.; YANG, W.; LI, K.; YAN, L.; DAI, Y.; GUO, H. Design of silver-deposited carbon nitride nanotubes by a one-step solvothermal treatment strategy and their efficient visiblelight photocatalytic activity toward methyl organge degradation. Energy and Environment Focus, v. 4, p. 107-115, 2015.

SKOOG, D. A.; HOLLER, F. J.; NIEMAN, T. A. Princípios de análise instrumental. 5. ed. Porto Alegre: Bookman, 2002. 838 p.

SUN, Y.; XIONG, T.; NI, Z.; LIU, J.; DONG, F.; ZHANG, W. Improving g-C $3 \mathrm{~N}_{4}$ photocatalysis for $\mathrm{NO}_{\mathrm{x}}$ removal by Ag nanoparticles decoration. Applied Surface Science, v. 358, n. 358 , p. 356-362, 2015.

TAHIR, M.; CAO, C.; BUTT, F. K.; BUTT, S.; IDREES, F.; ALI, Z.; ASLAM, I.; TANVEER, M.; MAHMOOD, A.; MAHMOOD, N.. Large scale production of novel $\mathrm{g}_{-} \mathrm{C}_{3} \mathrm{~N}_{4}$ micro strings with high surface area and versatile photodegradation ability. Crystengcomm, v. 16, n. 9, p. 1825-1830, 2014.

TAHIR, M.; MAHMOOD, N.; ZHU, J.; MAHMOOD, A.; BUUT, F. K.; IZWAN, S.; ASLAM, I.; TANVEER, M.; IDREES, F.; SHAKI, I.; CAO, C.; HOU, Y. One dimensional graphitic carbon nitrides as effective metal-free oxygen reduction catalysts. Scientific Reports, v. 5, n. 3, p. 12389, 2015.

TAUC, J.; GRIGOROVICI, R.; VANCU, A. Optical properties and electronic structure of amorphous germanium. Physica Status Solidi, v. 15, n. 2, p. 627-637, 1966.

TONG, J.; ZHANG, L.; LI, F.; LI, M.; CAO, S. An efficient top-down approach for the fabrication of large-aspect-ratio g- $\mathrm{C}_{3} \mathrm{~N}_{4}$ nanosheets with enhanced photocatalytic activities. Physical Chemistry Chemical Physics, v. 17, n. 17, p. 23532-23537, 2015.

WANG, H.; ZHANG, L.; CHEN, Z.; HU, J.; LI, S.; WANG, Z.; LIU, J.; WANG, X. Semiconductor heterojunction photocatalysts: design, construction, and photocatalytic performances. Chemical Society Reviews, v. 43, n. 15, p. 5234-44, 2014.

WANG, L.; YU, M.; WU, C.; DENG, N.; WANG, C.; YAO, X. Synthesis of Ag/g-C $\mathrm{C}_{4}$ composite as highly efficient visible-light photocatalyst for oxidative amidation of aromatic aldehydes. Advanced Synthesis \& Catalysis, v. 358, n. 16, p. 2631-2641, 2016.

WANG, X.; MAEDA, K.; THOMAS, A.; TAKANABE, K.; XIN, G.; CARLSSON, J. M.; DOMEN, K.; ANTONIETTI, M. A metal-free polymeric photocatalyst for hydrogen production from water under visible light. Nature Materials, v. 8, n. 1, p. 76-80, 2009.

WANG, X.; WANG, S.; HU, W.; CAI, J.; ZHANG, L.; DONG, L.; ZHAO, L.; HE, Y. Synthesis and photocatalytic activity of $\mathrm{SiO}_{2} / \mathrm{g}-\mathrm{C}_{3} \mathrm{~N}_{4}$ composite photocatalyst. Materials Letters, v. 115, p. 53-56, 2014. 
WANG, Y.; WANG, X.; ANTONIETTI, M.; ZHANG, Y. Facile one-pot synthesis of nanoporous carbon nitride solids by using soft templates. Chemsuschem, v. 3, n. 4, p. 435-439, 2010.

WU, P.; WANG, J.; ZHAO, J.; GUO, L.; OSTERLOH, F. E.. Structure defects in g-C $\mathrm{C}_{3} \mathrm{~N}_{4}$ limit visible light driven hydrogen evolution and photovoltage. Journal of Materials Chemistry A, v. 2, n. 47, p. 20338-20344, 2014.

XIANG, Q.; YU, J.; JARONIEC, M. Preparation and enhanced visible-light photocatalytic $\mathrm{H}_{2}$-production activity of graphene/ $\mathrm{C}_{3} \mathrm{~N}_{4}$ composites. The Journal of Physical Chemistry $\mathbf{C}$, v. 115, n. 15 , p. $7355-7363,2011$.

XIAO, J.; XIE, Y.; NAWAZ, F.; JIN, S.; DUAN, F.; LI, M.; CAO, H. Super synergy between photocatalysis and ozonation using bulk $\mathrm{g}-\mathrm{C}_{3} \mathrm{~N}_{4}$ as catalyst: a potential sunlight $/ \mathrm{O}_{3} / \mathrm{g}-\mathrm{C}_{3} \mathrm{~N}_{4}$ method for efficient water decontamination. Applied Catalysis B: Environmental, v. 181, p. $420-428,2016$.

XIE, Y. P.; LIU, G.; YIN, L.; CHENG, H. Crystal facet-dependent photocatalytic oxidation and reduction reactivity of monoclinic $\mathrm{WO}_{3}$ for solar energy conversion. Journal of Materials Chemistry, v. 22, n. 14, p. 6746, 2012.

XING, Z.; CHEN, Z.; ZONG, X.; WANG, L. A new type of carbon nitride-based polymer composite for enhanced photocatalytic hydrogen production. Chemical Communications, v. 50, n. 51, p. 6762-6764, 2014.

XU, H. Y.; WU, L.; ZHAO, H.; JIN, L.; QI, S. Synergic effect between adsorption and photocatalysis of metal-free $\mathrm{g}_{-} \mathrm{C}_{3} \mathrm{~N}_{4}$ derived from different precursors. Plos One, v. 10, n. 11, p. 1$20,2015$.

XU, L.; XIA, J.; XU, H.; YIN, S.; WANG, K.; HUANG, L.; WANG, L.; LI, H. Reactable ionic liquid assisted solvothermal synthesis of graphite-like $\mathrm{C}_{3} \mathrm{~N}_{4}$ hybridized $\alpha-\mathrm{Fe}_{2} \mathrm{O}_{3}$ hollow microspheres with enhanced supercapacitive performance. Journal of Power Sources, v. 245, p. 866-874, 2014.

XU, X.; LIU, G.; RANDORN, C.; IRBINE, J. T. S. g-C $3 \mathrm{~N}_{4}$ coated $\mathrm{SrTiO}_{3}$ as an efficient photocatalyst for $\mathrm{H}_{2}$ production in aqueous solution under visible light irradiation.

International Journal of Hydrogen Energy, v. 36, n. 21, p. 13501-13507, 2011.

YANG, S.; FENG, X.; WANG, X.; MÜLLEN, K. Graphene-based carbon nitride nanosheets as efficient metal-free electrocatalysts for oxygen reduction reactions. Angewandte Chemie International Edition, v. 50, n. 23, p. 5339-5343, 2011.

YANG, S.; GONG, Y.; ZHANG, J.; ZHAN, L.; MA, L.; FANG, Z.; VAJTAI, R.; WANG, X.; AJAYAN, P. M. Exfoliated graphitic carbon nitride nanosheets as efficient catalysts for hydrogen evolution under visible light. Advanced Materials, v. 25, n. 17, p. 2452-2456, 2013.

YE, S.; WANG, R.; WU, M.; YUAN, Y. A review on $\mathrm{g}-\mathrm{C}_{3} \mathrm{~N}_{4}$ for photocatalytic water splitting and co2 reduction. Applied Surface Science, v. 358, p. 15-27, 2015. 
YU, J.; QI, L. Template-free fabrication of hierarchically flower-like tungsten trioxide assemblies with enhanced visible-light-driven photocatalytic activity. Journal of Hazardous Materials, v. 169, n. 1-3, p. 221-227, 2009.

YUAN, B.; CHU, Z.; LI, G.; JIANG, Z.; HU, T.; WANG, Q.; WANG, C. NaCl water-soluble ribbon-like graphitic carbon nitride $\left(\mathrm{g}_{-} \mathrm{C}_{3} \mathrm{~N}_{4}\right)$ : green synthesis, self-assembly and unique optical properties. Journal of Materials Chemistry C, v. 2, n. 39, p. 8212-8215, 2014.

YUAN, P.; YIN, L.; CAO, S.; GU, L.; XU, G.; DU, P.; CHAI, H.; LIAO, Y.; XUE, C. Microwave-assisted heating synthesis: a general and rapid strategy for large-scale production of highly crystalline $\mathrm{g}-\mathrm{C}_{3} \mathrm{~N}_{4}$ with enhanced photocatalytic $\mathrm{H}_{2}$ production. Green Chemistry, v. 16, n. 11, p. 4663-4668, 2014.

YUAN, P.; CAO, S.; LIAO, Y.; YIN, L.; XUE, C. Red phosphor/g-C $\mathrm{C}_{3} \mathrm{~N}_{4}$ heterojunction with enhanced photocatalytic activities for solar fuels production. Applied Catalysis B: Environmental, v. 140-141, p. 164-168, 2013.

ZHANG, G.; ZHANG, J.; ZHANG, M.; WANG, X. Polycondensation of thiourea into carbon nitride semiconductors as visible light photocatalysts. Journal of Materials Chemistry, v. 22 , n. 16, p. 8083-8091, 2012.

ZHANG, J.; CHEN, Y.; WANG, X. Two-dimensional covalent carbon nitride nanosheets: synthesis, functionalization, and applications. Energy Environmental Science, v. 3092, n. 8, p. 3092-3108, 2015.

ZHANG, L.; WANG, X.; NONG, Q.; LIN, H.; TENG, B.; ZHANG, Y.; ZHAO, L.; WU, T.; $\mathrm{HE}, \mathrm{Y}$. Enhanced visible-light photoactivity of g- $\mathrm{C}_{3} \mathrm{~N}_{4}$ via $\mathrm{Zn}_{2} \mathrm{SnO}_{4}$ modification. Applied Surface Science, v. 329, p. 143-149, 2015.

ZHANG, S.; LI, J.; ZENG, M.; XU, J.; WANG, X.; HU, W. Polymer nanodots of graphitic carbon nitride as effective fluorescent probes for the detection of $\mathrm{Fe}^{3+}$ and $\mathrm{Cu}^{2+}$ ions. Nanoscale, v. 6, n. 8, p. 4157-4162, 2014.

ZHANG, Y.; ZHANG, Q.; SHI, Q.; CAI, Z.; YANG, Z. Acid-treated g- $\mathrm{C}_{3} \mathrm{~N}_{4}$ with improved photocatalytic performance in the reduction of aqueous $\mathrm{Cr}(\mathrm{VI})$ under visible-light.

Separation and Purification Technology, v. 142, p. 251-257, 2015.

ZHAO, J.; JII, Z.; SHEN, X.; ZHOU, H.; MA, L. Facile synthesis of $\mathrm{WO}_{3}$ nanorods/g- $\mathrm{C}_{3} \mathrm{~N}_{4}$ composites with enhanced photocatalytic activity. Ceramics International, v. 41, n. 4, p. 5600-5606, 2015.

ZHU, B.; XIA, P.; HO, W.; YU, J. Isoelectric point and adsorption activity of porous $\mathrm{g}_{-} \mathrm{C}_{3} \mathrm{~N}_{4}$. Applied Surface Science, v. 344, p. 188-195, 2015.

ZHUIYKOV, S.; KATS, E.; KALANTAR-ZADEH, K. Enhanced electrical properties in sub10-nm $\mathrm{WO}_{3}$ nanoflakes prepared via a two-step sol-gel-exfoliation method. Nanoscale Research Letters, v. 9, n. 1, p. 401-410, 2014. 
ZOU, J. P.; WANG, L.; LUO J.; NIE, Y.; XING, Q.; LUO, X.; DU, H.; LUO, S.; SUIB, S. Synthesis and efficient visible light photocatalytic $\mathrm{H}_{2}$ evolution of a metal-free g$\mathrm{C}_{3} \mathrm{~N}_{4}$ /graphene quantum dots hybrid photocatalyst. Applied Catalysis B: Environmental, v. 193, p. 103-109, 2016. 